Portland State University

PDXScholar

$1-1-2012$

\title{
Increasing Social Work Students' Political Interest and Efficacy: The Experience and Impact of a Social Welfare Policy Course from the Students' Perspective
}

Christie Dianne Bernklau Halvor

Portland State University

Follow this and additional works at: https://pdxscholar.library.pdx.edu/open_access_etds Let us know how access to this document benefits you.

\section{Recommended Citation}

Bernklau Halvor, Christie Dianne, "Increasing Social Work Students' Political Interest and Efficacy: The Experience and Impact of a Social Welfare Policy Course from the Students' Perspective" (2012). Dissertations and Theses. Paper 565.

https://doi.org/10.15760/etd.565

This Dissertation is brought to you for free and open access. It has been accepted for inclusion in Dissertations and Theses by an authorized administrator of PDXScholar. Please contact us if we can make this document more accessible: pdxscholar@pdx.edu. 
Increasing Social Work Students' Political Interest and Efficacy: The Experience and Impact of a Social Welfare Policy Course from the Students' Perspective

by

Christie Dianne Bernklau Halvor

A dissertation submitted in partial fulfillment of the requirements for the degree of

Doctor of Philosophy

in

Social Work and Social Research

Dissertation Committee:

Ann Curry-Stevens, Chair

Katharine Cahn

Pauline Jivanjee

Dannelle Stevens

Michael Taylor

Portland State University

(C)2012 


\title{
INCREASING POLITICAL INTEREST AND EFFICACY
}

\begin{abstract}
Students of accredited social work programs are expected to demonstrate ten core competencies, including the ability to "engage in policy practice to advance social and economic well-being and to deliver effective social work services" (Council on Social Work Education, 2008). Despite this expectation, almost half of licensed social workers surveyed disagreed with the notion that they were adequately prepared for political engagement by their social work education (Ritter, 2007). Because social welfare policy courses are the primary curricular means for preparing generalist social workers for political advocacy, this study explores how undergraduate students respond to social welfare policy instructors' efforts to prepare them for political engagement. Quantitative and qualitative data from social work students in two distinct social welfare policy courses support the idea that participation in such a course can contribute to an increase in political interest and internal political efficacy. Based on surveys $(n=31)$, focus groups $(n=28)$, and interviews $(n=11)$ with students, a model for social welfare policy instruction is proposed, which includes 11 recommended teaching methods and 7 key aspects of the students' learning experience. By listening to the voices and experiences of social work students, this study begins to fill a gap in the social work education and policy practice literature. The final conclusions of the study help clarify for social work educators methodologies by which they can more effectively support students in the development of political interest, internal political efficacy, and ultimately policy practice.
\end{abstract}




\section{INCREASING POLITICAL INTEREST AND EFFICACY}

\section{Acknowledgements}

It takes a village to raise up a doctoral candidate. Academically, I have been well supported and challenged by those on my dissertation committee. Thank you for your commitment of time to this project and your thoughtful feedback. I would especially like to thank my chair, Ann Curry-Stevens, who has provided rigorous feedback, enthusiastic conversation, and genuine respect for my efforts. I am also particularly grateful for Katharine Cahn's support of both my professional interests and my family's well-being for the many years of this journey.

Professionally, I have been inspired by my colleagues and the social work students at Concordia University - Portland. There are many practical ways in which you have made my teaching and doctoral research possible. Without the inspiration of being in the classroom with students every week, I am not sure how I would have finished. And to Jessica Ritter, whose research I am building upon, thank you for being a role model of political presence as a social worker and educator.

Personally, I appreciate being able to publicly thank my family for their patience, love, and support. Words are inadequate. But may we enjoy many summertimes to come! 


\section{INCREASING POLITICAL INTEREST AND EFFICACY}

\section{Table of Contents}

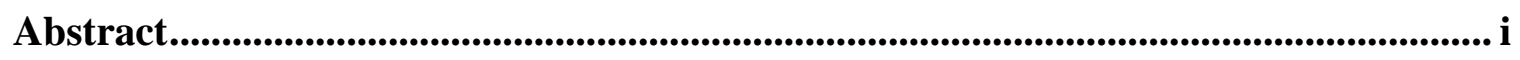

Acknowledgements ....................................................................................................... ii

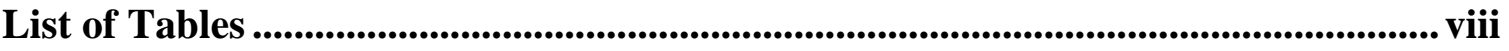

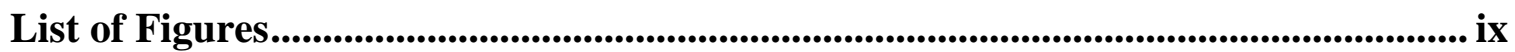

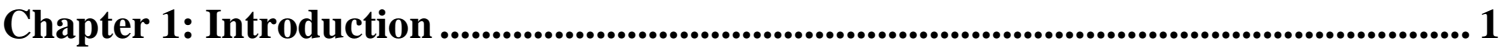

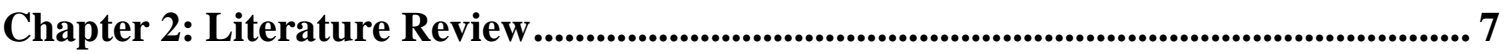

The Mandate for Political Advocacy ................................................................... 7

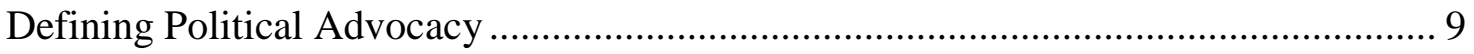

Political Advocacy Efforts of Contemporary Generalist Social Workers................... 12

Social Work Educators and Political Advocacy ................................................. 27

The Teaching of Political Advocacy with Undergraduate Social Workers ................. 29

Teaching of political advocacy: Knowledge. ..................................................... 31

Teaching of political advocacy: Motivation, values, and beliefs.......................... 33

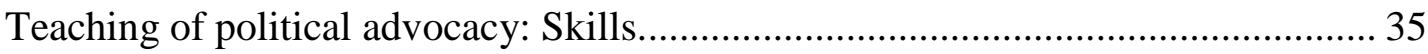

Teaching of political advocacy: Epistemological theory. .................................... 38

Teaching of political advocacy: Experiential teaching methods. ........................... 40

Teaching of political advocacy: Two planning models...................................... 46

Teaching of political advocacy: Comprehensive curriculums. ............................... 47

Teaching of political advocacy: Student perception............................................ 52

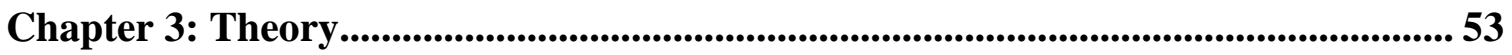




\section{INCREASING POLITICAL INTEREST AND EFFICACY}

The Citizen Participation Model ............................................................................ 54

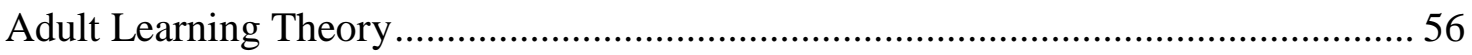

Conscientization: Integrating Critical Consciousness and Adult Learning Theory ...... 59

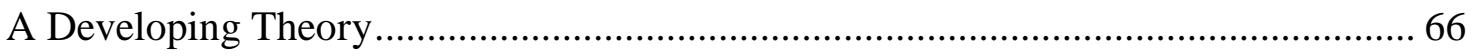

Chapter 4: Research Questions and Methods ...................................................................... 71

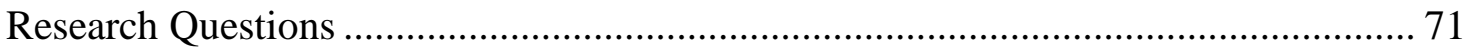

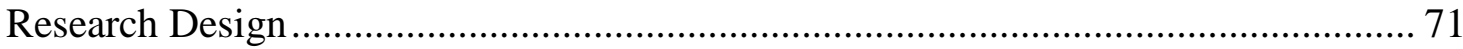

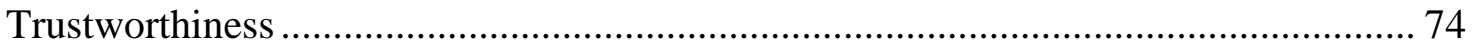

Participant Selection and Protection ....................................................................... 77

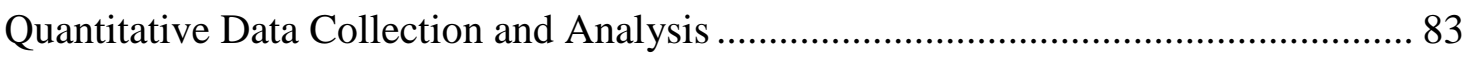

Qualitative Data Collection and Analysis ................................................................ 88

Chapter 5: Quantitative Results ..................................................................................................... 98

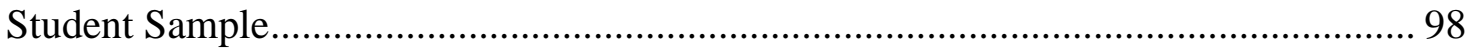

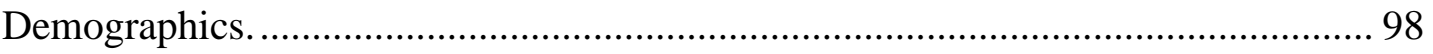

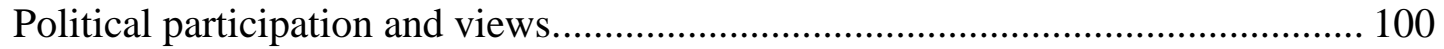

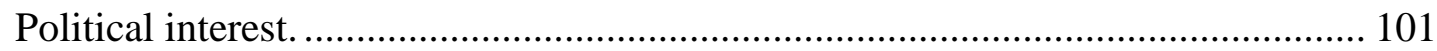

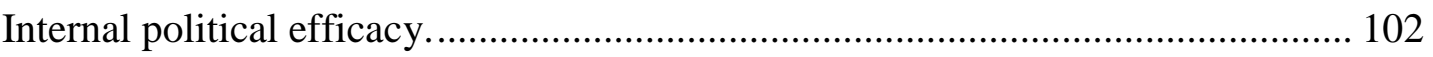

Change in Students' Political Interest during Social Welfare Policy Course ............. 103

Change in Students' Internal Political Efficacy during Social Welfare Policy Course

Chapter 6: Qualitative Results .................................................................................................. 110

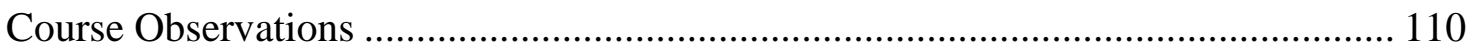




\section{INCREASING POLITICAL INTEREST AND EFFICACY}

The Impact of a Social Welfare Policy Course on Students ................................... 112

Political interest. ........................................................................................ 113

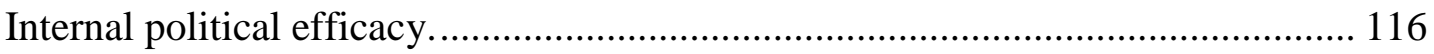

The Social Welfare Policy Student: Themes for Effective Learning ....................... 120

1. Intrinsic value of course and internal motivation to learn............................... 120

2. External motivation and support............................................................ 123

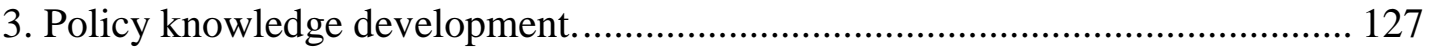

4. Genuine and diverse political dialogue. .................................................... 129

5. Political advocacy skill development. .......................................................... 138

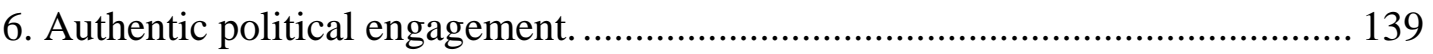

7. An expanded view of and appreciation for political advocacy. ....................... 142

The Social Welfare Policy Instructor: Themes for Effective Teaching .................... 143

1. Demonstrate basic instructional competencies............................................. 144

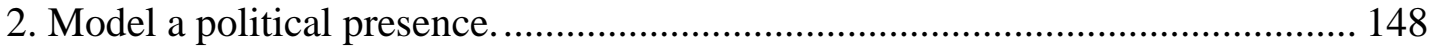

3. Communicate belief in students' ability to impact the political system............. 149

4. Create a course structure that encourages praxis........................................... 150

5. Emphasize local and "real" political exposure and engagement....................... 153

6. Ground learning activities in generative themes. ........................................ 162

7. Prioritize, model, and facilitate respectful and diverse political dialogue........... 164

8. Maintain an andragogical perspective; use pedagogical methods as needed...... 171

9. Expose students to a range of political advocacy methods. ............................. 174

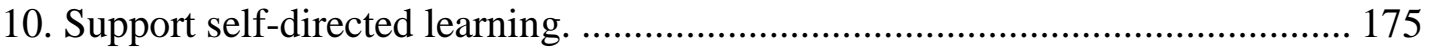




\section{INCREASING POLITICAL INTEREST AND EFFICACY}

11. Help students connect with advocacy groups relevant to their interests. ......... 179

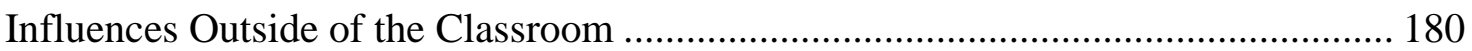

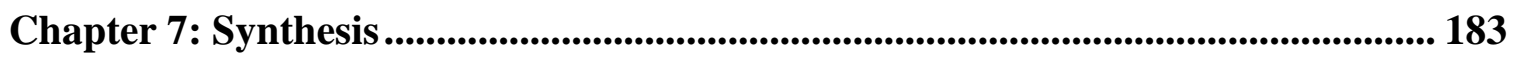

A Model for Social Welfare Policy Instruction ................................................ 183

Increasing political advocacy: The impact of interest and efficacy. ..................... 186

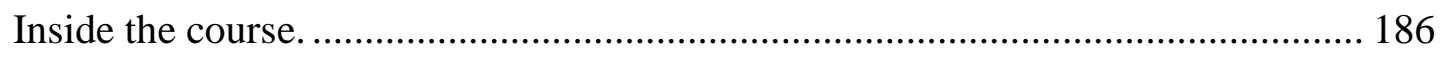

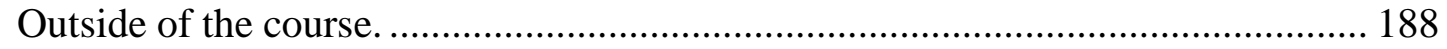

Integrating the Student Voice with the Professional Literature ............................... 189

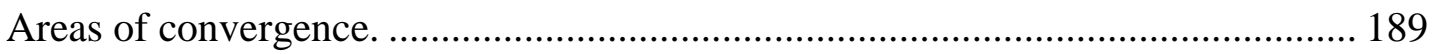

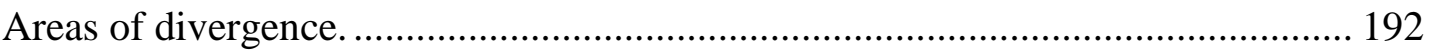

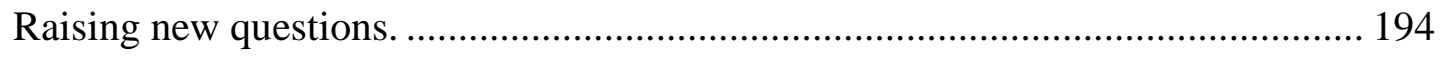

Opportunities and Challenges for Teaching Social Welfare Policy......................... 198

Balancing internal and external motivation.................................................. 200

Teaching students with a range of political knowledge and skills........................ 202

Facilitating diverse political dialogue, while modeling a political presence.......... 203

Incorporating one's instructional style and strengths into the core elements.......... 208

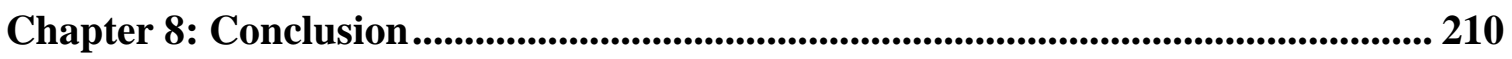

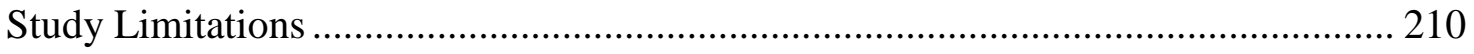

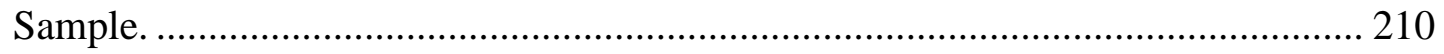

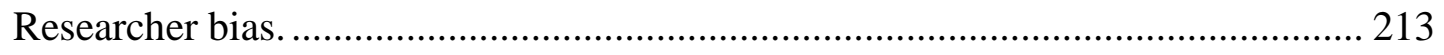

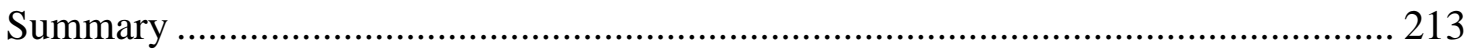

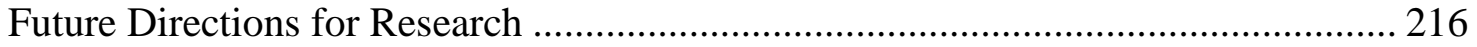


INCREASING POLITICAL INTEREST AND EFFICACY

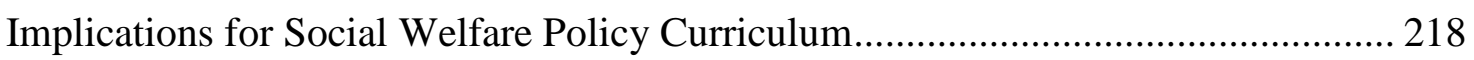

References............................................................................................................................. 220

Appendix A Consent Form for Instructor............................................................................... 234

Appendix B Pre-Test Survey...................................................................................................... 237

Appendix C Post-Test Survey ................................................................................................. 248

Appendix D Classroom Observation Guide .......................................................................... 255

Appendix E Focus Group Guide (2010)............................................................................ 257

Appendix F Interview Guide 1............................................................................................... 260

Appendix G Interview Guide 2 ............................................................................................. 262

Appendix H Human Subjects Application to IRB ............................................................. 265

Appendix I Notification of Approval from IRB ................................................................ 273 


\section{INCREASING POLITICAL INTEREST AND EFFICACY}

\section{List of Tables}

Table 1: Fundamental Principles of Foundational Theories ........................................68

Table 2: Demographic Characteristics of Study Participants .......................................99

Table 3: Baseline Political Participation and Views of Study Participants .....................101

Table 4: Baseline Political Interest of Study Participants..........................................102

Table 5: Baseline Internal Political Efficacy of Study Participants...............................103

Table 6: Descriptive Changes in Students' Political Interest........................................104

Table 7: Statistical Significance of Changes in Students' Political Interest ....................105

Table 8: Descriptive Changes in Students' Internal Political Efficacy...........................106

Table 9: Statistical Significance of Changes in Students' Internal Political Efficacy .....108 


\section{INCREASING POLITICAL INTEREST AND EFFICACY}

\section{List of Figures}

Figure 1: Initial Theoretical Model for Social Welfare Policy Instruction......................69

Figure 2: A Model for Social Welfare Policy Instruction.............................................185 


\section{INCREASING POLITICAL INTEREST AND EFFICACY}

\section{Chapter 1: Introduction}

The professional mandate for today's social worker includes a clear call for political advocacy on behalf of social justice. This mandate can be found in the National Association of Social Workers' Code of Ethics, as well as in the accreditation standards of the Council on Social Work Education (CSWE). The results of a recent study, however, suggest that social work programs have significant room for improvement in the preparation of social work students for political advocacy (Ritter, 2007). Almost half of licensed social workers surveyed disagreed with the notion that they were adequately prepared for political engagement by their social work education. A number of other social work educators and researchers have also highlighted the need to increase and improve the teaching of advocacy skills in generalist social work programs (Byers \& Stone, 1999; Hamilton \& Fauri, 2001; Hardina, 1995; Hoefer, 1999; Mary, 2001; Seipel, 1986; J. L. Wolk, 1981; Zubrzycki \& McArthur, 2004).

Existing research on the relationship between self-efficacy, motivation, and political action suggests a renewed focus on how social work educators teach social welfare policy practice rather than on what is taught. Students and social workers who exhibit higher levels of interest and internal efficacy in politics are more likely to participate in political action (Anderson \& Harris, 2005; Ezell, 1993; Hamilton \& Fauri, 2001; Ritter, 2007, 2008; Weiss, Gal, \& Katan, 2006). So how can educators engage students in the knowledge, theory, values, and skills of policy practice in such a way that 


\section{INCREASING POLITICAL INTEREST AND EFFICACY}

they are motivated and confident to act when they are in the field? Current literature suggests two approaches. First, many authors speak to the importance of teaching policy content in such a way that adult learners can see its relevance to their lives and work, and are thereby motivated to learn and apply the concepts. Second, researchers and educators emphasize the importance of increasing students' sense of political efficacy in order to remove a barrier to (or motivate for) political action. Skill development through the use of experiential pedagogical methods is the primary recommendation for increasing the sense of political efficacy among social work students. However, evidence exists that didactic pedagogical methods are still in frequent use (Pawar, 2004). There is a lack of research into the process by which adult learning and experiential teaching methods are believed to positively impact social work students' interest in and efficacy with political advocacy.

The primary motivation for my dissertation study is related to this larger professional context and was born from my recent professional struggle to create an undergraduate social welfare policy course that motivates students toward self-directed learning, strikes a satisfying balance between knowledge and skill development, inspires future policy practice efforts, and meets accreditation standards. It quickly became clear that "covering it all" well is not possible; there are practical restrictions within an already full generalist practice curriculum. Section 4.4 of the 2003 CSWE accreditation 


\section{INCREASING POLITICAL INTEREST AND EFFICACY}

standards under which this study was originally envisioned included the following content requirements for foundation social policy courses:

Programs provide content about the history of social work, the history and current structures of social welfare services, and the role of policy in service delivery, social work practice, and attainment of individual and social well-being. Course content provides students with knowledge and skills to understand major policies that form the foundation of social welfare; analyze organizational, local, state, national, and international issues in social welfare policy and social service delivery; analyze and apply the results of policy research relevant to social service delivery; understand and demonstrate policy practice skills in regard to economic, political, and organizational systems, and use them to influence, formulate, and advocate for policy consistent with social work values; and identify financial, organizational, administrative, and planning processes required to deliver social services. (Council on Social Work Education, 2003)

Although CSWE transitioned to outcome or competency-based accreditation standards in 2008 (Council on Social Work Education, 2008), the content expectations for social welfare policy instructors in undergraduate social work programs remain fundamentally the same. A literature review made evident that what initially felt like the struggle of a solitary professor to create an effective social welfare policy course can more accurately be described as an entire profession's struggle to meet its own standards. 


\section{INCREASING POLITICAL INTEREST AND EFFICACY}

While effective teaching is my primary motivation, I also bring to this study a deep commitment to the macro-practice thread of the social work profession. Intentional changes made within communities and organizations over the years have profoundly impacted human well-being, in both positive and negative ways (Long, Tice, \& Morrison, 2006; Segal, 2007; Trattner, 1999). In particular, I am interested in public policy and the ways in which it can impact human development, whether at the local, state, federal, or international level. In social welfare policy courses, it does not take students long to realize the impact of public policy on their lives, whether its child labor laws, Social Security, taxation, or civil rights legislation. A commitment and ability to incorporate macro practice strategies, including political advocacy, into one's social work practice is a commitment to adjusting social systems to meet the needs of people, rather than the other way around. Inspiring future policy practice efforts is, therefore, not only of interest to me because of CSWE requirements. I believe that policy practice is an essential means for creating a society in which human well-being and social justice are prioritized.

It is important to acknowledge that contentious issues arise when political advocacy is taught in the University classroom. Do the social work profession's explicit values of social justice and equality align with a clear political perspective? What does social justice look like, in terms of specific policies? How do academic freedom and the National Association of Social Workers' Code of Ethics impact political advocacy 


\section{INCREASING POLITICAL INTEREST AND EFFICACY}

training? What is the appropriate place for instructors' own political positions in the classroom? These are important issues that emerge alongside any consideration of political advocacy education. They were not, however, the predominant framework for this study. The methods by which political ideology and content were included in the study are discussed further in Chapter 4, while the input of students on these topics emerges in Chapter 6. My own conclusions and questions related to political ideology and content in social welfare policy courses will be presented in Chapter 7.

Because social welfare policy courses are the primary curricular means of preparing generalist social work students for political advocacy, this study explores how social welfare policy instructors can effectively support students in the development of political interest, efficacy, and ultimately advocacy efforts. There are three guiding research questions. First, how does a particular social welfare policy course impact social work students' political interest and internal political efficacy? Second, what do students convey about their participation in the course that impacted their political interest and internal political efficacy? Finally, to what teaching methods do students attribute any increase in political interest and internal political efficacy? By listening to the voices and experiences of social work students, this study begins to fill a gap in the social work education and policy practice literature. The final conclusions of the study help clarify for social work educators the methodologies by which they can more 


\section{INCREASING POLITICAL INTEREST AND EFFICACY}

effectively support students in the development of political interest and efficacy, and ultimately policy practice. 


\section{INCREASING POLITICAL INTEREST AND EFFICACY}

\section{Chapter 2: Literature Review}

The literature review that follows is intended to answer two primary and related questions: (1) What is known about the political advocacy efforts of contemporary generalist social workers, and (2) What is known about the teaching of political advocacy to generalist social work practitioners? The answers provide a context for this study, including existing knowledge on which to build and evidence of a research gap. It begins, however, with an overview of the social work mandate for political advocacy and definitional considerations.

\section{The Mandate for Political Advocacy}

As mentioned earlier, the professional mandate for today's social worker to be involved in political advocacy on behalf of social justice can be found in both the National Association of Social Workers' Code of Ethics and the profession's educational accreditation standards. As stated by Spicuzza (2003), “Advocacy is not a choice for professional social workers, it is a responsibility" (p. 49).

The National Association of Social Workers' Code of Ethics includes a section entitled Social Workers' Ethical Responsibilities to the Broader Society. Within this ethical code, social workers are called upon to "advocate for living conditions conducive to the fulfillment of basic human needs" and to "promote social, economic, political, and cultural values and institutions that are compatible with the realization of social justice" (National Association of Social Workers, 2008). Social workers are also expected to 


\section{INCREASING POLITICAL INTEREST AND EFFICACY}

expand beyond their own political action activities and "facilitate informed participation by the public in shaping social policies and institutions" (National Association of Social Workers, 2008). Specifically, social workers are directed to "act to expand choice and opportunity for all people, $\ldots$ promote policies and practices that demonstrate respect for difference, support the expansion of cultural knowledge and resources, advocate for programs and institutions that demonstrate cultural competence, and promote policies that safeguard the rights of and confirm equity and social justice for all people" (National Association of Social Workers, 2008). In addition, social workers should "prevent and eliminate domination of, exploitation of, and discrimination against any person, group, or class on the basis of race, ethnicity, national origin, color, sex, sexual orientation, gender identity or expression, age, marital status, political belief, religion, immigration status, or mental or physical disability" (National Association of Social Workers, 2008).

The Council on Social Work Education (CSWE), the sole accrediting body for social work education in the United States, has also published standards that clearly call for the training of social work students in policy practice. Through these Educational Policy and Accreditation Standards (EPAS), CSWE describes social work's purpose as the promotion of "human and community well-being" (Council on Social Work Education, 2008). This professional purpose is "actualized" through social workers' "quest for social and economic justice, the prevention of conditions that limit human rights, the elimination of poverty, and the enhancement of the quality of life for all 


\section{INCREASING POLITICAL INTEREST AND EFFICACY}

persons" (Council on Social Work Education, 2008). Students of accredited social work programs are, therefore, expected to demonstrate ten core competencies as outlined in the EPAS, one of which is to "engage in policy practice to advance social and economic well-being and to deliver effective social work services" (Council on Social Work Education, 2008). Under Educational Policy 2.1.8, social work students are expected to "know the history and current structures of social policies and services; the role of policy in service delivery; and the role of practice in policy development" (Council on Social Work Education, 2008). They should be able to "analyze, formulate, and advocate for policies that advance social well-being," as well as "collaborate with colleagues and clients for effective policy action" (Council on Social Work Education, 2008).

\section{Defining Political Advocacy}

It is generally recognized that advocacy can involve actively supporting people's rights and well-being on the individual, group, community, and societal levels. This is often referred to as engaging in either case advocacy on behalf of individuals and families or cause advocacy on behalf of groups of people. As Kirst-Ashman and Hall (2006) state, "All generalist social workers engage in advocacy at some level as part of their responsibility to clients" (p. 341).

However, for the purposes of this study, the focus is on advocacy as it relates to public or governmental policies of social welfare. Social welfare policies, as such, represent a "collective response to social problems" (Segal, 2007, p. 2). These responses 


\section{INCREASING POLITICAL INTEREST AND EFFICACY}

may involve a specific goal or course of action (or inaction) or they may involve rules and procedures for the administration of a public social welfare program. It is also important to note that social welfare policies, and therefore political advocacy, occur at multiple levels of society, including the local, state, federal, and international arenas. At all of these levels, there are existing policies, proposed policies, and absent policies. Again, for the purposes of this study, the focus is on advocacy related to public or governmental policies, which is consistent with the primary focus of generalist social welfare policy courses.

Current definitions of political advocacy in social work reflect both the nature and purpose of the work. Spicuzza (2003) presents advocacy as a systematic attempt to "address decisions and policies that are unjust and agencies and organizations that are unresponsive” (p. 50). Similarly, Gray, Collett van Rooyen, Rennie, and Gaha (2002) refer to political advocacy as "action taken by social workers to effect social change, which is in the best interests of, or in keeping with, the expressed needs of the clients or constituencies being served" (p. 100). Jansson (2008) more generally defines policy practice as "efforts to change policies in legislative, agency, and community settings, whether by establishing new policies, improving existing ones, or defeating the policy initiatives of other people" (p.14). Whereas, Freddolino, Moxley, and Hyduk (2004) propose a detailed model for understanding advocacy in social work that "encompasses four major traditions ... within the profession: protecting the vulnerable, creating 


\section{INCREASING POLITICAL INTEREST AND EFFICACY}

supports to enhance functioning, protecting and advancing claims or appeals, and fostering identity and control" (p. 119). Fundamentally, these are all descriptions of attempts to change social policies for purposes consistent with the social work profession's stated mission and values.

There are a broad range of activities that can be considered legitimate means of political advocacy, including persuasion, lobbying, petitioning, testifying, public education, legal actions, and social action to achieve institutional change. Domanski (1998) conducted a national random sample survey of social work leaders in health care policy, inquiring about their participation in 44 government, private sector, and personal political activities during the 1994 health policy reform debate. From her analysis, she identifies ten prototypes of social work political participation: lobbyist, voter, campaigner, collaborator, advocate, individualist, witness, activist, persuader, and communicator. Domanski (1998) proposes these prototypes as a "reliable empirical model for political participation that integrates routine social work professional functions with their political components" (p. 156).

For the purposes of this study, political advocacy is conceptualized as actions taken to change public or governmental social welfare policies for purposes consistent with the social work profession's stated mission and values. Additional terms commonly found in the professional literature which are understood to share a similar meaning with political advocacy include "political action," "social action," and "policy practice." 


\section{INCREASING POLITICAL INTEREST AND EFFICACY}

\section{Political Advocacy Efforts of Contemporary Generalist Social Workers}

While there may be a professional mandate for today's social worker to engage in political advocacy on behalf of social justice, research suggests that political participation and social activism among professional social workers is moderate and inconsistent (Byers \& Stone, 1999). A small set of social work researchers have conducted studies into the beliefs and actions of professional social workers as they relate to political advocacy. However, most of the research has used a sampling frame of members from the National Association of Social Workers (NASW), making the results biased toward the political advocacy efforts of MSWs and clinically-oriented practitioners. Little is known about the interests, activities, and ideas regarding political advocacy among generalist BSW-level practitioners. However, these studies do suggest barriers to political advocacy that may be helpful in the development of social work curriculum at the generalist level.

Reeser conducted a national random sample survey of NASW members in 1984 and uses the data to explore a variety of issues related to social workers' political and social activism (Reeser, 1988a, 1988b, 1991, 1992; Reeser \& Epstein, 1987). Reeser (1991) defines social activism as "attitudes that support and behaviors that attempt to influence the social distribution of status, power, and resources" (p. 7). She mailed 1,333 social workers "a self-administered, eight-page questionnaire consisting of 81 items regarding their professionalization, commitment to social action, and demographic and 


\section{INCREASING POLITICAL INTEREST AND EFFICACY}

agency characteristics" (Reeser, 1988a, p. 45). With a return rate of 57 percent, Reeser then removed unemployed, retired, and student social workers from the analysis for a sample total of 682 professional social workers.

The questionnaire administered by Reeser was designed to allow a limited comparison between the attitudes of social workers in the 1960s and 1980s toward poverty, social class of clients, professional attributes, social activism, and goals for the profession (Reeser \& Epstein, 1987). Reeser compares her data with results from a 1968 survey by Epstein, in which he "sampled every third member of the New York City chapter of NASW (for) a total of 1,020 social workers" (Reeser \& Epstein, 1987, p. 612). To the authors' surprise, respondents in 1984 were significantly more likely to agree with a social structural explanation of poverty. However, the 1984 respondents were also significantly less likely to support activist goals for the social work profession itself. Fifty-three percent of 1968 respondents approved of the social work profession emphasizing social change efforts as opposed to 37 percent of 1984 respondents. Likewise, 51 percent of 1968 respondents supported "devoting social work's resources to the problems of the poor, compared with 23 percent in 1984" (Reeser \& Epstein, 1987, p. 618). Though the social workers in 1984 were more likely to approve of the use of protest as an activism strategy, both groups expressed a clear preference for consensus strategies. 


\section{INCREASING POLITICAL INTEREST AND EFFICACY}

Turning her focus to the social workers of 1984, Reeser (1988a) reports that “caseworkers, group workers, community organizers, and private practitioners differ significantly in their support of and participation in social activism" (Reeser, 1988a, p. 56). Community organizers were more likely than caseworkers and group workers "to endorse activist goals, approve conflict strategies for the profession, and participate in social action behavior" (Reeser, 1988a, p. 49). When comparing private practitioners with social workers employed in other auspices, private practitioners were "the least likely to approve of activist goals for the profession" (Reeser, 1988a, p. 49), but "more likely than other social workers to participate in political action" (p. 50). Political action was measured using three instruments. Private practitioners reported significantly greater involvement based on an index of Political Social-Action Behavior (e.g. contributing money to political campaigns, attending public rallies) and an index of Professional Social-Action Behavior (e.g. licensing, social work lobbying). However, there was not a significant difference between the two groups in reported involvement in Institutionalized Social-Action Behavior (e.g. visiting a public official, serving on a professional organizations' social action committee). It is important to note that the number of community organizers in the sample was so small $(n=7)$ that this is really a comparison of caseworkers and group workers to private practitioners. The results may have been different with a substantial sample of community-based practitioners. 


\section{INCREASING POLITICAL INTEREST AND EFFICACY}

Reeser also uses her data to explore the relationship between professionalization and social action among social workers, referring to a historic concern within social work "that professionalization will diminish its commitment to social activism" (Reeser, 1991, p. 1). The relationship suggested between professionalization and social action in Reeser's study is complex, due largely to the use of five different indexes to measure professionalization, some of which were original to her research. These five indexes include measurements of participation in NASW chapters, papers published or presented, conferences attended, readership of journals, attainment of a graduate degree in social work, identification with professional peers, perceptions of decision-making autonomy, and "attitudinal commitment" to the values of "professional self-regulation, professional decorum, and emotional and political neutrality" (Reeser, 1988a, p. 46). Private practitioners reported a significantly higher degree of professionalization overall, though professionalization was not found to intensify differences in political action among practice groups as had been suggested in earlier literature. Commitment to professional values, as defined by Reeser to include self-regulation, professional decorum, and emotional and political neutrality, were found to be negatively associated with political activism. However, later statistical analysis did not support the researcher's hypothesis that the social work profession is organized around these values (Reeser, 1991). Participation in professional associations and conferences was found to be positively associated with political activism for caseworkers and group workers, while this 


\section{INCREASING POLITICAL INTEREST AND EFFICACY}

relationship did not appear for psychotherapists. Finally, Reeser examines the effects of professional role orientation (degree of identification with professional peers as a reference group) on social activism. A bureaucratic orientation was found to discourage social activism. A client orientation encouraged social activism. A professional orientation was found to have an insignificant effect on social activism, unless it was coupled with a client orientation, in which case it intensified the activist effect (Reeser, 1992). Overall, Reeser concludes that professionalization does not decrease participation in political advocacy.

However, the complexity of Reeser's findings suggests a need for further research into the impact of professionalization on the political advocacy of social workers. Social work education is commonly understood to play an important role in the development of social workers' professional identity (Council on Social Work Education, 2003; Daniel, 2007; Leighninger, 1978, 1984; Payne, 2007; Witkin \& Saleebey, 2007). Therefore, further clarification of how professional identity and role orientation impact social action could prove helpful in more effectively integrating the professional development and political advocacy education of social work students.

Ezell also examines the advocacy activities of social workers, concluding that American social workers are primarily involved in case-based advocacy work as opposed to political advocacy (Ezell, 1993, 1994). Ezell randomly sampled approximately 500 members of the Washington State Chapter of NASW and 77 graduates of the University 


\section{INCREASING POLITICAL INTEREST AND EFFICACY}

of Washington School of Social Work (BSW, MSW, and Ph.D.). Of the 353

respondents, 311 were NASW members and 42 were non-members. This means that "the sample was predominantly female, MSWs, white, and very experienced (i.e., more than 13 years experience on the average)" (Ezell, 1993, p. 84). Ezell's survey collected data related to respondents' demographics, frequency and type of participation in advocacy, and participation in political action. Of the approximately 90 percent of respondents who indicated involvement in advocacy as part of their job, 75 percent advocated for individual cases and 25 percent advocated for groups of clients (Ezell, 1994). Respondents in Ezell's survey (1994) tended to be "involved in case advocacy while at work and class advocacy while volunteering" (p. 36).

Ezell compares his data with that of Wolk (J. L. Wolk, 1981), who surveyed a random sample of NASW members in Michigan just prior to the Reagan administration. Wolk's sample was also predominantly MSW-educated (84\%). Both utilized "a modified version of the Political Activity Index used by Woodward and Roper in their research" (J. L. Wolk, 1981, p. 284). The most common form of political (or cause-oriented) advocacy engaged in by Ezell's sample was writing letters to public officials, followed by discussing political issues with friends, belonging to politically active organizations, and attending political meetings (Ezell, 1993). Wolk's (1981) sample indicated the same primary forms of political engagement among social workers, with the most common at that time being membership in politically active organizations (66\%). Both researchers 


\section{INCREASING POLITICAL INTEREST AND EFFICACY}

used the Political Activity Index to categorize respondents as inactive, active, or very active in politics. Based on this categorization, Ezell (1993) concludes that there was an increase in political activity among social workers during the Reagan era.

Ezell also explores the primary motivation for social workers to engage in political advocacy. Respondents were asked to identify their top three reasons for participating in political advocacy from the following list:

because it's my professional responsibility; because I've experienced oppression; because of previous work experience; because it's my job to do it; because I'd feel guilty if I didn't; because of previous volunteer experience; because of my personal values; because I enjoy advocacy; because I think it's the best approach for certain problems; because of peer pressure; and because I'd like to see things change. (Ezell, 1993, p. 89)

The three most commonly identified motivations for political action were personal values, a sense of professional responsibility, and a desire to see things change. Only one item from the above list of motivations correlated with respondents' degree of political activity: previous volunteer experience. In other words, those social workers who identified previous volunteer experience as a primary reason for their current political advocacy efforts were significantly more likely to engage in political actions. No other source of motivation demonstrated this consistency of impact. The dynamics of this impact have not, to my knowledge, been further explored in the literature. Was it due to 


\section{INCREASING POLITICAL INTEREST AND EFFICACY}

a level of passion or interest expressed by or further developed through volunteering?

Did volunteering offer an opportunity to practice taking action on an issue of concern?

Were activist role models accessed through volunteer opportunities?

Both Ezell and Wolk hypothesize about factors that weaken social workers'

political activity and impact. Ezell (1993) suggests the following two factors as reasons social workers may choose not to engage in political advocacy: a perceived correlation between politics and inequality and the perception of politics as "a dirty business" (p. 82). However, neither of these is currently supported by research. Wolk (1981) proposes that “social workers' participation in the political arena may be as active as the profession has any right to expect" (p. 287). However, he argues that "despite the apparent numbers of professional social workers engaged in political activism, the profession plays a minimal role in shaping policies and decisions at the local, state, and national levels" (J. L. Wolk, 1981, p. 288). Wolk (1981) suggests that social workers may have inadequate or "insufficient skills" for engaging in "overt political behavior - personal legislative contact, campaigning, and testifying" (p. 288).

In 1997, Hamilton and Fauri (2001) surveyed 242 certified (MSW-level) social workers in New York State regarding their political activities. The authors conclude that the social workers represented by this study are more politically active than the general public. The most frequent political activity reported was voting in the presidential election of 1996 (92\%), followed by "contacting government officials by phone, fax, 


\section{INCREASING POLITICAL INTEREST AND EFFICACY}

letter, or email" (60\%) (Hamilton \& Fauri, 2001, p. 325). The most infrequently reported political advocacy tactics were participating in demonstrations (25\%), meeting in-person with government officials (17\%), volunteering in a political campaign (13\%), and testifying before a legislative body (3\%).

Several of these researchers offer insight into predictors of political activism on the part of professional social workers (Ezell, 1993; Hamilton \& Fauri, 2001; J. L. Wolk, 1981). Wolk (1981) analyzed differences in political activity based on "sex, race, age, educational degree, years in practice, and salary" (p. 285). Significant differences were found only in the areas of age, years in practice, and salary. The correlation between increasing age and increasing political participation were consistent, suggesting that older social workers engage in more political activity than younger social workers. However, while there were differences in political participation rates based on length of practice and salary range, they did not have a consistent trend. For example, social workers in practice for 15-20 years were significantly more likely to engage in political advocacy than those in practice 2 or less years and 9-14 years, but no such difference existed with those in practice 3-8 years (J. L. Wolk, 1981, pp. 285-286). Wolk also found that social workers practicing in community organization, administration, and teaching were significantly more likely to engage in political activity than other social workers. Ezell (1993) found that African American social workers, members of NASW, and macro practitioners were significantly more likely to participate in political activity than social 


\section{INCREASING POLITICAL INTEREST AND EFFICACY}

workers in other racial groups, non-NASW members, and micro practitioners.

Educational degree was also found to be correlated with level of political action in Ezell's study. The highest political activity index scores were found among those with both an MSW and another MS degree. Those with Ph.D.s and DSWs were more active than MSWs. MSWs and those with a BA or BS degree reported similar average scores. Respondents with a BSW reported the lowest political activity level. The strongest predictors of political participation among Hamilton and Fauri's (2001) respondents were encouragement of political participation by professional associations and a sense of political efficacy or effectiveness.

In 2003, Dickinson surveyed NASW members in South Carolina regarding their attitudes toward social action and compared those responses to the results of a similar survey conducted in 1972 (Dickinson, 2005). Attitudes toward professional responsibility for engaging in social action and agreement with specific tactics of social action were measured. With a response rate of 42 percent, the author reports that " 83 percent of the respondents strongly agreed or agreed with the statement, 'Actions for improving social conditions should be a primary responsibility for all social workers"” (Dickinson, 2005, p. 52). She also measured respondents' attitudes toward campaign and contest tactics. Campaign tactics are those used to persuade opponents or decisionmakers, such as writing letters, testifying, and lobbying. Contest tactics include advocacy methods intended to pressure decision-makers into taking specific actions or adopting 


\section{INCREASING POLITICAL INTEREST AND EFFICACY}

specific policies, such as picketing, demonstrating, and striking. The 2003 respondents indicated significantly greater approval of contest tactics than the respondents from 1972, but both groups clearly preferred campaign tactics as a means for political action. For those respondents not involved in social action, the "2003 respondents seemed to provide more reasons that were due to the demands of their jobs, in comparison to the 1972 respondents ... In 2003, fewer respondents indicated a lack of inclination or the lack of opportunities to engage in social action" (Dickinson, 2005, p. 50).

Finally, in 2005, Ritter (2007, 2008) conducted a study evaluating political participation among social workers, as well as the degree to which resources, psychological engagement, and attachment to recruitment networks can explain the various levels of political action found. She conducted a telephone survey of 396 randomly-selected licensed social workers from 11 states across the United States, representing a $75 \%$ response rate. "The majority of respondents had an MSW degree (67.4\%), and identified as working directly with individuals and families in a nonadministrative position (63.4\%)" (p. 68).

Ritter's study supports previous conclusions that social workers are more politically active than the general public, though she suggests a more modest level of political advocacy among social workers than do Ezell (1993) and Wolk (1981). According to Ritter (2007), slightly less than half (46\%) of respondents can be “characterized as 'active' or 'very active,' while 54 percent can be considered 'inactive' 


\section{INCREASING POLITICAL INTEREST AND EFFICACY}

or "somewhat active", (p. 73). This is primarily attributed to the use of more stringent criteria for reported political action. Rather than asking respondents whether they had ever participated in certain activities or had done so in the past four years, Ritter asked respondents to identify the political actions they had taken in the past one to two years. As in previous studies, the political action most frequently reported by those surveyed was voting (97\%), followed by persuading someone to vote for a political party or candidate (61\%) and contacting federal or local officials (55\%) (p. 69). Ritter (2007) supports the notion that social workers' political advocacy is predominantly exercised in the realms of voting and non-electoral activities. Respondents reported low levels of political involvement in the other three modes of political participation studied: “electoral political activities, job-related political advocacy, and unconventional political participation" (e.g. protests, marches, consumer boycotts) (p. 74).

In her study, Ritter (2008) applied Verba, Schlozman, and Brady’s Citizen Participation Model, "developed to explain why citizens become involved in politics" (p. 348). She used their Political Activities Scale to measure respondents' political activity level as a dependent variable. Then nineteen independent variables were measured for their explanatory power. In order to evaluate whether licensed social workers have access to the resources necessary for political participation, respondents' free time, annual family income, and political skills were measured. The psychological engagement of licensed social workers to participate in politics was operationalized to 


\section{INCREASING POLITICAL INTEREST AND EFFICACY}

include "level of interest in politics, degree of partisanship, level of political efficacy, knowledge about politics, and family influences" (Ritter, 2008, p. 350). Finally, in order to measure attachment to recruitment networks, respondents were asked whether they had been invited "to vote or take some other political action on the job, in church, or in a nonpolitical organization" (Ritter, 2008, p. 351).

"Two of the three major components of the civic voluntarism model psychological engagement and recruitment networks - contributed to explaining licensed social workers' political participation" (Ritter, 2008, p. 352). The resource variables were not significant predictors. Four of the five psychological engagement variables were significant predictors: interest in politics, internal political efficacy, family influences, and political knowledge. Degree of partisanship was not significantly correlated with higher levels of political activity. Attachment to recruitment networks was also a positive and significant indicator of political participation. The strongest predictors of respondents' political participation were interest in local politics and NASW membership.

Research conducted on political advocacy among social workers and social work associations outside of the U.S. is growing, as well (M. Gray et al., 2002; Hardina, 1995; Mendes, 2003a; Weiss-Gal \& Gal, 2008). Though unique variations are found, the international literature reflects similarly moderate levels of involvement and analogous preferences for less risky advocacy tactics (e.g. voting, letter writing, educating). Weiss- 


\section{INCREASING POLITICAL INTEREST AND EFFICACY}

Gal and Gal (2008) conducted a convenience sample survey of 411 social workers throughout various agencies and regions in Israel, in order to explore the impact of social and professional values on "social workers' attitudes toward, and engagement in, policy practice" (p. 16). One of Weiss-Gal and Gal's statistically strongest findings was that social workers who place a high importance on the social work goal of promoting social justice are more likely to approve of policy practice as a fitting intervention for social work $(p<.001)$. They also identified a strong correlation between social workers' belief that poverty is caused primarily by structural or environmental factors and both support for, and engagement in, policy practice. Though support for policy practice as a fitting intervention in social work was found to be the strongest predictor of actual political engagement among social workers in Weiss-Gal and Gal's study, the actual correlation between support for policy practice and engagement in policy practice was only moderate. They offer to possible explanations for this: (1) the disparity between attitudes and behaviors often found in the research literature and (2) the lack of "knowledge, skills, or sense of competence to engage in policy practice" (Weiss-Gal \& Gal, 2008, p. 25).

Only one research study geared specifically to the political activism of BSW trained social workers was found. Byers and Stone (1999) present qualitative research results from eleven interviews with "socially/politically active BSW students and recent BSW graduates" (p. 1). The study was motivated by unpublished data suggesting a low 


\section{INCREASING POLITICAL INTEREST AND EFFICACY}

level of political and social activism among undergraduate social work students. It was designed to explore what motivates social workers who are politically active to assume that role. Salient themes that emerged in terms of motivation to act included the following: a personal philosophy about activism and social justice, strong feelings of personal connection to an issue, a sense of efficacy, a belief that change is possible, and a sense of belonging to an activist group or community. Little is known about the actual political advocacy efforts of BSW trained social workers overall.

Hodge (2003) conducted a study on value differences between graduate-level social workers, bachelor's-level social workers, the middle class, and the working class that supports the need for further research on the political attitudes and actions of BSWlevel social work practitioners. Based in "new-class" theory, which posits the relatively recent development of a knowledge (or professional) class, the study used data on political, economic, and social views taken from the General Social Surveys of 1972 through 1998. Hodge reports that "graduate social workers affirm value positions to the left of working- and middle-class clients," while bachelor's-level social workers hold value positions in between those of graduate social workers and clients. He also concludes that these value differences provide a challenge for social workers who are mandated to advocate on behalf of their clients or consumers. The distinctions found between the political, economic, and social stances of graduate and bachelor's-level 


\section{INCREASING POLITICAL INTEREST AND EFFICACY}

social workers suggest that there may also be differences in the goals and methods of political advocacy between these two professional groups.

\section{Social Work Educators and Political Advocacy}

Research suggests that social work program personnel may also have conflicting values and actions with regard to political advocacy. For a dissertation at Brandeis University, Montgomery (1980) surveyed field placement agency coordinators and school field instructors in New England regarding the relative importance of fifteen skill areas previously identified as important for social work practice. All respondents agreed that seven skill areas typically associated with casework were essential. The remaining eight, including those associated with group work, community organization, advocacy, and social action, were not deemed essential. Then, in 2003, Corvo, Selmi, and Montemaro (2003) conducted an exploratory study of recruitment materials from 48 graduate schools of social work, in order to determine how universities portray social work and especially macro social work in their marketing materials. The authors evaluated the photography and curricular descriptions in course catalogs, bulletins, and other print materials provided by the schools. They report that the micro-oriented or therapeutic activities of social work are overwhelmingly emphasized both in photographic images and curriculum content, as opposed to macro-oriented or community-based practices, including political advocacy. 


\section{INCREASING POLITICAL INTEREST AND EFFICACY}

Mary (2001) reports on the political involvement and values of 155 MSW classroom and field educators in the southwestern United States, as determined by a surveys conducted in 1989 and 1999. In order to measure political involvement, Mary used an expanded version of Milbrath's Hierarchy of Political Involvement (1965), asking whether the respondents had ever engaged in the various political activities identified within the model. Milbrath conceptualized three levels of political involvement: (1) "gladiator" activities, such as being elected to public office or contributing time to a political campaign; (2) "transitional" activities, such as letter writing, testifying, and attending a demonstration; and (3) "spectator" activities, such as voting or initiating a political conversation. Both the 1989 and 1999 results suggest a greater level of political involvement among social workers (at least those connected to social work education) than in the general population. Voting was the most frequently reported political activity, followed by writing letters to candidates and initiating political conversations. Macrolevel practitioners were found to be more politically involved than direct practitioners (62\% of supervisors and $63 \%$ of macro practitioners scored "high" in political involvement compared to $27 \%$ of direct practitioners, $\mathrm{p}<.05)$. And public agency employees were found to be more politically involved than private human service employees $(\mathrm{p}<.002)$. The study "did not confirm earlier studies which concluded that older and higher paid individuals have significantly higher political participation rates" (Mary, 2001, p. 8). Four open-ended questions were asked of respondents related to 


\section{INCREASING POLITICAL INTEREST AND EFFICACY}

motivators for and barriers to political leadership. The most common barrier identified (33\% of the comments) was a lack of "fit," that "social workers are not trained in politics and don't see what they do within a political context" (Mary, 2001, p. 13). The second most commonly identified barrier to seeking positions of political leadership (25\% of comments) was practical concerns, such as a lack of time, energy, or money. Two other related barriers commonly identified were conceptualized as "Politics as Dirty Business" (20\%) and "Value Conflicts" (18\%).

These findings about the moderate and inconsistent political advocacy efforts of social workers, especially those concerning educators themselves, suggest the need for continued research, discussion, and development around the teaching of political advocacy to social work students.

\section{The Teaching of Political Advocacy with Undergraduate Social Workers}

Both anecdotal and research-based evidence suggest that the teaching of political advocacy in social work programs is as inconsistent as the advocacy activities of individual social workers discussed above. Seipel (1986) presents data from a questionnaire and exploratory content analysis of $66 \mathrm{MSW}$ and $78 \mathrm{BSW}$ programs' social welfare policy curricula; all programs in the study were CSWE-accredited. In the questionnaire, policy sequence coordinators were asked to provide an estimate of the amount of course content represented by "1) skills/analytical components (e.g., policy research, cost/benefit analysis), 2) substantive components (e.g., social security 


\section{INCREASING POLITICAL INTEREST AND EFFICACY}

legislation, housing policies), and 3) historical/philosophical components (e.g., reform movements, values)" (Seipel, 1986, p. 57). Respondents were also asked to send copies of the course outlines used in foundational social welfare policy classrooms. Seipel (1986) reports finding a great variety of credit requirements, course content, and specific tasks in foundational policy courses, and suggests that this reflects a "laissez-faire doctrine" with regard to policy curriculum in social work (p. 53). Ultimately, Seipel concludes that the substantive content area of policy studies receives the greatest amount of attention in foundational social work courses and the skill/analytical content area receives the least. He also argues that the data demonstrate a lack of agreement in social work education over what skills and analytical content ought to be covered in foundational policy courses.

Seipel (1986) makes four recommendations with regard to policy curriculum. First, "there should be only minimal differences between BSW and MSW foundation contents except in the level of content sophistication" (Seipel, 1986, p. 59). Second, in order to better facilitate the establishment of professional guidelines, "more effort should be made to shape and articulate consensual philosophical bases for the social work profession" (Seipel, 1986, pp. 59-60). Third, "educators need to generate curriculum design models of principles that are useful for distinguishing appropriate course contents along the BSW and MSW continuum" (Seipel, 1986, p. 60). And fourth, "ongoing learning opportunities should be made available so that social work educators and 


\section{INCREASING POLITICAL INTEREST AND EFFICACY}

practitioners can learn and develop 'state-of-the-art' policy analysis/formulation techniques, curriculum design methodologies, and curriculum content issues" (Seipel, 1986, p. 60).

Other researchers have articulated a similar desire to Seipel's for a more comprehensive and consistent model of policy education in social work (Abel \& Kazmerski, 1994). However, it was not until recently that more comprehensive models have been proposed for teaching political advocacy to social work students at the foundational level (Weiss et al., 2006; Zubrzycki \& McArthur, 2004). Most of the professional literature related to the teaching of political advocacy in social work involves specific teaching methods, suggested assignments, or concerns related specifically to knowledge, motivation, values, or skills as they relate to political advocacy.

\section{Teaching of political advocacy: Knowledge.}

Most of the literature related to the knowledge component of social welfare policy courses agrees with Seipel's (1986) conclusion that substantive information regarding specific policies is already well covered, arguing instead for the need to provide a stronger knowledge base in the political economy. Hoefer (1999) presents the MSW program at the University of Texas at Arlington as a model for how to integrate politics into the social work curriculum without drastically changing the program, beginning with creation of a Politics and Social Work course. Other educators focus on the liberal arts 


\section{INCREASING POLITICAL INTEREST AND EFFICACY}

component of social work education as the opportune place to address this perceived knowledge deficit. For example, Abel and Kazmerski (1994) recommend requiring economics and political science in the liberal arts foundation required of social work students. Tully, Nadel, \& Lesser (2005) take it a step further, presenting a new social issues-related economics course as a way to overcome the intimidation of economics for social work students and more effectively engage them in drawing connections between economic concepts and social welfare. Dempsey (2008) echoes the urgency of incorporating more electoral politics and economics into social welfare policy training if the profession is serious about creating "an inclusive and representative electorate" and managing "our free market economy for everyone's benefit" (Dempsey, 2008, pp. 103104). "Major social change requires the concerted political activity of large groups working cooperatively to win government control rather than just lobbying the existing government" (Dempsey, 2008, p. 102). More specifically, Ersing and Loeffler argue that the concept of social capital should be mainstreamed into social welfare policy content, in order to help prepare students to influence anti-poverty policies from the local to international levels (Ersing \& Loeffler, 2008).

A final challenge is offered by Rosenthal (1992) who analyzes the social policy statements of NASW's Delegate Assembly and concludes that the profession does not appear to value verified, empirical knowledge in its political advocacy efforts. Rosenthal found assertions of knowledge throughout NASW's social policy statements, but a severe 


\section{INCREASING POLITICAL INTEREST AND EFFICACY}

lack of documentation to verify those assumed facts. Instead, she concludes that the profession relies heavily upon values and unsubstantiated beliefs, which she argues is not an effective form of persuasion for those with differing values and beliefs. "In order to most effectively carry out its mission, the profession must better document its knowledge beliefs, especially those which are made public, so that it will more likely be heard by

those it must influence both within and outside the profession" (B. S. Rosenthal, 1992, p. 45). If subscribed to, Rosenthal's argument would impact the teaching of a knowledge foundation in social welfare policy.

\section{Teaching of political advocacy: Motivation, values, and beliefs.}

Motivation, values, and beliefs are understood to be internal influences on the purpose and frequency of social work engagement in political advocacy. Motivation to engage in political advocacy is addressed in the literature primarily in two ways. First, many authors speak to the importance of teaching policy content in such a way that adult learners can see its relevance to their lives and work and are thereby motivated to learn and apply the concepts. This will be discussed later under the topic of pedagogy. Second, researchers and educators speak to the importance of increasing students' sense of political efficacy in order to remove a barrier to (or motivate for) political action. Hamilton and Fauri (2001) report that the strongest predictors of political participation among MSW-level social workers are encouragement of such efforts by professional associations and a sense of personal effectiveness in political action. Skill development 


\section{INCREASING POLITICAL INTEREST AND EFFICACY}

is their primary recommendation for increasing the sense of political efficacy among social work students and will be discussed in the following section.

While values and beliefs are the foundation of social workers' mandate to engage in political advocacy (Council on Social Work Education, 2008; National Association of Social Workers, 2008), these values and beliefs pose what may be a particularly challenging set of questions for social work educators around political advocacy. According to NASW, the purpose of political action in social work is to "advocate for living conditions conducive to the fulfillment of basic human needs" and to "promote social, economic, political, and cultural values and institutions that are compatible with the realization of social justice" (National Association of Social Workers, 2008). Social justice is commonly understood to involve a sense of fairness, an equal distribution of "the same basic rights, protections, opportunities, and social benefits, as well as the same social obligations" (Segal, 2007, p. 91). But what are these basic rights, protections, opportunities, benefits, and obligations? If the social work profession is to speak in a unified voice about policy issues, should it be able to back those positions up not only with value stances but with evidence, as suggested by Rosenthal (1992)? What if social workers' values and beliefs around social justice and policies differ substantially from the clients or consumers on whose behalf social workers are mandated to advocate, as suggested by Hodge (2003)? Additional literature addressing these challenging questions was not found. 


\section{INCREASING POLITICAL INTEREST AND EFFICACY}

There is, however, evidence that social work education can impact the sociopolitical values and beliefs of its students. Van Soest (1996) studied the impact of an MSW course on students' beliefs about societal oppression using a pre- and post-test design with 222 students from two universities. Though students' belief that the world is already a just place was expected to lessen due to participation in the course, she found instead a small but statistically significant increase in students' acceptance of a just world ideology. Students also reported an increase in their advocacy efforts on specific issues. Van Voorhis and Hostetter (2006) studied MSW students' beliefs around empowerment of both social workers and oppressed population groups. Sixty-one percent of the 85 students who entered the MSW program at Indiana University at one point in time were surveyed. The students indicated an existing belief in such empowerment upon entering the program. Still, a significant increase in both areas occurred over the course of the graduate program. Finally, in a pre- and post-test survey of social work students' social policy preferences in Israel and the United States, Weiss, Cnaan, and Gal (2005) found significant differences among the three cohorts at the beginning of their studies. However, by the end of their programs, students at all three schools demonstrated an increased acceptance of the welfare state model and core principles of social justice, with the most notable change occurring in a program that emphasized social activism among social workers.

\section{Teaching of political advocacy: Skills.}




\section{INCREASING POLITICAL INTEREST AND EFFICACY}

Effective political action requires not only knowledge, motivation, and beliefs, but a range of advocacy skills. As stated earlier, a number of social work educators and researchers have called for a need to increase and improve the teaching of advocacy skills in generalist social work programs (Byers \& Stone, 1999; Hamilton \& Fauri, 2001; Hardina, 1995; Hoefer, 1999; Mary, 2001; Seipel, 1986; J. L. Wolk, 1981; Zubrzycki \& McArthur, 2004). Zubrzycki and McArthur (2004) describe the current teaching of social welfare policy as emphasizing attainment of knowledge, both in terms of the development of the welfare state and of policies in particular fields of practice. "Where skills are highlighted, they tend to be the skills required to analyse policy, such as research, critical and analytical skills" (Zubrzycki \& McArthur, 2004, p. 452).

A number of authors focus on which advocacy skills should be taught, with some proposing a set of general political advocacy skills. For example, Mary (2001) emphasizes the need for more attention to ethical behavior and compromise in political decision-making. This leads her to propose the following set of skills identified by social work politicians and compiled by NASW as most necessary for successful political action in social work: "listening, responding, caring; linking, advocacy, and brokering; posing alternative solutions and seeking consensus around them; negotiation and mediation" (as cited in Mary, 2001, p. 16). Austin, Coombs, and Barr (2005) identify the following fundamental skills necessary for both micro and macro-level practitioners: relationship building, assessment, promoting helping processes and engaging in change strategies, 


\section{INCREASING POLITICAL INTEREST AND EFFICACY}

effective use of self in fostering client empowerment, and use of empathy and cultural sensitivity. The need for communication and critical thinking skills in effective policy work is commonly noted (Gregory \& Holloway, 2005; Long et al., 2006). And Spicuzza (2003) provides a persuasive argument for BSW programs to focus more on developing leadership skills among their students, in order to foster future advocacy efforts. He specifically proposes relationship leadership as a model particularly suited to social work values and goals, because of its emphasis on "being purposeful, collaborative, empowering others, and ethical" (Spicuzza, 2003, p. 51).

Other educators advocate for the need to train social workers in specific advocacy skills along the continuum of collaborative, campaign, and contest strategies. For example, Hardina (1995) highlights the need for education in lobbying techniques, social protest, and electoral politics. Later, she argues for the inclusion of direct confrontation skills in community organization courses, stating that "the profession has neither developed a theory or a teaching methodology for confrontation" (Hardina, 1997, p. 52). Hoefer (1999) also emphasizes lobbying and electoral politics, but adds the importance of teaching students how to effectively work with the media. There have been an array of recent articles on the need to teach media-related advocacy skills (Brawley, 1997; Hawkins, 1996; Lens, 2002), as well as electronic advocacy skills (Fitzgerald \& John, 1999; McNutt, 2007; Moon \& DeWeaver, 2005; Tower \& Hartnett, 2011). Other specific political action techniques highlighted are interorganizational collaboration 


\section{INCREASING POLITICAL INTEREST AND EFFICACY}

(Bailey \& Koney, 1996), cost-benefit analysis (Dodd \& Rivera, 2003), and argumentation or debate (Lens, 2005).

\section{Teaching of political advocacy: Epistemological theory.}

Conversation in the professional literature related to the teaching of political advocacy includes debate over which philosophical or theoretical traditions would most effectively contribute to the preparation of politically active social workers. One line of thought involves moving the social work academy increasingly towards postmodern and post-positivist methods. Positivism emphasizes the gaining of knowledge and understanding through "objective" observation and rational analysis, whereas postpositivism recognizes the subjective nature of social reality and emphasizes meaning and interpretation. Specific recommendations include the use of narratives (Gorman, 1993; Iversen, 2001), emphasizing client voices in the policy formulation process (Gibbons \& Gray, 2005), and the use of service learning and community-based research (Anderson, 2006).

Consistent with this call to the use of more post-positivist methods, Coates (1994) proposes a merger of humanist and radical traditions, in order to more effectively prepare social workers who are committed to positive social change. Four principles, based on the work of Bell and Schniedewind (as cited in Coates, 1994), are recommended as the basis of a model for education aimed at social transformation: (1) personal power, (2) group support, (3) critical-consciousness, and (4) action. Personal power involves the 


\section{INCREASING POLITICAL INTEREST AND EFFICACY}

development of self-awareness and self-esteem, which requires self-reflection and can often result in temporary depression, anxiety, and/or confusion on the part of students. Journal writing and role-playing are recommended methods for teaching and supporting personal power. Group support is described as "a climate of mutual trust and respect" (Coates, 1994, p. 8), facilitated by the teacher, in order to provide a safe (though not necessarily comfortable) environment for developing a new consciousness and an opportunity for collective and democratic action. Critical awareness includes recognition of "assumptions which underlie our own and others' beliefs and behaviors" (Coates, 1994, p. 10). Teachers encourage students to question and reflect upon "prevailing values and ideologies, and economic and political structures" (Coates, 1994, p. 11). Action is described as necessary for consolidating learning and strengthening one's sense of personal integrity. Action also provides an opportunity for students to get connected with community groups and activists who might support their efforts following graduation. Coates encourages a continuing cycle of action and reflection. He also identifies how teachers model the use of authority in the classroom and can serve in the role of teacher/learner rather than teacher/expert.

Papers offering encouragement for a more positivistic approach to policy practice can also be found. Thyer (2008) offers a fairly general argument that the contemporary evidence-based practice movement in social work provides the profession with an opportunity to ground direct practice and policy practice more solidly in "scientific" or 


\section{INCREASING POLITICAL INTEREST AND EFFICACY}

"objective" research. Rosenthal (1992), meanwhile, more directly challenges NASW, social work advocates, and thereby social welfare policy educators to base policy statements and political advocacy efforts in verified and documented empirical knowledge. As discussed previously, Rosenthal analyzed the social policy statements of NASW's Delegate Assembly and found a dramatic lack of documentation to back up its knowledge statements and policy stands.

\section{Teaching of political advocacy: Experiential teaching methods.}

A strong theme in the literature related to the teaching of political advocacy is the importance of using applied or experiential teaching methods in classroom activities and assignments. In some cases, these authors cite the importance of applying adult learning in order to effectively engage students. Others emphasize the importance of students practicing and thereby increasing their advocacy skills. Adult learning theory will be described in greater detail in the theory chapter.

Rocha (2000) conducted an exploratory study into "the effects of experiential learning on policy-related values, competency, and activity levels" (p. 53). Two groups of recent MSW graduates from the University of Tennessee - Knoxville were surveyed. The study group included those who had received experiential service learning in the MSW program and the comparison group included those who had not. The experiential service learning occurred primarily through an advanced policy course which emphasized persuasion skills, task groups, coalitions, use of the media, testifying before legislative 


\section{INCREASING POLITICAL INTEREST AND EFFICACY}

committees, and other organizing skills. Results of the survey indicate that students in both experiential and traditional courses placed a high value on political skills.

"However, the experiential group was significantly more likely to perceive themselves as competent policy practitioners and to perform policy-related activities after graduation" (Rocha, 2000, p. 53). This held true even when results were controlled for older students and students in the administration and planning concentration.

Spicuzza (2003) presents evaluation results from the University of Tennessee's BSSW program, in which curricular changes were made for the explicit purpose of increasing student leadership skills and advocacy efforts. The changes made included the following: (1) a revision of the program's mission statement and goals to emphasize the development of generalist practitioners "who are strategic thinkers, life-long learners and

opinion shapers" (Spicuzza, 2003, p. 53); (2) identifying key learning experiences within the classroom for meeting that mission, including an increased use of active learning techniques and a required service learning project; and (3) identifying key learning experiences outside of the classroom for meeting that mission, including a concerted effort on the part of faculty advisors to "link students to campus programs that put them in a position to learn leadership skills" (Spicuzza, 2003, p. 58). The program also initiated a lab time common to all social work students which was used for the weekly meeting of the student social work organization. The importance of such learning experiences inside and outside of the classroom is based largely on Terenzini and 


\section{INCREASING POLITICAL INTEREST AND EFFICACY}

Pascarella's (1994) research, which identified "the extent of active student involvement in the teaching-learning process, the frequency and quality of students' nonclassroom interaction with faculty, and the nature of students' peer group interactions as essential components of a quality undergraduate educational experience" (Spicuzza, 2003, p. 53). After three years, the author conducted an evaluation of the program changes through student portfolio assessments, administration of the California Critical Thinking Skills Test, a service-learning survey, and student evaluation of the advising process and the student social work organization. Though there is not a comparison group, students are described as having "become involved as leaders and advocates" (Spicuzza, 2003, p. 49).

Anderson and Harris (2005) conducted a comparative study of two experiential teaching models, both engaged in with undergraduate social work policy students. One social welfare policy class was taught as a service learning course, in which students worked with a local health clinic serving immigrant families to determine clients' familiarity with the Violence Against Women Act and what the most appropriate role would be for the clinic around domestic violence and Latina patients. The second social welfare policy class was taught concurrently with practicum and included assignments designed to integrate policy learning with field work, culminating in student presentations related to their practicum agencies' policies. Following analysis of their survey results, Anderson and Harris conclude that the experiential approaches were equally effective. They also note that students appeared to engage in those policy-related activities after 


\section{INCREASING POLITICAL INTEREST AND EFFICACY}

graduation "in which they had received the most instruction and experience during their social work education, suggesting that the types of assignments, activities, and experiences offered in social welfare policy courses require thoughtful deliberation and planning if our goal is to increase students' sense of self-efficacy in working on social welfare policy issues" (Anderson \& Harris, 2005, pp. 522-523).

Many other experiential teaching methods are described as having a positive impact on students' interest in and application of policy practice skills. Butler and Coleman (1997) present The Advocacy Project, in which foundation-level social work students work in small groups to "plan, implement and evaluate an advocacy strategy aimed at promoting change at the organizational, community or state level" (p. 68). Weaver and Nackerud (2005) describe a brief in-class policy construction exercise that appears to have increased students' interest in social policy. Tower and Hartnett (2011) describe an Internet-based assignment in which students are required to join e-action alert lists, respond to several alerts, and report back on their experience. Almost all students reported an expectation that they would remain on their e-action alert lists following completion of the course. Debate is also recommended as a pedagogical tool in social welfare policy courses, due largely to its incorporation of the following policy practice skills identified by Keller, Whittaker, and Burke (2001): "value clarification, policy conceptualization, interacting with others' viewpoints, political/strategic skills, and persuasive/advocacy skills" (as cited in Gregory \& Holloway, 2005, p. 631). Saulnier 


\section{INCREASING POLITICAL INTEREST AND EFFICACY}

(2000) describes an advanced policy course in which intervention assignments engaged primarily direct-practice MSW social work students in policy practice; a post-test survey indicated continued policy practice following graduation. And several other researchers explore the use of practicum as an optimal yet underutilized avenue for teaching and practicing political advocacy skills (Dickinson, 2007; Fisher, Weedman, Alex, \& Stout, 2001; Hoefer, 1999; Raber \& Richter, 1999; J. Wolk, Pray, Weismiller, \& Dempsey, 1996).

A number of educators describe experiential teaching methods used in social welfare policy courses, but without presenting a formal research evaluation. For example, Johnson (1994) presents a task force simulation exercise used in an advanced policy course on homelessness. Moore and Dietz (1999) describe a community intervention course in which students organize to change their university's policy to recognize Martin Luther King, Jr.'s birthday as a university holiday. Moore and Johnston (2002) offer detailed instruction for implementing a Student Day at the Legislature in which students participate in a statewide workshop on policy advocacy at the state level. Sundet and Kelly (2002) describe the pedagogical use of legislative policy briefs. Gray, Wolfer, and Maas (2005) propose use of the decision case method, in order to help develop students' critical thinking and leadership skills. And Carey (2007) describes a campus-based community organization project for undergraduate social work students 


\section{INCREASING POLITICAL INTEREST AND EFFICACY}

focused on rape and sexual assault prevention, in which students could make connections between "a social problem, social policy, action research, and social action" (p. 61).

Other applied and experiential teaching methods are also mentioned in the literature. Coates (1994) recommends journal writing, supported group activities, genograms, metaphor analysis, learning teams/learning partners, group grades, role play, options regarding evaluation, learning agreements, and self-selected projects. Hardina (1997) presents several specific assignments and in-class activities, such as "dialogue during class time to identify common themes related to personal experiences of oppression related to social class, heterosexism, race, ageism, ableism, and sexism" (p. 55); "written assignments and class exercises that require students to analyze legislative processes, political campaigns, or community meetings" (p. 56); and "role plays that involve staging a community forum on local issues" (p. 58). Medina (2010) proposes use of a structured process recording format for policy practice projects, in order to raise selfawareness and assess skill development. Other recommended methods include preparing and implementing a policy practice project, preparing legislative testimony, writing a letter to the editor, and simulating decision-making deliberations (Weiss et al., 2006).

Despite these calls for more experiential teaching methods, evidence exists that didactic pedagogical methods may still be in frequent use. Pawar (2004) presents an analysis of the content and teaching methods used in social policy courses in Australia, with the ultimate goal of creating a policy curriculum development model for social 


\section{INCREASING POLITICAL INTEREST AND EFFICACY}

workers. Content analysis was used to analyze the following elements of subject outlines from $15(68 \%)$ of the 22 Australian social work schools: (1) objectives, (2) topics covered in social policy subjects, (3) reading material, (4) teaching methods, and (5) assessment methods. Most relevant to this study is Pawar's observation that teachercentered teaching methods (e.g. lecture) continue to dominate the teaching of social policy, though more student-centered methods (e.g. case study) are believed to be more effective. Gibbons \& Gray (2005) present a model for applying the strengths perspective to policy practice, as well as a model for integrating policy content throughout the social work curriculum. They are convinced that it is effective, though they "cannot yet argue conclusively that our approach to teaching policy is any more or any less effective than in didactic pedagogical approaches; however, evaluations of experience-based learning models consistently show that they are more enjoyable for the teacher and the student" (Gibbons \& Gray, 2005, p. 73).

\section{Teaching of political advocacy: Two planning models.}

The final theme identified in this literature review is a debate over whether

political social work education should be method-focused or integrated. Method-focused models emphasize the teaching of political action as a macro-oriented practice method, by which social justice, community organizing, or political practice become a form of specialization. An integrated model "views (all) social work as fundamentally political" (Fisher, 1995, p. 7), infusing political action-oriented content throughout the curriculum 


\section{INCREASING POLITICAL INTEREST AND EFFICACY}

and making clear links between policy and practice. The University of Houston's MSW concentration in Political Social Work is a prime example of a method-focused model (Fisher, 1995; Fisher et al., 2001).

The focus of most of the literature in this area is on the integrated model. A number of educators provide examples of how an integrated model might look. For example, exchange theory, organizational theory, and community theory would be taught in the general Human Behavior and the Social Environment course (Abel \& Kazmerski, 1994). Interorganizational collaboratives would be discussed under human systems theory (Bailey \& Koney, 1996). Both micro and macro-level practice courses would integrate social policy content (Abel \& Kazmerski, 1994; Meenaghan \& Gruber, 1986; Mendes, 2003b; Saulnier, 2000). Participatory action research and narrative techniques would be included in the research sequence (Bailey \& Koney, 1996; Vodde \& Gallant, 2002). Political science and economics might be required liberal arts content for all social work majors (Abel \& Kazmerski, 1994; Hoefer, 1999; Seipel, 1986; Tully et al., 2005). Political policy placements would be facilitated in the practicum portion of the program (Dickinson, 2007; Hoefer, 1999; Raber \& Richter, 1999; J. Wolk et al., 1996). Development of leadership skills would be explicitly built into the curricular and social structure of the program (Spicuzza, 2003).

\section{Teaching of political advocacy: Comprehensive curriculums.}




\section{INCREASING POLITICAL INTEREST AND EFFICACY}

Due largely to the inconsistent way in which political advocacy content is provided in social work education, proposals for a comprehensive teaching model for social policy foundational content have begun to emerge. In Australia, Zubryzcki and McArthur (2004) observe that "social policy has been taught primarily as a key knowledge area for social workers to understand rather than an explicit area of practice where knowledge, values and skills are required" (p. 452). In response, Australian Catholic University developed a policy sequence in their BSW program that teaches policy as an area of practice and provides students with significant opportunities to apply political action knowledge, values, and skills. In the first of two years, students take a course on social welfare history and an introduction to social policy analysis. An historical overview, fundamental theories, economic concepts, policy analysis skills, and introduction to social work practitioners engaged in political action are emphasized. This is consistent with others' recommendation that social work professors serve as mentors and role models in political activism (Butler \& Seguino, 2000; Byers \& Stone, 1999). In the second year, students take a course specifically on policy practice. The integration of policy and practice, understanding of the policy process, knowledge of particular policy areas, application of social work values to policy development, and a range of political advocacy skills are emphasized. Included in the second year course is a four week policy workshop in which students engage in a current policy problem with a social work policy practitioner. Zubrzycki and McArthur (2004) propose that "the elements put in place in 


\section{INCREASING POLITICAL INTEREST AND EFFICACY}

these units meet the requirements to provide adult learners with an interactive environment where they are able to develop and practice skills and integrate policy into practice" (p. 456).

Weiss, Gal, and Katan (2006) published a proposed teaching agenda for social welfare policy in social work, including a conceptual framework and a detailed teaching program. In their literature review, Weiss et al. (2006) identify what is generally agreed upon with regard to policy practice in social work education: (1) political action by social workers is limited, (2) training in social policy and policy practice in schools of social work is minimal, and (3) current practitioners lack the policy practice knowledge and skills necessary to analyze and intervene in the policy process. Six categories of social policy teaching goals are then identified: (1) enhancing factual knowledge, (2) providing tools for social policy analysis, (3) enhancing critical thinking and a commitment to social justice, (4) linking social work and social policy, (5) developing intervention skills necessary to engage in policy practice, and (6) creating graduates with "the motivation, self-efficacy, and self-confidence ... to engage in policy practice as an integral part of their social work practice" (p. 795). Two primary themes related to social policy teaching methods are also highlighted. First, they identify a need to emphasize the connection between social policy and social work practice, especially direct practice. Second, they identify a need to utilize methods of active or experiential learning. 


\section{INCREASING POLITICAL INTEREST AND EFFICACY}

Following their extensive literature review, Weiss et al. propose a program for social welfare policy teaching. It is specific to the needs of Israeli social work, but the authors assert that it can be useful to social work programs in various countries. There are two primary assumptions identified in the model: (1) "political engagement ... is an integral part of social work practice," and (2) "social policy teaching cannot take a valuefree, neutral form" (Weiss et al., 2006, p. 797). Additional guidelines include a recognition that not all possible content related to social policy can reasonably be included, the importance of utilizing teaching methods found to be most effective in research on adult learning and in policy education, and encouragement for social work programs to recruit "staff members with knowledge and expertise in social policy and in policy practice who can integrate policy practice into existing and more traditional modes of intervention in social work" (Weiss et al., 2006, p. 798). Recommended program outcomes and components are outlined, including the following three components: (1) required foundational courses in social policy, (2) integration of social policy content in methods courses and field work, and (3) provision of an advanced policy practice concentration for those students with a particular interest in the field. The required foundational courses in social policy are encouraged to include the following units: Introduction to Social Policy, The Welfare State, Social Security Programs, Social Care, Specific Fields of Social Policy, and Policy Practice in Social Work (Weiss et al., 2006, pp. 800-801). 


\section{INCREASING POLITICAL INTEREST AND EFFICACY}

Heidemann, Fertig, Jansson, and Kim (2011) present the most recently published comprehensive model for training social work students in policy practice, entitled the Practicing Policy, Pursuing Change, and Promoting Social Justice (3P) approach.

Developed for an MSW program, the 3P approach involves eight stages that incorporate both theoretical and practical applications of policy. Social work instructors, students, alumni, and community stakeholders work together over many years to impact a specific policy issue in their community. The eight stages include (1) committing to this new approach that will involve making a concrete political impact in the community, (2) choosing a pressing issue that will be relevant to most social work students and feasible to address, (3) identifying a leadership and instructional team with appropriate expertise and sufficient time for planning, (4) designing the course structure, objectives, activities, assignments, and syllabus so that the necessary policy practice can occur and be supported, (5) developing a multifaceted strategy for mobilizing support based on student conducted research, (6) implementing the strategy for political advocacy, primarily through the academic course, (7) evaluating student learning and policy success at the end of each year, and (8) reflecting and revising the process accordingly. Heidemann, Kim, Fertig, and Jansson (as cited in Heidemann et al., 2011) found that students who engaged in the 3P course at a case study university had an increased appreciation for the connection between direct practice and social welfare policy and the importance of policy practice in social work. Students also reported increased confidence in "making ethically 


\section{INCREASING POLITICAL INTEREST AND EFFICACY}

based, reasoned arguments for policy proposals" (as cited in Heidemann et al., 2011, p. 49).

\section{Teaching of political advocacy: Student perception.}

Only one study was found that sought social workers' perception of their educational preparation for political action. The results suggest that social work programs have significant room for improvement in this area. In her telephone survey of 396 randomly-selected licensed social workers from across the United States, Ritter (2007) asked respondents "whether they believe that the social work program that they graduated from adequately prepared them for engaging with the political system" (p. 72). Almost half of respondents disagreed with the notion that they were adequately prepared for political engagement by their social work education (21\% strongly disagreed, $27 \%$ somewhat disagreed). Forty-two percent of respondents indicated that they were adequately prepared (29\% somewhat agreed, 14\% strongly agreed). Eight percent gave a “neutral" response. No additional questions related to respondents' educational preparation for political advocacy were asked. 


\section{INCREASING POLITICAL INTEREST AND EFFICACY}

\section{Chapter 3: Theory}

Three theoretical models inspired and informed this study. Verba, Schlozman, and Brady’s Citizen Participation Model (1995) was applied to social work practitioners and tested by Ritter (2007, 2008), whose results contribute two key concepts to the focus of this study: political interest and internal political efficacy. It is a comprehensively researched model, though not designed from the perspective of social work or professional political advocacy. Ritter's research is, therefore, an important lens through which to view it. Adult learning theory plays a primary role in the professional literature related to the teaching of political advocacy in social work and provided conceptual guidance for the researcher's data collection and analysis. However, because it is a process oriented theory and social work policy education is designed with specific goals or products in mind, it is limited in its ability to fully address the research question at hand. Freire's theory of conscientization, or critical consciousness, helps connect process and product in a manner consistent with the social work profession's mandate to be involved in political advocacy on behalf of social justice. Conscientization integrates a respect for the learning motivation and styles of adults with a critical analysis of power and a goal of transformative action on behalf of positive social change. As such, it provided conceptual guidance for this study, as well as theoretical inspiration in terms of decisions about methodology. However, the lack of studied application of conscientization to social work education is a notable limitation. 


\section{INCREASING POLITICAL INTEREST AND EFFICACY}

\section{The Citizen Participation Model}

Verba, Schlozman, and Brady’s Citizen Participation Model (1995) outlines three key determinants of people's political involvement: (1) psychological engagement, (2) resources, and (3) recruitment networks. Psychological engagement is the term used to describe a "variety of psychological predispositions toward politics" (Verba et al., 1995, p. 270). People must have a desire, interest, and degree of confidence in order to participate in the voluntary activity of political involvement. Verba et al. propose five specific constructs within the larger category of psychological engagement: (1) political interest (one's level of interest in politics), (2) political efficacy (the degree to which one feels competent to participate in political activity), (3) political information (one's knowledge of government and politics), (4) party identification (the degree of one's partisan leanings), and (5) family influences (the degree to which one's parents were politically active while raising children). In terms of resources, the Citizen Participation Model emphasizes three kinds: time, money, and civic skills (i.e. organizational and communication skills). Finally, Verba, Schlozman, and Brady identify recruitment networks as a key influence on people's political involvement. People who have the psychological engagement and resources necessary to be politically active are more likely to do so when they are asked (Verba et al., 1995, p. 3). Verba et al. also theorize that recruitment networks offer opportunities for people to develop the organizational and communication skills important for political action. 


\section{INCREASING POLITICAL INTEREST AND EFFICACY}

In her study of licensed social workers' political participation, Ritter (2008) concludes that two of the three major determinants of political participation as outlined in the Citizen Participation Model hold explanatory power: psychological engagement and recruitment networks. The resource variables were not significant predictors. To review, four of the five psychological engagement variables were significant predictors: interest in politics, internal political efficacy, family influences, and political knowledge. Degree of partisanship was not significantly correlated with higher levels of political activity. Attachment to recruitment networks was also a positive and significant indicator of political participation. The strongest predictors of respondents' political participation were interest in local politics and NASW membership.

Because this current study was designed to identify effective methods for encouraging future social workers' political advocacy efforts through the teaching of social welfare policy courses, it focused on two specific constructs from within the Citizen Participation Model: political interest and internal political efficacy. As explained earlier, the professional literature suggests social welfare policy courses already emphasize the development of students' political knowledge. Early family influences are not within the realm of social work education's influence. And while increased NASW membership among social work students may be a reasonable goal that could contribute to future social workers' advocacy efforts, it was not included within this study as a significant pedagogical concern. 


\section{INCREASING POLITICAL INTEREST AND EFFICACY}

\section{Adult Learning Theory}

It is clear that adult learning theory has played a primary role in the professional literature related to the teaching of political advocacy in social work. As discussed earlier, social work researchers and educators have consistently encouraged an experiential, applied model of teaching social work policy and political advocacy. This is for two primary reasons. First, applied learning is believed to enhance students' sense of the relevance and importance of policy to the practice of social work. Second, experiential teaching methods are believed to be more effective for developing political advocacy skills. An understanding of adult learning theory, therefore, provided conceptual guidance for my data collection and analysis.

Adult learning theory (or andragogy) proposes a model of the adult learning process and methods believed to be particularly effective in the teaching of adults. Six core principles lie at the heart of andragogical theory (Knowles, Holton III, \& Swanson, 2005). The first is that adults need to understand why they need to learn something before they engage in the learning process. The second principle is that adult learners desire a sense of autonomy and self-direction. Third, adults bring a variety of prior experience to the classroom, which should serve as a key resource in the learning process. Fourth, adults typically become ready to learn when life presents them with a relevant challenge or there is a need to perform a specific task. The fifth principle asserts that adults are problem-centered learners who do best when provided with a context and an 


\section{INCREASING POLITICAL INTEREST AND EFFICACY}

opportunity to develop a sense of competency in addressing problems. And, finally, andragogical theory proposes that adults are internally motivated learners who seek "intrinsic value" and a sense of "personal payoff" through their education (Knowles et al., 2005, p. 159). There are situations in which adult students must learn a completely new body of knowledge and are, therefore, solely dependent on their teacher. In such situations, traditional pedagogical assumptions and methods would be appropriate. However, according to Knowles (1979), approaching adult learners from an andragogical perspective would require doing "everything possible to provide [students] with whatever foundational content [they] would need and then encourage [them] to take increasing initiative in the process of further inquiry" (as cited in Knowles et al., 2005, p. 146).

Some critics of andragogy have argued that adult learning theory is too focused on the individual, neglecting the importance of critical theory and social change. These critics argue that the theory should move "beyond the teaching/learning transaction to encompass some elements of desired outcomes" (Knowles et al., 2005, p. 142). However, Knowles, Holton, and Swanson (2005) argue that andragogy was never intended to speak to the achievement of particular goals and purposes, but rather is "rooted in humanistic and pragmatic philosophy" and intentionally focuses on the individual learning transaction (p. 142). It is a theory of process, not of product.

If one accepts this process-focused intention of adult learning theory, then it becomes necessary for the profession of social work to utilize a more complex theoretical 


\section{INCREASING POLITICAL INTEREST AND EFFICACY}

framework in the creation and evaluation of its policy curriculum. After all, social work is a profession with explicit values, purposes, and goals. As creators of and experts in adult learning theory, Knowles, Holton, and Swanson (2005) support the combining of andragogy with other theories that address specific goals and purposes.

So, for example, one could engage in adult learning for the purpose of social change (critical theory) and use an andragogical approach to adult learning. Similarly, one could engage in adult learning for performance improvement in an organization (performance/human capital theory) and use an andragogical approach. (Knowles et al., 2005, p. 144)

They, therefore, propose a systematic framework for adapting andragogy to various situations.

The "Andragogy in Practice Model" incorporates three dimensions presented as concentric circles (Knowles et al., 2005). The inner ring includes the six core adult learning principles, as described above. The middle ring addresses individual, situational, and subject matter differences. Individual differences include such variables as learning styles, cognitive abilities, personality, and prior knowledge. Situational differences include local variables (e.g. rural or urban settings, small or large groups) and “socio-cultural influences" (both prior to and during learning) (p. 153). Subject matter differences refer to the unique demands made by different content. For example, some subjects (e.g. complex technical content) may not lend themselves to self-directed 


\section{INCREASING POLITICAL INTEREST AND EFFICACY}

learning as well as others. The outer ring of the Andragogy in Practice Model includes the goals and purposes for learning. These learning or developmental outcomes may include individual growth, institutional growth, or societal growth. Knowles et al. (2005) offer the following example of an adult literacy program:

Such programs may be conducted by an adult education center to help individuals improve life skills (an individual goal); by a corporation to improve job and organizational performance (an institutional goal); or by some other entity seeking to help a disadvantaged group of citizens improve their socio-economic position (a societal goal) ... When offered for societal improvement purposes, extra emphasis may be placed on developing self-directedness among the learners. When offered for work-related performance improvement, extra emphasis might be placed on relating the content to work situations. (p. 151)

The adult learning principles are applicable in all three situations, but the established goal and the theoretical perspective behind it will require unique applications.

\section{Conscientization: Integrating Critical Consciousness and Adult Learning Theory}

Paulo Freire's theory of conscientization, or critical consciousness, integrates a respect for the learning motivation and styles of adults with a critical analysis of power and a goal of transformative action on behalf of positive social change. This integration of adult learning, critical analysis, and positive social change resonates well with the context and purpose of social work education. It has, therefore, served as theoretical 


\section{INCREASING POLITICAL INTEREST AND EFFICACY}

inspiration for this study. Whereas andragogical theory can effectively inform our choice of classroom activities and assignments, placing that methodological concern within a critical consciousness framework points the profession toward more complex and pertinent questions. For example, how can social work educators most effectively train and support students in the development of power analysis and policy practice skills, so that future social workers can indeed identify discrimination and oppression, as well as promote social justice and "informed participation by the public in shaping social policies and institutions" (National Association of Social Workers, 2008)?

Informed by his practical experience organizing mass literacy campaigns in Brazil, Freire's theory of conscientization contrasts transformative education with "banking" education (Freire, 2000). Conscientization involves the development of a critical awareness - learning to perceive social, political, and economic contradictions so that people can take transformative action and "create a new situation, one which makes possible the pursuit of a fuller humanity" (Freire, 2000, p. 47). Teaching from this model involves both the instructor and the student as active learners and developers of knowledge, bringing experience and understanding to the table through different roles. Freire (1998) argues that "to teach is not to transfer the comprehension of the object to a student but to instigate the student, who is a knowing subject, to become capable of comprehending and of communicating what has been comprehended" (p. 106). Dialogue is at the center of this exchange, as is self-reflection for the purpose of better 


\section{INCREASING POLITICAL INTEREST AND EFFICACY}

understanding one's role as an active participant in society. In contrast, "banking" education refers to the view of the teacher as an "expert" who deposits his or her knowledge into the empty mind of the student. In such situations, knowledge is treated primarily as a static product that can be passed from one source to another.

Hope and Timmel (1996) effectively outline six key principles of Freire's work around conscientization. The first principle is that the goal of education should be radical transformation, "based on the vision of a new, more just society" (Hope \& Timmel, 1996, p. 16). Transformation occurs at the individual, community, and societal levels.

Secondly, dialogue is at the heart of transformative education. It involves sharing and listening. Both teacher and student are respected as bringers and developers of knowledge. Working from this perspective requires a substantial degree of trust in people's ability to think, desire to learn, and contribution of valuable information and insight. This emphasis on careful listening is not presented as a substitute for the sharing of information. Rather, it is argued that "a group is far more likely to absorb and benefit from this [information] if the program is started with dialogue, which brings to the surface all the latent questions in their minds. A relevant input will then challenge them to deeper thinking and further dialogue" (Hope \& Timmel, 1996, p. 19). Attentive listening on the part of all parties in education also contributes to an atmosphere in which people can welcome challenging perspectives. 


\section{INCREASING POLITICAL INTEREST AND EFFICACY}

Only the person who listens patiently and critically is able to speak with the other, even if at times it should be necessary to speak to him or her. Even when, of necessity, she/he must speak against ideas and convictions of the other person, it is still possible to speak as if the other were a subject who is being invited to listen critically and not an object submerged by an avalanche of unfeeling, abstract words. (Freire, 1998, pp. 110-111)

Dialogue encourages critical thinking and enhanced awareness.

A related and equally important goal of dialogue is to stimulate curiosity and, thus, actively resist passivity. "As a teacher, I ought to know that I can neither teach nor learn unless driven, disturbed, and forced to search by the energy that curiosity brings to my being" (Freire, 1998, p. 80). Modeling curiosity requires a teacher to be open to not knowing something in front of one's students. Freire recognizes the discomfort this may cause, but offers a transformed perspective: "I feel myself secure because there is no reason to be ashamed that there may be something I do not know. To live in openness toward others and to have an open-ended curiosity toward life and its challenges is essential to educational practice" (Freire, 1998, pp. 120-121).

A third key principle in Freire's theory of conscientization is the importance of "generative themes" (Freire, 2000). Through intentional listening, people are encouraged to identify for themselves the issues that are central to their learning and development. Students are encouraged to reflect on the political content of their daily lives. This 


\section{INCREASING POLITICAL INTEREST AND EFFICACY}

requires an appreciation for the importance of strong feelings, those feelings that break through apathy and generate energy and hope (Hope \& Timmel, 1996, p. 17). Freire argues that a teaching program should be based in these generative themes, as identified through the intentional listening involved in dialogue.

Fourthly, Freire argues for education based in the posing of problems and the search for solutions. Dialogue clarifies the pressing problem(s). The teacher then poses questions to help the group describe and analyze the problem, encouraging students to search deeply for its root causes (Hope \& Timmel, 1996, p. 19). This is where skills for the critical analysis of power are learned. After critical reflection, effective plans for action can be developed. "The role of the [teacher] throughout the process is not to give the answers, but to set up a process through which the group can search for the answers themselves in a systematic way" (Hope \& Timmel, 1996, p. 19).

A fifth key principle of conscientization is this constant cycle of reflection and action, commonly referred to by Freire as "praxis." At the same time he encourages praxis, he discourages either "pure action" without critical analysis or "pure verbalism" without action (Payne, 2005, p. 236). Authentic dialogue and reflection leads to action, and action should be followed by critical reflection on its consequences (Freire, 2000, p. 66). In the classroom, teachers can name and help create an optimal space for praxis to occur, as well as help students to identify the inputs most needed during each cycle, 


\section{INCREASING POLITICAL INTEREST AND EFFICACY}

whether that be information, a framework for analysis, relevant case studies, or tools for the creation of an action plan (Hope \& Timmel, 1996).

Finally, Freire argues that education is inherently political. He embraces a more subjective view of knowledge as ever changing and culturally informed. And he identifies the very presence of a teacher in a school as an "intrinsically ... political presence, something that students cannot possibly ignore. In this sense, [a teacher] ought to transmit to the students [his or her] capacity to analyze, to compare, to evaluate, to decide, to opt, to break with" (Freire, 1998, p. 90). The application of Freire's theory of conscientization to the teaching of political advocacy is not intended as an argument for the application of Freire's (or anyone's) specific political convictions to the curriculum. Rather, it is partially an argument for recognizing the importance of the teacher as a model of critical consciousness and political presence.

It is my ethical posture in the course of teaching these contents that will make the difference ... It is a posture of unconditional respect for the students, for the knowledge they have that comes directly from life and that, together with the students, I will work to go beyond. My coherence in the classroom is as important as my teaching of contents. A coherence of what I say, write, and do. (Freire, 1998, p. 94)

Demonstrating intellectual respect for the continuum of political opinion through the presentation and critical consideration of diverging views is one way in which this is 


\section{INCREASING POLITICAL INTEREST AND EFFICACY}

done. Another is the teaching and support of political action. "It's impossible for me to help someone without teaching him or her something with which they can start to do by themselves. That is my own testimony of respect for them" (Horton \& Freire, 1990, p. 193). There is an inherent risk in this approach, because it flies in the face of indoctrination. As Stanley Aronowitz notes in his introduction to Pedagogy of Freedom, "The risk of critical education is that if schools are constructed as genuine public spheres, outcomes are not guaranteed" (Freire, 1998, p. 18).

Freire's emphasis on work and education with people who are oppressed seems appropriate to social work education in three ways. First, the social work profession holds as a primary goal the elimination of discrimination and oppression. Second, social workers engage with people who come from oppressive situations on a daily basis. Finally, there is an imbalance of power in the teacher-student relationship that must be acknowledged. This is not to suggest that education is inherently oppressive. However, the degree to which Freire's principles and teaching tools are sensitive to the impact of power and focused on the empowerment of students seems particularly appropriate to the teaching of political advocacy and related knowledge.

Freire's theory of conscientization inspired and grounds this study, in particular with regard to decisions about research methodology. It highlights some fundamental, philosophical issues. For example, who sits at the curriculum planning table? Whose knowledge and experience are valued? To whom do educator-researchers most need to 


\section{INCREASING POLITICAL INTEREST AND EFFICACY}

listen? How can research be conducted in such a way as to maximize dialogue? Blank and Russell (2000) present a model for curricular program planning that places the adult learner at the center. The following five planning steps are outlined: (1) determining needs, (2) stating objectives, (3) designing instruction, (4) delivering instruction, and (5) evaluating learning. How much have the voices of students and generalist social work practitioners informed these five steps with regard to the policy content of generalist social work education? Freire's theory of conscientization would suggest that listening for the voice and insights of students and practitioners is critical to answering how generalist practice social workers can most effectively be prepared for policy practice. It is also believed that approaching this research with a theoretical understanding of not only adult learning styles, but also critical consciousness brings greater coherence to social work's educational planning process. The methods used, the knowledge gained, and the challenges posed are more likely to be consistent with the stated goals of the profession.

\section{A Developing Theory}

While each of these three models or theories provides valuable guidance, it is important to note that this study is exploratory in nature. It seeks to explain the process by which participation in a social welfare policy course impacts social work students' political interest and internal political efficacy. A fully developed theory is not being tested. Rather, existing research, theory, and practice were gathered and integrated into 


\section{INCREASING POLITICAL INTEREST AND EFFICACY}

initial theoretical conceptualizations. Ritter's $(2007,2008)$ research results, based on the Citizen Participation Model, have been accepted and integrated into the developing theory as support for the expectation that an increase in students' interest in politics and internal political efficacy will lead to increased political advocacy on their part when they become social work practitioners. The emerging portion of the theory (and the focus of this study) is related to how a social welfare policy course can most effectively support students' development of political interest and internal political efficacy.

Fundamental principles of adult learning theory and conscientization were integrated into a single set of concepts and inserted into a developing model that represented my initial thinking on how students' policy practice development might be most effectively supported in a social welfare policy course. These initial conceptualizations were based on research and practice, but required deliberate examination and further exploration in order to develop into a more complete and sound model. The fundamental principles of both adult learning theory and Freire's theory of conscientization are outlined in Table 1. The integration of the two theories into eight potential concepts and the concepts' place in the initial model developed prior to data collection and analysis are illustrated in Figure 1. 


\section{INCREASING POLITICAL INTEREST AND EFFICACY}

\section{Table 1}

\section{Fundamental Principles of Foundational Theories}

Adult Learning Theory

(1) Adults need to understand why they need to learn something before they engage in the learning process.

(2) Adult learners desire a sense of autonomy and self-direction.

(3) Adults bring a variety of prior experience to the classroom, which should serve as a key resource in the learning process.

(4) Adults typically become ready to learn when life presents them with a relevant challenge or there is a need to perform a specific task.

(5) Adults are problem-centered learners who do best when provided with a context and an opportunity to develop a sense of competency in addressing problems.

(6) Adults are internally motivated learners who seek "intrinsic value" and a sense of "personal payoff" through their education.
Theory of Conscientization

(1) The goal of education should be radical transformation towards a more just society at the individual, community, and societal levels.

(2) Dialogue is at the heart of transformative education. Both the teacher and students are respected as bringers and developers of knowledge.

(3) A teaching program should be based on generative themes: the issues that are central to each student's learning and development.

(4) Education should be based on the posing of problems and the search for solutions.

(5) Education should involve a constant cycle of reflection and action ("praxis").

(6) Education is inherently political. The teacher is an important model of critical consciousness and political presence. 


\section{INCREASING POLITICAL INTEREST AND EFFICACY}

Figure 1.

\section{Initial Theoretical Model for Social Welfare Policy Instruction}

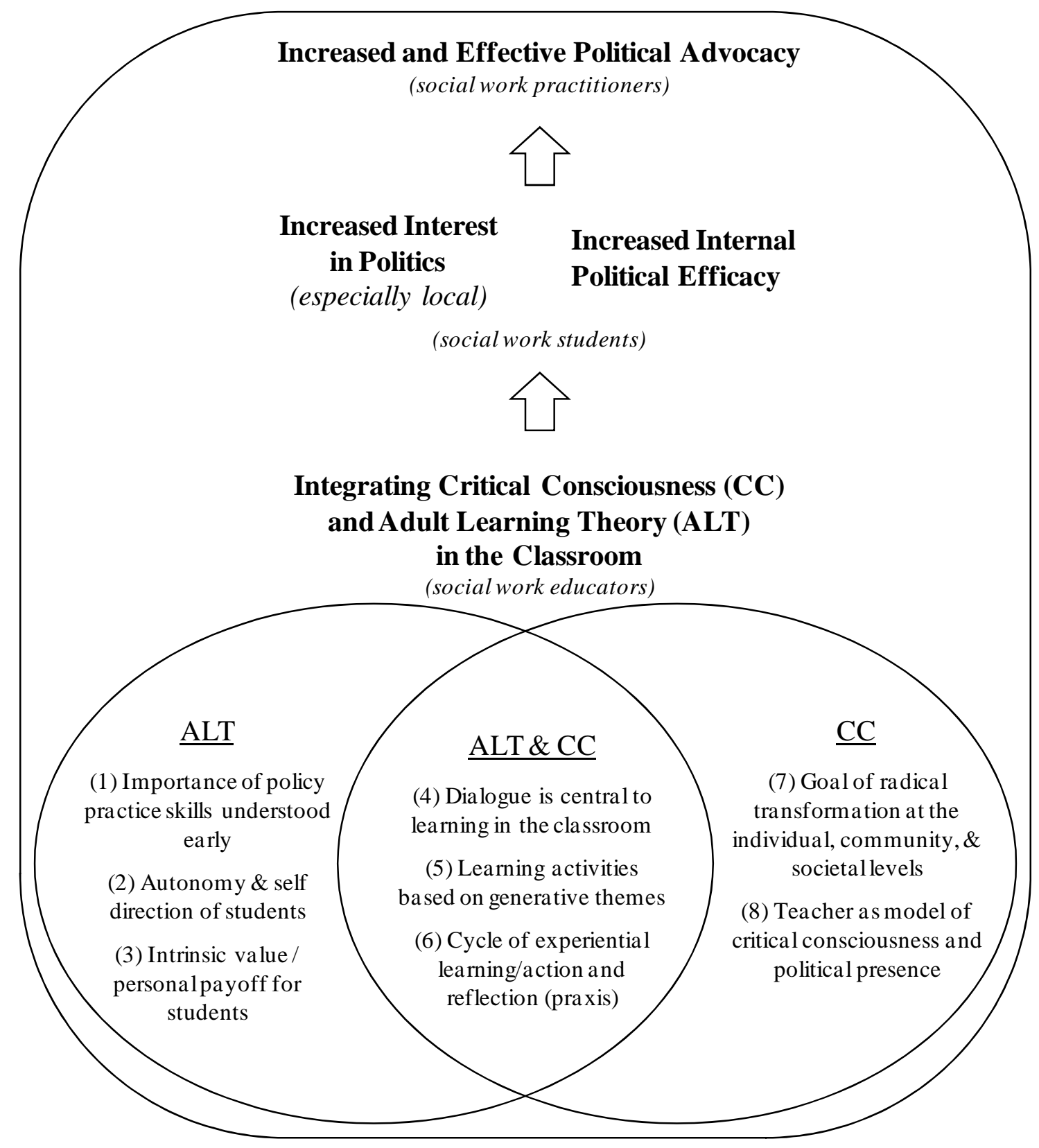




\section{INCREASING POLITICAL INTEREST AND EFFICACY}

Again, a fully developed theory or model was not being tested through this study. Instead, the three theories outlined above provided methodological guidance and a conceptual foundation. When observing, interviewing, analyzing and synthesizing the data, I remained open to concepts and influences outside of these three theories, as well as to changing or removing existing concepts. Student voices were the primary source and interpretive lens for the study. The intention was to observe and listen for the experience and priorities of the students, without structuring their reflections around specific theoretical constructs. Specific concepts from these three theories were explored further in focus groups and interviews only if students first identified them as an important influence in their development of political interest and internal political efficacy. 


\section{INCREASING POLITICAL INTEREST AND EFFICACY}

\section{Chapter 4: Research Questions and Methods}

Three research questions guided this study, resulting in a mixed methods design in which both quantitative and qualitative data informed the emergent model for social welfare policy instruction. After listing the research questions, this chapter will provide a detailed description of the research design, address issues of trustworthiness, explain the process of participant selection and protection, and outline both the quantitative and qualitative data collection and analysis process.

\section{Research Questions}

This study explored how social welfare policy instructors can effectively support students in the development of political interest, internal political efficacy, and ultimately policy practice. It was designed to answer the following research questions:

(1) How does a particular social welfare policy course impact social work students' political interest and internal political efficacy?

(2) What do students convey about their participation in the course that impacted their political interest and internal political efficacy?

(3) To what teaching methods do students attribute any increase in political interest and internal political efficacy?

\section{Research Design}

A mixed methods Embedded Design was used, which emphasized qualitative data collection and analysis conducted with grounded theory methods (Creswell \& Plano 


\section{INCREASING POLITICAL INTEREST AND EFFICACY}

Clark, 2007). Data were collected from two social welfare policy courses in two separate undergraduate social work programs in the Pacific Northwest. The researcher observed both courses in their entirety. Quantitative pre-test and post-test surveys were administered to participating students at the beginning and end of both courses. A focus group was held on the last day of each course, which included all participating students. Ideas identified in these focus groups were then explored further through individual indepth interviews conducted with a sub-sample of students from each course.

The primary reason for the selection of a mixed methods Embedded Design was that the research questions lent themselves to different research methods. The first research question required measurement of two key concepts: political interest and internal political efficacy. Quantitative measurement tools already existed and had been tested for both of these concepts within a social work setting (Ritter, 2007), suggesting a likely benefit of quantitative data collection and analysis. However, because the sample size of this study was small and the previous applications of the quantitative measurement tools were limited, two additional measurement tools were used to address the impact of the course. First, two simple quantitative questions were asked at the end of the post-test survey. Second, qualitative exploration of the type and degree of impact of the course on students' political interest and internal political efficacy was conducted through focus groups and interviews. This mixed method approach to answering the first 


\section{INCREASING POLITICAL INTEREST AND EFFICACY}

research question increased the likelihood of detecting any changes that occurred in these areas and added nuance to the understanding of the courses' impact.

The second research question was exploratory by nature. Research seeking to describe the process by which a social welfare policy course impacts students' level of political interest and internal political efficacy had yet to be done. Thus, the qualitative methods of observation, focus groups, and in-depth interviews were used to gather relevant data from students about how their participation in the social welfare policy course impacted their political interest and internal political efficacy.

Embedding quantitative data analysis within a primarily qualitative study was also deemed necessary in order to most effectively answer the third and final research question. The ultimate goal was to contribute insight into how social welfare policy instructors can effectively enhance students' political interest, internal political efficacy, and ultimately political advocacy. As explained above, this required using both quantitative and qualitative methods to determine whether or not such an impact had been made in the first place. While confirming that an impact had been made was an important step, the emphasis of this study was on qualitatively describing the nature of the impact and theorizing about the process by which this impact was made. Thus, the quantitative data were used to help describe the research sample and answer a more basic research question prior to qualitatively exploring effective teaching methodologies for 


\section{INCREASING POLITICAL INTEREST AND EFFICACY}

social welfare policy courses. Classroom observations, focus groups, and in-depth interviews were used to collect data for the qualitative portion of the study.

\section{Trustworthiness}

Concern for the trustworthiness of the qualitative results at the heart of this study was central to decisions about sampling, data collection, and data analysis.

Trustworthiness or credibility in qualitative research is "analogous to establishing validity and reliability" in quantitative research (Belcher, 1994, p. 128). Fundamentally, it is concerned with whether or not consumers of the research results should believe or place trust in them. Information related to the validity and reliability of quantitative measurements taken in this study is provided in the Quantitative Data Collection and Analysis section below.

The strategies employed to establish qualitative trustworthiness in this study were clarifying researcher bias, prolonged engagement and persistent observation, triangulation, member checking, and an audit trail. A thorough literature review and theoretical analysis were conducted prior to designing and conducting the research. The practical experience and theoretical concepts informing the researcher have been clearly presented in the first three chapters, so that readers can understand 'the researcher's position and any biases or assumptions that impact the inquiry" (Creswell, 2007, p. 208). Prolonged engagement and persistent observation provide the researcher with an opportunity to build trust with research participants, learn the culture, and check for 


\section{INCREASING POLITICAL INTEREST AND EFFICACY}

misinformation or distortions (Belcher, 1994; Creswell, 2007). For this study, I observed the entire term of both courses from which focus group and interview participants were drawn. Triangulation involves the "use of multiple and different sources, methods, investigators, and theories to provide corroborating evidence" (Creswell, 2007, p. 208). Doing so provides the researcher with an opportunity to benefit from the different strengths of various methods, as well as compensate for their weaknesses. In this study, data were collected across two different social work programs, through classroom observations, quantitative pre- and post-test surveys, focus groups, and individual interviews.

The second focus group and series of interviews also provided me with an opportunity to member check with participating students. As concepts and theoretical connections emerged, I would bring those into the focus group and interviews, asking students to let me know if they agreed or disagreed and to help me better understand the phenomenon. For example, some students talked about the benefit of being able to pick their own policy research topic; doing so increased their interest and motivation to do the work. Other students talked about how much they had learned by having to research a topic outside of their typical interest area; they felt their knowledge and interests were expanded. During my last interviews, I described those messages to the students and asked for their insights and clarification. One surprise for me during the first focus group and set of interviews was the strong desire of students to talk about the diversity of 


\section{INCREASING POLITICAL INTEREST AND EFFICACY}

political content and conversation in class. I made sure to ask about this emerging theme in each of my second set of interviews, because I wanted to look for areas of agreement or disagreement from the widest set of students possible. Content and insights from these two examples of member-checking can be found in Chapters 6 and 7.

Finally, an audit trail of the data and analysis is available for examination by a third party, if deemed necessary to evaluate the credibility of the results. My literature review and initial theoretical model for social welfare policy instruction provides insight into the focus and early conceptualizations of this research study. A classroom observation form was created, in part, to help me stay accountable to noting elements of my initial theoretical model that were or were not present in each course. My notes from each class session are available for auditing purposes, as are other field and decision notes. Surveys, recordings, transcripts, coding guides, and coding documents were collected and maintained throughout the project.

Ultimately, it was the transcripts that kept me most accountable to analyzing and synthesizing the students' perspective of what was effective in the classroom, in terms of increasing their political interest and internal efficacy. All themes emerged out of the transcripts. Classroom observations and survey data served a corroborating role. No themes emerged that were not expressed across both courses. Exceptions could be raised by participants in a single course, but all themes can be found in transcripts from both social work programs. 


\section{INCREASING POLITICAL INTEREST AND EFFICACY}

\section{Participant Selection and Protection}

Due to the study's focus on undergraduate social work education and the emphasis on student voice, sampling occurred on two levels (Jones, Torres, \& Arminio, 2006). First, specific courses were purposively selected to serve as case examples of a social welfare policy course. Identifying themes that can apply across social work programs, instructors, and social welfare courses was a central goal. Therefore, two social welfare policy courses in two separate undergraduate social work programs in the Pacific Northwest were selected based on the following four criteria: (1) the BSW program was accredited or granted candidacy for accreditation by the Council on Social Work Education, (2) the social welfare policy course had at least one learning objective or assignment that indicated a clear intention on the part of the instructor to enhance students' political advocacy skills, (3) evidence of experiential teaching methods on the part of the instructor, determined by personal communications and/or the syllabus, and (4) willingness of the instructor to have a researcher present throughout the course.

Written consent was sought first from the two social welfare policy course instructors. Both instructors provided written consent to having their course observed, allowing the researcher to spend approximately 30 minutes on the first day of class and 45 minutes on the last day of class directly with students, and not being present during study recruitment or data collection. The instructors were promised that confidentiality would be maximized, though confidentiality could not be guaranteed due to student 


\section{INCREASING POLITICAL INTEREST AND EFFICACY}

participation in focus groups and interviews. Within the instructors' informed consent

form, I promised to share my results with them prior to final publication and not identify them by name or university. The informed consent form also stated that "all published results will reflect integrated data from two courses, two instructors, and two universities" (see Appendix A).

Within these two selected social welfare policy courses, student research participants were then sampled. One course included a total of 15 registered students, 14 of which self-identified as social work students; the one political science major in this course was not included in the study sample. The other course included 25 self-identified social work students. This resulted in a total sample of 39 self-identified undergraduate social work students registered for and attending a social welfare policy course at one of two undergraduate social work programs in the Pacific Northwest. All 39 students met the following eligibility criteria for potential inclusion in the study:

(1) Age 18 or older.

(2) Capable of giving informed consent.

(3) Enrolled in a BSW program that is accredited or granted candidacy for accreditation by the Council on Social Work Education.

(4) Participating in a social welfare policy course that has been selected based on its having (a) at least one course learning objective or assignment that indicates a clear intention on the part of the instructor to enhance students' political advocacy 


\section{INCREASING POLITICAL INTEREST AND EFFICACY}

skills, (b) evidence of experiential teaching methods on the part of the instructor, determined by personal communications and/or the syllabus, and (3) willingness of the instructor to have a researcher present throughout the course.

After receiving permission from the course instructors and the Dean or Director of the targeted BSW programs, I recruited study participants at the end of their first social welfare policy class. Instructors introduced me and then left the room before recruitment began. The study was explained, both verbally and in writing, after which informed consent forms were distributed, completed, and collected. Students were able to indicate consent for participation in the surveys, the focus group, and/or the in-depth interviews. All 39 potential study participants consented to participation in the surveys. Twentyeight students consented to participation in a focus group, and 22 students consented to potential participation in an interview. Some students consented to a potential interview but not participation in a focus group, and vice versa.

Nonprobability purposive sampling methods were used throughout the study, due to its exploratory nature (Creswell \& Plano Clark, 2007; Jones et al., 2006; Strauss \& Corbin, 1990). The two social welfare policy course cases were selected purposively based on their meeting of the established criteria described above. All consenting students in both courses participated in a focus group at the end of their term. However, invitation of individual students for an in-depth interview occurred purposefully in the first observed course, in order to maximize diversity (or variation) of experience and 


\section{INCREASING POLITICAL INTEREST AND EFFICACY}

perspective, and therefore, theoretical relevance. At the end of the first course, I identified students to invite for an interview, based on diversity of age, ethnicity, gender, political identity and views, political experience, and observed verbal participation in class. Due to time away from campus at the end of the term, some students expressed interest but were unavailable for an interview within the two month time frame established in the study design. Therefore, all students who had consented to participate in an interview during the second course were promptly invited, in order to maximize participation and ultimately heterogeneity. This is consistent with Strauss and Corbin (1990), leaders in the methodology of grounded theory development, who emphasize that "the specific sampling decisions evolve during the research process itself" (p. 192). Time away from campus at the end of the term still created a barrier to participation for some students. Ultimately, eleven students participated in an in-depth interview following participation in a focus group.

Nonprobability purposive sampling served the purposes of this exploratory study well. The focus was on better understanding the process by which a social welfare policy course positively impacts social work students' political interest and internal political efficacy. Social work students were considered the experts on the student experience, and no existing research offered insights into the components and dynamics of effective social welfare policy instruction from the student perspective. Therefore, it was appropriate and useful to purposively sample cases and students that met established 


\section{INCREASING POLITICAL INTEREST AND EFFICACY}

criteria, in order to seek their insights and develop a deeper understanding (Creswell \& Plano Clark, 2007; Jones et al., 2006; Strauss \& Corbin, 1990). The goal was not to test an existing theory or make empirical generalizations.

As will be further discussed below, a reasonable level of saturation was achieved through the two focus groups and eleven interviews. Saturation, the ultimate sampling goal in grounded theory research, is defined by Creswell (2007) as finding "as many incidents, events, or activities as possible" to provide support for the categories of information created by on-going data analysis. In qualitative research, sampling and data collection are "guided by the goal of maximizing opportunities to uncover data relevant to the purpose of the study ... the sampling process interacts with data analysis" (Jones et al., 2006, p. 71).

Confidentiality of study participants was maintained throughout the research process and in the period thereafter, though confidentiality could not be guaranteed in the focus group setting. No one other than the researcher and participating students were present during study recruitment, survey administration, focus groups, or interviews. I outlined in the students' informed consent form and reiterated at the beginning of each focus group why I could not guarantee focus group confidentiality. At the same time, I stressed the importance of all focus group members honoring other participants' confidentiality. 


\section{INCREASING POLITICAL INTEREST AND EFFICACY}

Potential risks for participants were minimal. There were no foreseeable physical, legal, or economic risks to participants in this study. However, for students who participated in the focus group, it was possible that they could experience a minimal level of social and/or psychological discomfort if there were disagreements related to experiences in the course. As an experienced social worker who has conducted focus groups previously, I made my contact information available to all participants, in case they wanted to discuss their experience in the study further. No discomfort was noted during the focus groups and no contact by study participants was made after data collection. For students who participated in an interview, it was also possible that a minimal level of social and/or psychological discomfort could be experienced. However, the topic of research was not anticipated to be a distressing one. Again, all students who participated in an interview were given the researcher's contact information and no postinterview communication was made.

Potential benefits for participants were also minimal. For students who participated in the surveys and focus group, no direct benefit to the participant was likely to occur, except the opportunity to have their experience and opinions sought out and utilized. Students who participated in an interview received a $\$ 10$ gift certificate to their campus bookstore as a modest "thank you" for their time.

A key benefit of this mixed methods design is research triangulation. Both quantitative and qualitative data, gathered through written surveys and focus groups, 


\section{INCREASING POLITICAL INTEREST AND EFFICACY}

helped clarify the type and degree of impact of the course on students' level of political interest and internal political efficacy. In order to describe the process by which a social welfare policy course impacts students' in these areas, student insight was solicited in both group and individual settings. All of these data were compared with and validated by less obtrusive data collected during class observations and recorded in my field notes.

\section{Quantitative Data Collection and Analysis}

Quantitative data were gathered through pre- and post-test surveys (see Appendices B and C), in order to help describe the study sample and determine the type and degree of change that occurred in students' political interest and internal political efficacy as they participated in these particular social welfare policy courses. Attendance at the first and last class session of a course was necessary in order for a student to complete both the pre- and post-test surveys. Ultimately, complete quantitative data were gathered from 31 social welfare policy students enrolled in a Bachelor of Social Work (BSW) program accredited or granted candidacy for accreditation by CSWE.

During the first class meeting, participating students were asked to complete a pre-test survey. In addition to basic demographics, this pre-test survey explored students' recent political participation, level of political interest, and internal political efficacy. The measurement tools used to assess these three variables were borrowed from Ritter (2007, 2008), as described below. 


\section{INCREASING POLITICAL INTEREST AND EFFICACY}

Ritter (2008) used Verba and colleagues' Political Activities Scale to measure respondents' recent level of political participation. It is an additive scale with 22 items measuring electoral participation, nonelectoral participation, civic engagement, and "unconventional" political participation (Verba et al., 1995). The eight categories of political activity scored include: "voting in the last presidential election; working as a volunteer for a candidate running for national, state, or local office; making a financial contribution to an individual candidate, a party group, a political action committee, or any other organization that supports candidates in elections; contacting local, state, or federal legislators to voice an opinion on an issue of concern; taking part in a protest, march, or demonstration; working informally with others in the community to deal with a community issue or problem; serving in a voluntary capacity on any local governmental board or council, or attending meeting of such a board or council regularly; and being a member of a political organization" (Ritter, 2008, p. 350). With regard to internal consistency, Verba and colleagues reported a Cronbach alpha coefficient of .6192; in Ritter's study, the Cronbach alpha coefficient was .609. However, in this study, the Political Activities Scale was intended for descriptive purposes only.

To measure level of political interest, Ritter (2008) used Verba and colleagues' Political Interest Scale, which consists of two questions concerning one's interest in both local and national politics. As is common with short scales, the Cronbach alpha coefficient was low (.54) in Ritter's study. However, when local and national interest 


\section{INCREASING POLITICAL INTEREST AND EFFICACY}

were run separately in her regression analysis, "interest in local politics was shown to be a significant predictor of social workers' political participation, whereas interest in national politics was not" (Ritter, 2008, p. 350). Due to the previous low reliability score, the two items on the Political Interest Scale were tested separately.

To measure internal political efficacy, Ritter (2008) chose to use Niemi, Craig, and Mattei's (1991) four item Internal Political Efficacy Scale rather than the efficacy scale used by Verba, et al. (1995). Verba and colleagues did not separate internal efficacy from external efficacy in their measurements. Later research demonstrated a conceptual distinction between internal and external efficacy (Ritter, 2008). Internal political efficacy refers to the belief or confidence in one's own ability to impact the political system. External political efficacy reflects one's belief in the political system's responsiveness to citizen actions. Thus, Ritter turned to Niemi, Craig, and Mattei's study, which demonstrated that "inter-item correlations among the four questions indicated a high internal consistency, factor analysis demonstrated that the items measure a single concept distinct from external efficacy and political trust, and the scale is externally valid and provides a good distribution of efficacy scores across the population" (p. 351). The Cronbach alpha coefficient for the Internal Political Efficacy Scale in Ritter's study was a solid .74. Therefore, for this study, the Internal Political Efficacy Scale was scored both as a scale and as individual items. 


\section{INCREASING POLITICAL INTEREST AND EFFICACY}

At the final class meeting of each course, students were asked to complete a posttest survey, which included the same items related to political interest and internal political efficacy. Two questions asking the student to rate the impact of the course on their political interest and ability to influence policy and the political system (i.e. internal political efficacy) were also included. Any change in political participation over the course of a single academic term was expected to be due primarily to involvement in an experiential social welfare policy course, so questions related to political participation were not post-tested. While it would be interesting and likely helpful to conduct a longitudinal study that examines changes in the level of political participation well beyond a social welfare policy course itself, it was not within the scope of this study to do so. Instead, the initial data on political participation were used purely as descriptive data for the sample.

It was recognized that a researcher's presence in the classroom and administration of surveys could influence course dynamics, such as instructor comfort and student attentiveness to policy practice issues. I attempted to minimize this influence in three ways. First, I maintained a quiet and unobtrusive presence in the back of the room. Second, the surveys were administered with a clear consent process and set of instructions, but minimal emphasis on the topic of study. Finally, I emphasized with the instructors that I was looking for what works, rather than barriers or problems. 


\section{INCREASING POLITICAL INTEREST AND EFFICACY}

In terms of quantitative data analysis, it is important to note that the data from the two courses were pooled for human subject protection purposes. Within the instructors' informed consent form, I promised to maximize their confidentiality, in part by integrating the data "from two courses, two instructors, and two universities" (see Appendix A). In many ways these two student groups were similar. They were all social work students attending a university in the Pacific Northwest. The two groups had similar demographic diversity, in terms of age, income, sex, and race/ethnicity. However, they had different instructors, classmates, textbooks, and assignments. These differences were a qualitative strength, but a quantitative limitation.

In terms of quantitative data analysis of the six pre- and post-test individual variables measuring students' level of political interest and internal political efficacy, as well as the Internal Political Efficacy Scale, it was important to take into consideration the sample and the level of measurement. As noted previously, it was a small $(n=31)$, nonprobability sample. The six variables under consideration were Likert scales, which is conceptually an ordinal level of measurement. Therefore, a nonparametric measurement tool, Wilcoxin's Signed Ranks Test, was applied. Applying nonparametric analysis to a small, nonrandom sample helps protect against Type I errors (false positives) (Fayers, 2011).

However, Norman (2010) argues that if data from Likert scales is "reasonably distributed, we can make inferences about their means, differences or whatever" (p. 629). 


\section{INCREASING POLITICAL INTEREST AND EFFICACY}

In other words, parametric analysis may be appropriate given a careful determination that the data have a reasonably normal distribution (Fayers, 2011; Norman, 2010). Using parametric analysis helps protect against Type II errors (false negatives) (Norman, 2010). For this reason, the distribution of differences scores on the six variables and the scale measuring students' level of political interest and internal political efficacy were evaluated. The distribution of differences for all six variables and the scale appeared roughly normal or slightly skewed ("reasonably normal"). Therefore, it was decided to also run a parametric analysis of the data, using the paired samples $t$ test.

Finally, in order to evaluate whether differences in pre- and post-test scores had practical significance, as well as statistical significance, effect size was calculated. Cohen's $d$ was utilized for this purpose, with the calculations based on original standard deviations and means. The quantitative data from this study were not intended to stand alone or be generalizable to a large population, but rather to provide one means of confirming whether a change in students' political interest and internal efficacy occurred as they participated in the course, and if so, describing those changes.

\section{Qualitative Data Collection and Analysis}

Qualitative data were gathered through in-class observations, the post-test survey, focus groups, and in-depth interviews conducted individually with students. As many sessions of both courses were observed as possible, in order to become familiar with the teaching methods employed by the instructors and with the in-class engagement and 


\section{INCREASING POLITICAL INTEREST AND EFFICACY}

experiences of the students in the study. Ultimately, I observed $88 \%$ of the class time for the first course and $85 \%$ of the class time for the second course. I used a classroom observation guide to assist in the recording of both descriptive and reflective notes during and immediately following each class session (see Appendix D). Attention was paid to the quality and quantity of political advocacy content during class time, as well as to specific teaching methodologies. These observational data were used to verify and clarify student insights, as well as enhance my knowledge of the context from which the data emerged.

Near the end of the post-test survey, after rating the impact of the course on their political interest and efficacy, students answered two open-ended questions intended to provide insight into the process by which the course impacted their political interest and internal political efficacy, as well as to prompt their thinking about the topics to be explored further in the focus group that immediately followed the post-test survey. The two qualitative questions on the post-test survey included the following:

(1) If your interest in politics has increased or decreased as a result of this course, what about the course do you believe made this difference? Please be as specific as possible.

(2) If your political advocacy skills have increased or decreased as a result of this course, what about the course do you believe made this difference? Please be as specific as possible. 


\section{INCREASING POLITICAL INTEREST AND EFFICACY}

Answers to these questions were reviewed prior to interviews, in order to identify any topics or potential themes that were not raised in the focus group. No new topics or themes were identified through qualitative analysis of the post-test surveys; all relevant topics and themes emerged through the focus groups.

Immediately following completion of the post-test survey during the final class session, consenting students participated in a focus group discussion facilitated by the researcher without the course instructor present. The group discussion was audiotaped and guided by a set of prepared, open-ended questions focused on how participation in the course impacted students' level of political interest and internal political efficacy (see Appendix E). Because the intention of the study was to identify and better understand effective teaching methodologies from the student perspective, I began with broad questions and utilized more specific prompts only when necessary. For example, I asked both focus groups an open-ended question along the lines of, "If your interest in politics has changed as a result of this course, what about the course do you believe made this difference?" If it appeared difficult for the students to be specific or think broadly regarding this question, I would move to more specific prompts, asking about general areas of the educational process (e.g. teaching methods, content covered, assignments). I did not explore specific concepts from the developing theory further through my focus group questions unless students identified them first as being an important influence in their development of political interest or internal political efficacy. 


\section{INCREASING POLITICAL INTEREST AND EFFICACY}

The guiding questions for the focus group were open-ended and designed to give the researcher "a way to keep track of the progress of the group and steer discussions in desirable directions" (Hatch, 2002, p. 137). However, I also strived to maintain a flexible environment for discussion, in order to take greatest advantage of the focus group methodology. A primary benefit of focus groups is the interaction between participants (Creswell, 2007; Hatch, 2002). While these students participated in the same social welfare policy course, it was expected that their unique experiences with and reflections on the class content, interactions, and assignments would stimulate discussion and hopefully encourage deeper and more nuanced insights into the process by which their political interest and efficacy were impacted. "While moderators are prepared with specific questions, they are sensitive to going where the group wants to go with particular topics, and this opens the opportunity for richer, more meaningful data" (Hatch, 2002, p. 132). This methodological advantage was also believed to be consistent with the inspiration taken from Freire's theory of conscientization described earlier.

Potential methodological disadvantages of which I remained aware while facilitating the focus groups were participants who dominate the conversation or are reluctant to speak in a group setting, group think, and the influence of the researcher herself (Creswell, 2007; Hatch, 2002). Focus group participants were not observed dominating the conversation. However, I did on occasion ask the group if I could hear from people who had not yet shared on a topic. I also routinely asked focus group 


\section{INCREASING POLITICAL INTEREST AND EFFICACY}

participants for other ideas, for differing opinions, and for examples that might be different from those already discussed. In terms of my own influence on the group, I made every effort to remain a calm, curious, and neutral presence. When students appeared energized by a line of thought, I let them lead the conversation until comments became redundant. When students did not seem to relate to or have anything to add to a raised topic, I moved on. Regardless of whether comments were positive or negative regarding the course, I used neutral responses, such as "OK," "thanks," and "anything else along those lines?"

In the weeks following each focus group, students were purposively invited to participate in an in-depth, follow-up interview. These individual interviews were guided by an interview guide, which was modified slightly before the second group of students were interviewed based on emerging concepts and categories identified during the focus groups and first set of interviews (see Appendices F and G). The interview questions were overwhelmingly open-ended and designed to explore emerging categories in greater depth. Additional follow-up questions to participants' responses were generated during the interviews themselves. Because the interviews served as the final data collection method, they also provided an opportunity for member checking. As I interviewed the second set of students, I began to share categories and themes that were emerging from the first set of interviews and both focus groups. I would ask the students whether a particular idea resonated for them or whether they had had a different experience. The 


\section{INCREASING POLITICAL INTEREST AND EFFICACY}

categories and themes were then supported or modified based on specific examples offered by the participants. As described earlier, sampling, data collection, and analysis were cyclical and interactive.

Consistent with the goal of exploring and developing a model for the process by which social work students' political interest and internal efficacy can be positively impacted in a social welfare policy course, data analysis was conducted using grounded theory techniques. Creswell (2007) effectively summarizes grounded theory analysis as "a procedure for developing categories of information (open coding), interconnecting the categories (axial coding), building a 'story' that connects the categories (selective coding), and ending with a discursive set of theoretical propositions" (p. 160). While I began this study with some potential categories gleaned from three educational theories loosely linked together by the existing literature, I was committed to looking for new theoretical categories and connections, as well as to modifying existing ones. It was not assumed that the student perspective would reflect concepts identical to those proposed by researchers and professional educators.

Data collection and analysis were cyclical processes throughout this study, though there were two specific periods of more intense data analysis. Field notes created during in-class observations and after the first focus group demonstrate initial data collection and analysis efforts. However, after making these observations, administering surveys, facilitating a focus group, and conducting interviews with students from the first social 


\section{INCREASING POLITICAL INTEREST AND EFFICACY}

welfare policy course, I entered into the first intense phase of data analysis during which I did a significant amount of open coding and some early axial coding. Transcripts were read multiple times and coding notes expanded, as I moved from identifying key ideas to developing categories to making initial connections between them. The second focus group and set of interviews were influenced by these initial categories and connections, as discussed earlier. These categories and connections were gradually and increasingly introduced into the second focus group and set of interviews, in order to member check, identify exceptions, and develop greater theoretical richness and trustworthiness (Sherman \& Reid, 1994; Strauss \& Corbin, 1990).

A number of specific grounded theory analysis techniques from Strauss and Corbin (1990) were used to enhance my theoretical sensitivity and the explanatory power of the developing theory itself. Theoretical sensitivity is a personal quality of the researcher, including "the attribute of having insight, the ability to give meaning to data, the capacity to understand, and capability to separate the pertinent from that which isn't" (Strauss \& Corbin, 1990, p. 42). In addition to the most obvious technique of asking detailed questions of the data (e.g. Who? When? How? Why?), I would pull out specific words, phrases, and sentences to analyze. For example, one student in the first focus group stated, "If it's not an assignment, then I didn't do it. Lack of something." I brainstormed possible meanings for "something" in that context, looked for clues in interview transcripts, and explored the idea further with students in the second observed 


\section{INCREASING POLITICAL INTEREST AND EFFICACY}

course. I was looking for potential meanings and eventually for connections to other concepts. I also employed the "flip-flop technique," in which I would imagine the opposite of an important concept that seemed to be emerging (Strauss \& Corbin, 1990, p. 84). For example, students spoke a lot about "real" political engagement. I imagined what "unreal" political engagement would look like and searched for examples of this in existing data and future observations and interviews. Phenomena were systematically compared, exceptions were sought out, and emerging concepts and theoretical connections were regularly checked against the raw data.

After all focus groups and interviews were complete, a second period of intense analysis commenced. I reviewed and continued to code the first transcripts before moving on to the second set. Categories occasionally emerged (open coding), but the emphasis gradually shifted to connecting those categories in meaningful ways in order to develop a "story" (axial and selective coding). As I moved through the final interview transcripts a third time, I realized that I was reaching a reasonable level of saturation. New concepts were not emerging. Connections and examples became mostly predictable. The first version of the developing model for social welfare instruction was then created (see Figure 2 for the final version). The interview transcripts were read in their entirety a final time and illustrations of the instructional themes laid out in the developing model were color-coded. Hatch (2002) encourages qualitative findings to also be "shaped by the writing process" (p. 225). Indeed, minor revisions to the model or 


\section{INCREASING POLITICAL INTEREST AND EFFICACY}

"story" continued through the writing of this dissertation, as meanings, connections, and ways of communicating those became clearer.

Ultimately, qualitative data analysis occurred across both courses, creating themes that represent effective teaching by two different instructors. No qualitative themes emerged that were not expressed by students in both courses. Any differences of opinion between students on important themes were explored during qualitative data collection and are identified and further discussed in Chapters 6 and 7.

Promises of confidentiality have influenced the presentation of qualitative data. In order to help protect the confidentiality of both instructors and students, reported quotations are not differentiated by course. When students refer to assignments, activities, and textbooks, that information is included with non-identifying descriptors. In order to further protect the confidentiality of students, quotations have also been disconnected from their demographic context, including age, sex, race, income, and political party and views. No differences in qualitative themes were noticed based on student diversity, though neither collecting extensive demographic data nor analyzing data based on such demographic diversity were primary foci of this study. The quality of disclosure between focus groups and interviews was not deemed different enough to require identifying quotations by data source.

The results and conclusions of this study are intended to clarify for social work educators the instructional methodologies by which they can more effectively support 


\section{INCREASING POLITICAL INTEREST AND EFFICACY}

students in the development of political interest and internal political efficacy. Based on research by Ritter and others (Anderson \& Harris, 2005; Ezell, 1993; Hamilton \& Fauri, 2001; Ritter, 2007, 2008; Weiss et al., 2006), it is reasonable to conclude that increased

political interest and internal political efficacy among social work students will ultimately lead to more political advocacy on the part of social work practitioners. 


\section{INCREASING POLITICAL INTEREST AND EFFICACY}

\section{Chapter 5: Quantitative Results}

Quantitative data were gathered in this study for two purposes. First, it provides descriptive information regarding the student participants, both in terms of demographics and political participation. Second, it provides one way of analyzing whether or not changes in students' political interest and internal political efficacy occurred during their participation in the social welfare policy course.

\section{Student Sample}

As described in greater detail in the previous chapter, the quantitative data from this study came from pre- and post-test surveys completed by 31 undergraduate social work students enrolled in a social welfare policy course at one of two participating social work programs in the Pacific Northwest. In accordance with the instructors' consent forms, "all published results will reflect integrated data from two courses, two instructors, and two universities."

\section{Demographics.}

As indicated in Table 2, the sample for this study was predominantly white, female, and of "traditional" college age. Most student participants were not in practicum, had no paid social work experience, and were not members of NASW. Because students could choose to participate in all or some combination of the surveys, the focus group, and an interview, the groups for each of those data sets varies slightly. 


\section{INCREASING POLITICAL INTEREST AND EFFICACY}

Table 2

Demographic Characteristics of Study Participants

\begin{tabular}{|c|c|c|c|}
\hline & $\begin{array}{l}\text { Pre- and Post- } \\
\text { Test Surveys } \\
(\mathrm{n}=31)\end{array}$ & $\begin{array}{l}\text { Focus Group } \\
\text { Participants } \\
(\mathrm{n}=28)\end{array}$ & $\begin{array}{l}\text { Interview } \\
\text { Participants } \\
(\mathrm{n}=11)\end{array}$ \\
\hline Age Range & $19-51$ years & $19-51$ years & 19-31 years \\
\hline Median Age & 20 years & 20 years & 20 years \\
\hline Mean Age & 22 years & 23 years & 22 years \\
\hline \multicolumn{4}{|l|}{ Sex } \\
\hline Female & $28(90 \%)$ & $24(86 \%)$ & $10(91 \%)$ \\
\hline Male & $3(10 \%)$ & $3(11 \%)$ & $1(9 \%)$ \\
\hline \multicolumn{4}{|l|}{ Race } \\
\hline White/Caucasian & $25(81 \%)$ & $21(75 \%)$ & $8(73 \%)$ \\
\hline Asian or Pacific Islander & $5(16 \%)$ & $4(14 \%)$ & $3(27 \%)$ \\
\hline Latino/Hispanic & $1(3 \%)$ & $2(7 \%)$ & 0 \\
\hline American Indian & 0 & 0 & 0 \\
\hline Black/African-American & 0 & 0 & 0 \\
\hline Other & 0 & 0 & 0 \\
\hline \multicolumn{4}{|l|}{ Income $^{\mathrm{a}}$} \\
\hline Less than 15,000 & $9(29 \%)$ & $7(25 \%)$ & $3(27 \%)$ \\
\hline 15,000 to 34,999 & $4(13 \%)$ & $4(14 \%)$ & $1(9 \%)$ \\
\hline 35,000 to 49,999 & $5(16 \%)$ & $3(11 \%)$ & 0 \\
\hline 50,000 to 74,999 & $3(10 \%)$ & $3(11 \%)$ & $2(18 \%)$ \\
\hline 75,000 to 124,999 & $6(19 \%)$ & $6(21 \%)$ & $2(18 \%)$ \\
\hline 125,000 or higher & $3(10 \%)$ & $3(11 \%)$ & $2(18 \%)$ \\
\hline \multicolumn{4}{|l|}{ Years of Paid S.W. Practice } \\
\hline No Paid S.W. Experience & $29(94 \%)$ & $26(93 \%)$ & $11(100 \%)$ \\
\hline Range of Years of Experience & $0-4$ years & $0-4$ years & 0 \\
\hline \multicolumn{4}{|l|}{ Current Practicum Student } \\
\hline No & $25(81 \%)$ & $20(71 \%)$ & $8(73 \%)$ \\
\hline Yes & $6(19 \%)$ & $7(25 \%)$ & $3(27 \%)$ \\
\hline \multicolumn{4}{|l|}{ NASW Member } \\
\hline No & $21(68 \%)$ & $19(68 \%)$ & $8(73 \%)$ \\
\hline Yes & $10(32 \%)$ & $8(29 \%)$ & $3(27 \%)$ \\
\hline
\end{tabular}

Note. Percentages in each category may not add up to $100 \%$ due to rounding or a missed pre-test survey or answer.

a "The total 2008 income before taxes of all members of your family living in your home. Please include salaries, wages, pensions, dividends, interest, and other income. (If you are claimed as a dependent on someone else's taxes, please indicate the total income of that household.)" 


\section{INCREASING POLITICAL INTEREST AND EFFICACY}

\section{Political participation and views.}

On the pre-test survey, students $(n=31)$ indicated their recent level of political participation, including electoral participation, nonelectoral participation, civic engagement, and "unconventional" political participation (Verba et al., 1995). The most common political activities engaged in by study participants were voting in the 2008 presidential election (74\%), discussing national politics with others at least once or twice a week (71\%), and gathering with others in their community or neighborhood to try to deal with some community issue or problem $(58 \%)$. The political activities in which study participants were least likely to have participated were volunteering for a political party or political candidate (7\%), testifying at a public hearing (7\%), and contacting a federally elected official or someone on the staff of such an official about problems or issues with which they were concerned (10\%).

As indicated in Table 3, the student participants in this study were predominantly independent voters with a strong Democratic leaning. Most students described themselves as either liberal or moderate, in terms of their political views. The majority of study participants were registered to vote. Because students could choose to participate in all or some combination of the surveys, the focus group, and an interview, the groups for each of those data sets varies slightly. 


\section{INCREASING POLITICAL INTEREST AND EFFICACY}

Table 3

Baseline Political Participation and Views of Study Participants

\begin{tabular}{llll}
\hline & $\begin{array}{l}\text { Pre- and Post- } \\
\text { Test Surveys } \\
(\mathrm{n}=31)\end{array}$ & $\begin{array}{l}\text { Focus Group } \\
\text { Participants } \\
(\mathrm{n}=28)\end{array}$ & $\begin{array}{l}\text { Interview } \\
\text { Participants } \\
(\mathrm{n}=11)\end{array}$ \\
\hline Registered to Vote & $25(81 \%)$ & $20(71 \%)$ & $8(73 \%)$ \\
Yes & $6(19 \%)$ & $6(21 \%)$ & $3(27 \%)$ \\
No & 0 & $1(4 \%)$ & 0 \\
Not Eligible & & & \\
Political Party & $5(16 \%)$ & $4(14 \%)$ & $3(27 \%)$ \\
Strong Democrat & $7(23 \%)$ & $8(29 \%)$ & $1(9 \%)$ \\
Democrat & $10(32 \%)$ & $8(29 \%)$ & $4(36 \%)$ \\
Independent, Lean to Democrats & $5(16 \%)$ & $4(14 \%)$ & $2(18 \%)$ \\
Independent, No Leaning & $3(10 \%)$ & $3(11 \%)$ & $1(9 \%)$ \\
Independent, Lean to Republicans & 0 & 0 & 0 \\
Republican & 0 & 0 & 0 \\
Strong Republican & 0 & 0 & 0 \\
Other & & & \\
Political Views & $5(16 \%)$ & $4(14 \%)$ & $3(27 \%)$ \\
Very Liberal & $13(42 \%)$ & $12(43 \%)$ & $4(36 \%)$ \\
Liberal & $9(29 \%)$ & $9(32 \%)$ & $4(36 \%)$ \\
Moderate & $3(10 \%)$ & $2(7 \%)$ & 0 \\
Conservative & 0 & 0 & 0 \\
Very Conservative & & &
\end{tabular}

Note. Percentages in each category may not add up to $100 \%$ due to rounding or a missed pre-test survey or answer.

\section{Political interest.}

As indicated in Table 4, almost half of the student participants described themselves as "somewhat interested" in both local and national politics. Because students could choose to participate in all or some combination of the surveys, the focus group, and an interview, the groups for each of those data sets varies slightly. 


\section{INCREASING POLITICAL INTEREST AND EFFICACY}

Table 4

Baseline Political Interest of Study Participants

\begin{tabular}{clll}
\hline & $\begin{array}{l}\text { Pre- and Post- } \\
\text { Test Surveys } \\
(\mathrm{n}=31)\end{array}$ & $\begin{array}{l}\text { Focus Group } \\
\text { Participants } \\
(\mathrm{n}=28)\end{array}$ & $\begin{array}{l}\text { Interview } \\
\text { Participants } \\
(\mathrm{n}=11)\end{array}$ \\
\hline $\begin{array}{c}\text { Local Political Interest } \\
\text { Very Interested }\end{array}$ & $8(26 \%)$ & $7(25 \%)$ & $4(36 \%)$ \\
$\begin{array}{l}\text { Somewhat Interested } \\
\text { Slightly Interested }\end{array}$ & $13(42 \%)$ & $13(46 \%)$ & $4(36 \%)$ \\
Not At All Interested & $10(32 \%)$ & $7(25 \%)$ & $3(27 \%)$ \\
National Political Interest & 0 & 0 & 0 \\
$\quad$ Very Interested & $9(29 \%)$ & $9(32 \%)$ & $3(27 \%)$ \\
Somewhat Interested & $15(48 \%)$ & $12(43 \%)$ & $7(64 \%)$ \\
Slightly Interested & $6(19 \%)$ & $6(21 \%)$ & $1(9 \%)$ \\
Not At All Interested & $1(3 \%)$ & 0 & 0 \\
\hline
\end{tabular}

Note. Percentages in each category may not add up to $100 \%$ due to rounding or a missed pre-test survey or answer.

\section{Internal political efficacy.}

Student participants rated themselves on the following four internal political efficacy items: (1) I feel I have a pretty good understanding of the important political issues facing our country. (2) I consider myself to be well qualified to participate in politics. (3) I think that I am better informed about politics and government than most people. (4) I feel that I could do as good a job in public office as most other people. As indicated in Table 5, most students did not see themselves as having strong political efficacy. Because students could choose to participate in all or some combination of the surveys, the focus group, and an interview, the groups for each of those data sets varies slightly. 


\section{INCREASING POLITICAL INTEREST AND EFFICACY}

Table 5

Baseline Internal Political Efficacy of Study Participants

\begin{tabular}{|c|c|c|c|}
\hline & $\begin{array}{l}\text { Pre- and Post- } \\
\text { Test Surveys } \\
(\mathrm{n}=31)\end{array}$ & $\begin{array}{l}\text { Focus Group } \\
\text { Participants } \\
(\mathrm{n}=28)\end{array}$ & $\begin{array}{l}\text { Interview } \\
\text { Participants } \\
(\mathrm{n}=11)\end{array}$ \\
\hline \multicolumn{4}{|l|}{ Good Understanding of Issues } \\
\hline Strongly Agree & $2(7 \%)$ & $3(10 \%)$ & 0 \\
\hline Somewhat Agree & $15(48 \%)$ & $12(43 \%)$ & $8(73 \%)$ \\
\hline Neither Agree/Disagree & $6(19 \%)$ & $7(25 \%)$ & $2(18 \%)$ \\
\hline Somewhat Disagree & $3(10 \%)$ & $3(11 \%)$ & 0 \\
\hline Strongly Disagree & $5(16 \%)$ & $2(7 \%)$ & $1(9 \%)$ \\
\hline \multicolumn{4}{|l|}{ Well Qualified to Participate } \\
\hline Strongly Agree & $1(3 \%)$ & $1(4 \%)$ & 0 \\
\hline Somewhat Agree & $6(19 \%)$ & $7(25 \%)$ & $3(27 \%)$ \\
\hline Neither Agree/Disagree & $9(29 \%)$ & $8(29 \%)$ & $3(27 \%)$ \\
\hline Somewhat Disagree & $8(26 \%)$ & $6(21 \%)$ & $4(36 \%)$ \\
\hline Strongly Disagree & $7(23 \%)$ & $5(18 \%)$ & $1(9 \%)$ \\
\hline \multicolumn{4}{|l|}{ Better Informed Than Most } \\
\hline Strongly Agree & $3(10 \%)$ & $3(11 \%)$ & $2(18 \%)$ \\
\hline Somewhat Agree & $5(16 \%)$ & $5(18 \%)$ & $3(27 \%)$ \\
\hline Neither Agree/Disagree & $10(32 \%)$ & $8(29 \%)$ & $3(27 \%)$ \\
\hline Somewhat Disagree & $8(26 \%)$ & $8(29 \%)$ & $2(18 \%)$ \\
\hline Strongly Disagree & $5(16 \%)$ & $3(11 \%)$ & $1(9 \%)$ \\
\hline \multicolumn{4}{|l|}{ As Good a Job in Public Office } \\
\hline Strongly Agree & $2(7 \%)$ & $2(7 \%)$ & $1(9 \%)$ \\
\hline Somewhat Agree & $4(13 \%)$ & $3(11 \%)$ & $1(9 \%)$ \\
\hline Neither Agree/Disagree & $8(26 \%)$ & $9(32 \%)$ & $3(27 \%)$ \\
\hline Somewhat Disagree & $10(32 \%)$ & $5(18 \%)$ & $3(27 \%)$ \\
\hline Strongly Disagree & $7(23 \%)$ & $8(29 \%)$ & $3(27 \%)$ \\
\hline
\end{tabular}

Note. Percentages in each category may not add up to $100 \%$ due to rounding or a missed pre-test survey or answer.

\section{Change in Students' Political Interest during Social Welfare Policy Course}

All students who completed both pre- and post-test surveys $(n=31)$ indicated that their political interest had either increased $(68 \%, \mathrm{n}=21)$ or remained the same $(32 \%, \mathrm{n}=$ 10) as result of the social welfare policy course. No student indicated a decreased 


\section{INCREASING POLITICAL INTEREST AND EFFICACY}

political interest as a result of the course. Their responses to items on the Political Interest Scale further confirmed this. Table 6 provides a descriptive summary of the change in students' political interest at both the local and national levels.

Table 6

Descriptive Changes in Students' Political Interest $(n=31)$

\begin{tabular}{lll}
\hline & Baseline & Post-Test \\
\hline Local Political Interest & & \\
Very Interested & $8(26 \%)$ & $9(29 \%)$ \\
Somewhat Interested & $13(42 \%)$ & $17(55 \%)$ \\
Slightly Interested & $10(32 \%)$ & $5(16 \%)$ \\
Not At All Interested & 0 & 0 \\
& & \\
National Political Interest & $9(29 \%)$ & $9(29 \%)$ \\
Very Interested & $15(48 \%)$ & $17(55 \%)$ \\
Somewhat Interested & $6(19 \%)$ & $5(16 \%)$ \\
Slightly Interested & $1(3 \%)$ & 0 \\
Not At All Interested & &
\end{tabular}

Note. Percentages in each category may not add up to $100 \%$ due to rounding or a missed pre-test survey or answer.

The distribution of difference scores for both political interest items were roughly normal or slightly skewed. Therefore, for reasons described in Chapter 4, both the nonparametric Wilcoxin's Signed Ranks Test and the parametric paired samples $t$ test were applied to compare the pre-test and post-test scores of participating students on the following two political interest items: (1) Thinking about your state and local community, how interested are you in local politics and local community affairs?, and (2) How interested are you in national politics and national affairs? Students ranked their interest on a 4-point Likert scale ranging from "very interested" to "not at all interested." As 


\section{INCREASING POLITICAL INTEREST AND EFFICACY}

illustrated in Table 7, according to both quantitative tests, no significant difference in students' local political interest was found between the beginning and end of their social welfare policy course. Similarly, no significant difference in students' national political interest was found between the beginning and end of their social welfare policy course.

Table 7

Statistical Significance of Changes in Students' Political Interest $(n=31)$

\begin{tabular}{lllll}
\hline & Baseline & Post-Test & Paired $t$ Test & Wilcoxon \\
\hline Local Political Interest & $\mathrm{M}=2.06 \pm .77$ & $\mathrm{M}=1.87 \pm .67$ & $1.4, p=.161$ & $-1.4, p=.153$ \\
$\begin{array}{l}\text { National Political } \\
\text { Interest }\end{array}$ & $\mathrm{M}=1.97 \pm .80$ & $\mathrm{M}=1.87 \pm .67$ & $0.8, p=.414$ & $-0.8, p=.405$ \\
& & & & \\
\hline
\end{tabular}

\section{Change in Students' Internal Political Efficacy during Social Welfare Policy Course}

All students who completed both pre- and post-test surveys $(\mathrm{n}=31)$ indicated that their internal political efficacy had either increased $(74 \%, \mathrm{n}=23)$ or remained the same $(26 \%, \mathrm{n}=8)$ as result of the social welfare policy course. No student indicated a decreased internal political efficacy as a result of the course. Their responses to items on the Internal Political Efficacy Scale further confirmed this. Table 8 provides a descriptive summary of the changes in students' internal political efficacy. 


\section{INCREASING POLITICAL INTEREST AND EFFICACY}

Table 8

Descriptive Changes in Students' Internal Political Efficacy $(n=31)$

\begin{tabular}{lll}
\hline & Baseline & Post-Test \\
\hline Good Understanding of Issues & & $7(23 \%)$ \\
Strongly Agree & $2(7 \%)$ & $16(52 \%)$ \\
Somewhat Agree & $15(48 \%)$ & $7(23 \%)$ \\
Neither Agree/Disagree & $6(19 \%)$ & $1(3 \%)$ \\
Somewhat Disagree & $3(10 \%)$ & 0 \\
Strongly Disagree & $5(16 \%)$ & \\
& & $3(10 \%)$ \\
Well Qualified to Participate & & $12(39 \%)$ \\
Strongly Agree & $1(3 \%)$ & $8(26 \%)$ \\
Somewhat Agree & $6(19 \%)$ & $5(16 \%)$ \\
Neither Agree/Disagree & $9(29 \%)$ & $3(10 \%)$ \\
Somewhat Disagree & $8(26 \%)$ & \\
Strongly Disagree & $7(23 \%)$ & $8(26 \%)$ \\
& & $14(45 \%)$ \\
Better Informed Than Most & $3(10 \%)$ & $7(23 \%)$ \\
Strongly Agree & $5(16 \%)$ & $1(3 \%)$ \\
Somewhat Agree & $10(32 \%)$ & $1(3 \%)$ \\
Neither Agree/Disagree & $8(26 \%)$ & \\
Somewhat Disagree & $5(16 \%)$ & $3(10 \%)$ \\
Strongly Disagree & & $9(29 \%)$ \\
& $2(7 \%)$ & $10(32 \%)$ \\
As Good a Job in Public Office & $4(13 \%)$ & $2(7 \%)$ \\
Strongly Agree & $8(26 \%)$ & \\
Somewhat Agree & $7(23 \%)$ & \\
Neither Agree/Disagree & & \\
Somewhat Disagree & & \\
Strongly Disagree & & \\
\hline
\end{tabular}

Note. Percentages in each category may not add up to $100 \%$ due to rounding or a missed pre-test survey or answer.

The four item Internal Political Efficacy Scale was found to be highly reliable; the Cronbach's alpha for the pre- and post-test scale items were .87 and .84 , respectively. The distribution of difference scores for all four individual internal political efficacy items, as well as for the Internal Political Efficacy Scale, were also roughly normal or 


\section{INCREASING POLITICAL INTEREST AND EFFICACY}

slightly skewed. Therefore, for reasons described in Chapter 4, both the nonparametric Wilcoxin's Signed Ranks Test and the parametric paired samples $t$ test were applied to compare the pre-test and post-test scores of participating students on the Internal Political Efficacy Scale and the following four internal political efficacy items: (1) I feel I have a pretty good understanding of the important political issues facing our country. (2) I consider myself to be well qualified to participate in politics. (3) I think that I am better informed about politics and government than most people. (4) I feel that I could do as good a job in public office as most other people. Students ranked their interest on a 5point Likert scale ranging from "strongly agree" to "strongly disagree." As illustrated in Table 9, according to both quantitative tests, there was a significant difference in students' internal political efficacy, as measured by all four items and the Internal Political Efficacy Scale, between the beginning and end of their social welfare policy course. 


\section{INCREASING POLITICAL INTEREST AND EFFICACY}

Table 9

Statistical Significance of Changes in Students' Internal Political Efficacy $(n=31)$

\begin{tabular}{lllll}
\hline & Baseline & Post-Test & Paired $t$ Test & Wilcoxon \\
\hline $\begin{array}{llll}\text { Internal Political } \\
\text { Efficacy Scale }\end{array}$ & $\mathrm{M}=7.00 \pm 4.03$ & $\mathrm{M}=10.16 \pm 3.30$ & $5.1, p=.000$ & $-3.9, p=.000$ \\
Individual Items & & & & \\
\multicolumn{1}{c}{ Good Understanding } & $\mathrm{M}=2.81 \pm 1.22$ & $\mathrm{M}=2.06 \pm .77$ & $4.3, p=.000$ & $-3.5, p=.000$ \\
Well Qualified & $\mathrm{M}=3.45 \pm 1.15$ & $\mathrm{M}=2.77 \pm 1.15$ & $3.5, p=.001$ & $-3.0, p=.002$ \\
Better Informed & $\mathrm{M}=3.23 \pm 1.20$ & $\mathrm{M}=2.13 \pm .96$ & $5.7, p=.000$ & $-4.0, p=.000$ \\
\multicolumn{1}{c}{ As Good A Job } & $\mathrm{M}=3.52 \pm 1.18$ & $\mathrm{M}=2.87 \pm 1.09$ & $2.6, p=.014$ & $-2.5, p=.013$ \\
\hline
\end{tabular}

Finally, in order to evaluate whether these differences in pre- and post-test scores had practical significance, as well as statistical significance, effect size was calculated using Cohen's $d$ and judged based on Cohen's 1988 “classic work," Statistical Power Analysis for the Behavioral Sciences (as cited in J. A. Rosenthal, 1996). A large effect size was measured for the Internal Political Efficacy Scale $(d=.86)$, as well as the following two political efficacy items: (1) students feeling they have a pretty good understanding of the important political issues facing our country $(d=.73)$, and (2) students thinking they are better informed about politics and government than most people $(d=1.01)$. The effect size for the remaining two political efficacy items were deemed moderate: (1) students considering themselves well qualified to participate in 


\section{INCREASING POLITICAL INTEREST AND EFFICACY}

politics $(d=.59)$, and (2) students feeling they would do as good a job in public office as most other people $(d=.57)$.

In summary, the quantitative data indicate that students participating in these two social welfare policy courses experienced a statistically significant increase in internal political efficacy and a non-statistically significant increase or no change at all in their

political interest. Because this study did not employ a traditional experimental design, it cannot quantitatively be claimed that participation in the social welfare policy course caused the statistically significant increase in students' internal political efficacy. The changes observed could be attributed to a number of other factors, such as the simple passage of time, social desirability bias, and the effect of completing a measure twice. However, these quantitative results provide compelling descriptive data on the study sample and changes observed in students during a social welfare policy course. They also corroborate the qualitative reports of students, with regard to the impact of these social welfare policy courses on students' political interest and internal political efficacy. 


\section{INCREASING POLITICAL INTEREST AND EFFICACY}

\section{Chapter 6: Qualitative Results}

While the quantitative data provide a demographic and political context for the study's sample, as well as insight into changes in students' political interest and internal efficacy, the emphasis of this study is on qualitative data. Two social welfare policy courses were observed, after which students participated in focus groups and individual interviews. First, students were asked to describe the impact of the social welfare policy course on their political interest and internal political efficacy. Then they reflected on ways in which their participation in the course and their instructor's teaching methods impacted those two variables. Before considering the qualitative insights of students, it is helpful to have a basic understanding of the two courses purposively selected for inclusion in the study. Though limited by confidentiality considerations, a summary of course observations is provided below in order to provide a context for the interpretation and application of the study results.

\section{Course Observations}

Both social welfare policy courses were upper division, generalist courses required for graduation with a Bachelor's in Social Work. They were one term in length; neither was part of a policy sequence. The academic objectives of both courses included the development of policy knowledge and political advocacy skills. The content covered was consistent with the content required by the 2003 CSWE accreditation standards, as well as the policy-related competencies more recently outlined in the 2008 CSWE 


\section{INCREASING POLITICAL INTEREST AND EFFICACY}

accreditation standards (see Chapter 2). No additional information concerning the placement and specific objectives of the courses within their respective programs will be provided out of respect for confidentiality.

Both instructors combined didactic and experiential components in their social welfare policy course, though their teaching styles and assignments differed substantially. One instructor lectured for a significant portion of most class sessions, using PowerPoints and focusing on the content of the required reading. The other instructor lectured less and emphasized small group activities more; in this class, content from the required readings was not incorporated into class time as much. Both instructors showed a couple films over the course of the term, but one instructor incorporated other multi-media content (e.g. TV show clips, websites) considerably more than the other.

Both instructors employed experiential teaching methods, though in unique ways. In one course, students engaged in many small group activities during class and offered testimony at a mock political committee hearing. In the other course, groups of students created policy proposals to submit to a forum with state-level elected representatives. An assignment in one course required students to participate in a set number of political activity hours outside of class. Both instructors initially assigned a policy analysis or policy brief project, though it was dropped in one course so that students could spend more time on their policy proposal project. Political dialogue occurred in both courses, though topics for class and small group discussion were raised more often in one class 


\section{INCREASING POLITICAL INTEREST AND EFFICACY}

than the other. Both instructors took their students on at least one field trip. In one case, the field trip was to a political rally. In another, it was to a social service agency and a housing community. Both instructors involved guest speakers. In one case, it was a professional political advocate. In another, it was a community member who was homeless and a social service provider.

In summary, the instructors of the two courses represent a diversity of teaching styles and methods. Class time was structured differently. Technology and multi-media resources were used differently. Student input was incorporated to differing degrees and in different ways. Though they both utilized experiential learning methods, they did so in different ways. In both courses, however, the importance of political advocacy among social workers was communicated verbally and through exposure to some of the advocacy activities of the instructors outside of class time.

\section{The Impact of a Social Welfare Policy Course on Students}

While the quantitative data support the hypothesis that social welfare policy courses can positively impact students' internal political efficacy, the emphasis of this study is on the qualitative insights provided by students participating in these courses. Qualitatively, students confirmed and further described the impact of the social welfare policy course on their internal political efficacy. Most students also perceived themselves as having experienced an increase in their political interest due to participation in the course. Those who did not perceive themselves as having an 


\section{INCREASING POLITICAL INTEREST AND EFFICACY}

increased interest self-identified as having entered the course with an already strong level of political interest. Students then reflected on the process of those impacts in greater detail. Throughout the remainder of this chapter, excerpts or exemplars from focus group and interview transcripts are provided to illustrate specific concepts.

\section{Political interest.}

When students described the impact of the social welfare policy course on their political interest, most spoke of an increase in their interest. One student summarized, "Now I just like knowing things." Other students got more specific: "I think I will go back and look up the bill and just see how it's doing." And, "I've even seen the people who were in the class becoming more politically active ... I was just noticing on Facebook today, [students from the course] talking about policy change." This increase in students' political interest was conceptualized in two main ways: (1) a greater appreciation for the impact and relevance of policy and (2) a greater breadth of interests.

Students described caring more about politics and policy, because they could now see how it impacted people's lives. On one level, they began to recognize how policies impact their own life. "I am so surprised that I really liked the class. ... I really liked that kind of bringing it in..., 'And this is how it's affecting your life." Another student described making a mental connection in class between health care policy reform - a current event coinciding with the social welfare policy course - and a health problem she 


\section{INCREASING POLITICAL INTEREST AND EFFICACY}

was experiencing herself. "I had a situation that happened to me that made me, like, really want the health care reform to pass."

Students also described an increased appreciation for how policies impact other people's lives.

Going back to the issue that we had talked about with gun control and mental health, I mean, neither of those are particular topics that $I$ care about. But it was just a very ethically challenging discussion where you had to kind of reflect on what your own personal values were ... and also how that affects everyone around you on different scales.... To see how individual decisions affect these large groups of people and applying it to real life situations.

Students regularly referred to films and guest speakers from the course that helped them better understand the personal impact of social welfare policies. This newly made or strengthened connection between policy and the quality of individual lives represents an increased interest on the part of many students.

On another level, students expressed an increased appreciation for the role of policy and political advocacy in the profession of social work when describing their increased political interest.

If you don't have a good understanding of policy and you don't take an active interest, you're really doing a disservice to your clients. ... Especially writing the letters [for an Amnesty International table on campus] ... I saw myself in those 


\section{INCREASING POLITICAL INTEREST AND EFFICACY}

people that walked away and didn't get involved. And I really want to, as a social worker, be more involved in policy and stuff. I really want to be more involved and proactive.

Another student reflected, "I think I've become more interested personally because on a professional level it's so needed. ... It's come together in that sense." Politics becomes more interesting for students when it is recognized as an important area of practice within the profession to which you have committed your training.

In addition to an increased appreciation for the impact of policy on people's lives, students described their increased interest in politics as a greater breadth of interests. One student referred to a specific bill chosen for a policy analysis assignment:

I liked the bill a lot, actually. And now all of the sudden I'm passionate about a whole new issue. But it's also been through the system, like, seven times and would get into a committee and die in committee every single time. And the whole time I was writing it, it was just sitting in committee. And I was like, 'Hmm, I wonder what's going to happen with this bill that I now care so much about?' I'm frustrated that I care. ... I didn't even know it existed before.

Other students expressed new interest in broader policy areas to which they were exposed through the course, including state tax reform and low-income housing.

There were a few students who described their political interest remaining the same due to it already being high when they began the course. "I'm not sure that 


\section{INCREASING POLITICAL INTEREST AND EFFICACY}

'increased' is really the right term for what I experienced, but I did find my interest broadening a little bit more. Not so much how excited I was about it, because I love politics. But ... I got a bigger picture that I'll probably look for in future efforts." Several students who came into the course with strong political interest described their interest as "broadening" due to exposure to new areas of policy practice relevant to social work.

\section{Internal political efficacy.}

In focus groups and interviews, when students described the impact of the social welfare policy course on their internal political efficacy, all spoke of an increase in their sense of competence to engage with the political system. When referring to specific areas of policy practice they had engaged in through the course, such as political testimony or policy analysis, students would express belief in their abilities. "We can do it." "You really can do this!" These increases in students' internal political efficacy were conceptualized in four ways: (1) an expanded view of what political advocacy involves, (2) knowledge development, (3) skill development, and (4) decreased fears.

Students described an understanding of political advocacy that was broader and more suitable to their interests and skills then they originally believed to be the case. When asked to reflect on the idea of being a political advocate, one student shared:

The conflict of it ... is something that I want to stay away from. ... But I think from what I've learned in this class, ... there are a lot of pieces that I would enjoy 


\section{INCREASING POLITICAL INTEREST AND EFFICACY}

doing. ... I just never thought that, like, the things that I did for my [experiential assignment] hours were really policy. ... I always feel comfortable doing testimony. And that kind of educating others piece is really important to me. Another student shared about the impactful combination of writing a policy brief and then providing testimony on that policy at a mock committee hearing:

I had no history or experience in doing either of those things. You know, going through a bill and learning about it in that much detail and knowing what the process is to go before a committee. And I wouldn't have even known that that was so much of an option before.

This expanded view of political advocacy represents an increased internal political efficacy in these students, a sense that they can make a difference in the political realm using their existing or emerging interests and skills.

Students also described their increased sense of political efficacy as knowledge development: "I know what I'm talking about now." Specifically, they referred to increased knowledge of social welfare history, current policy issues, the legislative committee process, and political bodies at the local, state, and national levels.

Just really basic things about policy and politics and, like, history stuff. ... That had a piece in the confidence, because it was like, 'Well, now I know what I'm talking about and I know that what I'm saying makes sense and that it's correct. ... You don't want to sound stupid, especially in a political discussion. 


\section{INCREASING POLITICAL INTEREST AND EFFICACY}

Students equated knowing more about policies and the political process with being more capable.

Skill development was also an important component of increased internal political

efficacy for students. As a result of their participation in the social welfare policy course, they expressed confidence in their ability to engage in political conversations, read and understand bills, analyze policy, and offer testimony at a political committee hearing. "All the briefs and things that we did, I didn't really think that that was something that I could do." One student described knowing how to educate oneself on a bill as "selfempowering."

Having to find out where the resources are, as far as finding whose sponsoring the bill or what kind of funding is involved in it, is really valuable for me. Because it makes me feel like I can hear if a bill is coming up that's relevant to the practice that I'm doing right now and I can do the research quickly, and understand what I need to look at and where.

When asked about the idea of offering testimony at a committee hearing prior to participation in the social welfare policy course, a student responded:

Probably not, because I would have had no idea what to expect or what any of the process would have looked like. I mean, I would not have known to take a paper with me or what it should look like or even ... what it's polite to do in a hearing 


\section{INCREASING POLITICAL INTEREST AND EFFICACY}

of that sort. I mean, I would have had no clue, so it would have been, I think, a lot more intimidating to do something like that.

Students often described their increased sense of efficacy as the development of these new political advocacy skills.

Another way in which students described their increased sense of political efficacy was as a decrease in fears. These fears initially included fears of other people's reactions, as well as fears of not being able to advocate effectively. One student described overcoming fears of others disagreeing with her political opinions:

I think one of the first things that you have to get comfortable with is really expressing your view and not being scared of someone, just being able to answer what you really believe in. I think if you have to experience someone disagreeing with you, it actually encourages you to really stand up and start speaking up for what you believe.

Another student reflected back on providing testimony at a mock committee hearing: "Especially with the testimony, it was like making us feel really comfortable. ... Like, we can do this and people aren't going to just shoot you down. Basically all these fears you have in your head. Like, those aren't really true." And another student told the story of holding her own for the first time in a political conversation with a friend with whom she used to feel "really dumb" when discussing politics. Increased internal political efficacy was often experienced by students as a diminishment of fear. 


\section{INCREASING POLITICAL INTEREST AND EFFICACY}

\section{The Social Welfare Policy Student: Themes for Effective Learning}

After clarifying the impact of participation in a social welfare policy course on students' political interest and internal political efficacy, this study sought to identify how students believe their participation in the course impacted these two variables. Seven specific aspects of the student experience in a social welfare policy course that contribute to an increase in political interest and internal political efficacy emerged from qualitative data analysis. These seven aspects include both internal and external factors.

\section{Intrinsic value of course and internal motivation to learn.}

Students attributed their increased interest and internal efficacy in part to an internal motivation to learn about policy practice. "There was so much I wanted to learn." This internal drive came from the students' recognition that social welfare policy and political advocacy have an intrinsic value to them. For example, there was the student who had a health crisis and began to make connections between her own experience and health care policy reform. Instead of engaging in advocacy related to her original policy analysis topic, she participated in health care reform efforts because she had discovered a strong personal motivation to engage. "I had a situation that happened to me that made me, like, really want the health care reform to pass. So that wasn't even the bill I researched. ... I chose something that I really was interested in." Another student was motivated to learn about mental health care parity due to having lost 


\section{INCREASING POLITICAL INTEREST AND EFFICACY}

someone to suicide. Having a parent who receives Social Security benefits created intrinsic value in learning about that particular policy for yet another student.

While most students appeared to intellectually recognize the importance of a variety of social policy topics, it was when they could personally relate to an issue and placed particular value on it that they felt a strong motivation to engage and learn. One student who appeared less politically interested than most visibly lit up when talking about one particular policy:

But if it's like the Arizona immigration law, boom! Just came up in the news, what are people saying about it? You know, that was kind of interesting, because from the get go I'm like, 'No, I'm not okay with that.' So who agrees with me? Yeah!

For some students, this motivation came from a professional goal rather than personal experience.

Hunger is an issue I really want to work with, so I really wanted to learn and grow and know that, so I have information for the future. Whereas something that, though I think social issues are all important, if it wasn't something I was really excited in ... I probably wouldn't have worked as hard to find the information.

Students appreciated the powerful and positive influence that intrinsic value and internal motivation can have on their interest and willingness to engage in political advocacy activities, whether it was for personal or professional reasons. 


\section{INCREASING POLITICAL INTEREST AND EFFICACY}

Students described the intrinsic value of the course and their internal motivation to engage in learning activities as influencing various aspects of their course work. It appears to have been the primary influence on the topics they chose for analysis and advocacy assignments. For example, students interested in child welfare selected policies such as the Dream Act or oversight of psychotropic drugs used with foster children. And when students found internal motivation, they also described wanting to spend more time and energy on their research and advocacy efforts. One student who selected a policy concern related to child welfare found herself increasingly engaged in the research:

I really liked it. It definitely gave me an opportunity to look at the individual cases which were really important to me, but also to look at, like, the state averages and the national averages. And then also kind of dive into this corporate industry influence that happens with these things. ... Having to be able to look at it at different levels and different dimensions, to be able to look from the individual cases all the way up to the globalized industry status kind of thing, was really fun. ... I felt like the assignment put the opportunity out there. But also, I think the topic that I picked, as I did more and more research, I realized that that was kind of something I was going to have to research to be able to gain the whole picture. ... I don't think a lot of other people might have taken that route, but to me it was interesting." 


\section{INCREASING POLITICAL INTEREST AND EFFICACY}

In one of the courses, students were required to participate in a forum with state-level elected representatives. Following the forum, student groups submitted proposals to forum leaders for ways to improve the state's tax revenue and budgeting system. For those students whose political interest was increased by participation in the forum, having a personal or intrinsic interest in the topic was key. "Because I had interest, I like cared about doing the proposal. ... We live in [the state], so it's about something that actually affects us."

When students did not feel a personal connection to a topic or assignment, they were less interested and less willing to invest time and energy.

It was just an assignment. It wasn't that it wasn't helpful. It wasn't what affected me most in the class. It was just an assignment that I had to get done. ... I totally could have put more effort into it. ... I don't think I cared enough about the topic ... because I'm not from here. I was just like, 'What do you guys think?' ... Maybe if I was doing it in my own state I'd feel differently. Because when I did do things in my own state, I was very passionate about it.

As evident by these examples, intrinsic value and internal motivation can come from students' personal experiences, relationships, community identity, and professional interests.

\section{External motivation and support.}




\section{INCREASING POLITICAL INTEREST AND EFFICACY}

Another quality of the learning experience identified by students as key to increasing their political interest and internal political efficacy is external motivation and support. While students felt a clear need to engage with topics of intrinsic value to them, they also highlighted the value in being stretched or motivated by the requirements of a course. Students discovered new topics of interest and developed new competencies as a result of committing to course activities and assignments laid out initially by the instructors.

Students felt that in-class activities and outside assignments provided a challenge and external motivation to engage in learning that they would not otherwise have benefitted from due to intimidation, lack of time, or initial lack of interest.

We watched Sicko ... and I've been wanting to see that movie since it came out, and I just never got a chance to. So just kind of that pushing myself to do it, which is one of the greatest things, I think, about school in general, is that you get to do so many things that you wouldn't do, just because of time or, you know, motivation on your own.

Another student recalled struggling to write objectively in the first part of her assigned policy brief, but went on to describe the benefits of having to do that:

I think I gained a lot in the sense that it forced me to really be able to understand my bill and to verbalize that bill or to type it out, which I think made me - in the long run - more passionate about it when I did get to part three [of the 


\section{INCREASING POLITICAL INTEREST AND EFFICACY}

assignment]. So even though I kind of wavered on wanting to do it in the beginning and didn't do well on it, I think the knowledge that I gained from it was really good, because ... I could summarize it really well when I would talk to other people about it.

Students offered many other examples of activities with which they would not have engaged without a course requirement, including a community presentation on poverty and research on a specific component of the state tax system. The interests and skills developed through these externally motivated activities were clearly valued by students.

Expanding political interest and efficacy through a social welfare policy course seemed to involve students having their personal interests valued and engaged, while also being externally challenged to consider new policy areas and practice new advocacy skills. The tension required for this effective balance to occur was recognized by students. For example, one student described [the instructor] as giving students "ownership over a lot of the process." When asked how the instructor provided students with a sense of ownership, the student explained, "Giving us the policy briefs, letting us choose, and kind of forcing us to go through the process. Because it's not fun to read a bill. But having to do it, I think, was beneficial. ... Teaching someone how to be comfortable with the process and what that process is, if you want to advocate for something." 


\section{INCREASING POLITICAL INTEREST AND EFFICACY}

A common area of externally motivated learning for students was current events. Instructors raised up current events, such as health care reform and the war in Afghanistan, as discussion topics on a weekly basis.

I kind of felt like you have to be up on topics because we're going to talk about them [in class]. So I had to kind of know what was going on a little bit more. And I don't have a TV or anything, so I have to go out and actually sit down at my computer and watch the news or something, which was good for me, but I hadn't been doing it for awhile.

This external motivation to pay attention to events happening in the world around them was appreciated by students and identified as contributing to their increased interest and sense of efficacy. "I felt I'm learning, you know, current events in this class and stuff that I wouldn't necessarily be doing on my own, but wish I was."

A couple students even expressed disappointment about an initial assignment to write a letter to their legislator being removed as a course requirement. "I really wanted to write [a letter to my legislator]. But for me it was almost like, 'If it's not an assignment, then I didn't do it.' Lack of something."

However, as students struggle with new and externally-motivated challenges, it is important that their instructor provides both practical and emotional support along the way. There is a risk of decreasing political internal efficacy if students engage in externally-motivated challenges and do not feel supported or well received. Only one 


\section{INCREASING POLITICAL INTEREST AND EFFICACY}

instance of this was identified in these two courses. It is included here as an exception to the remaining students' reported experiences, because it raises an important consideration. In this case, the student did not feel well received when providing testimony at a mock committee hearing.

[The instructor] just drilled me with 101 questions about my policy. And like, I mean, I felt like I was prepared. But when I went up, what [the instructor] did felt like I didn't prepare for it at all. ... I'm definitely not going to want to go up to a legislator and, like, people who really don't know me. And, like, doing it in a professional aspect? Like, that just made me really not want to do it at all.

If social welfare policy instructors challenge students with policy practice exercises in order to expand interest and increase internal political efficacy, the risk of students not being or feeling well prepared and supported needs to be acknowledged and minimized.

The remaining students in these courses expressed appreciation for their instructors' practical and emotional support. Students recalled their instructor helping them identify a policy in their area of interest, clarify the extent of research necessary for a policy brief, brainstorm the relevant social context for their policy, and locate relevant advocacy organizations. This support from instructors is a critical component of students experiencing success with externally-motivated learning challenges.

\section{Policy knowledge development.}




\section{INCREASING POLITICAL INTEREST AND EFFICACY}

A greater breadth and depth of social welfare policy knowledge contributes to students' increased political interest and internal political efficacy. As discussed earlier, students recognized when their political interests had broadened and equated that broadening of interests with increased interest. "I got a bigger picture that I'll probably look for in the future." Even students who self-identified as entering the course with a high level of political interest described a broadening and deepening of their policy knowledge.

I was already aware of health care and things like that, but I think really learning more about the welfare system and TANF and things like that. I mean, I knew they were policy, but I think it really connected everything, I guess. You know how you can just know something, but not understand it?

In this case, the deepening of knowledge involved a greater understanding of the complexity of and connections within the social welfare policy system. A deepening of policy knowledge may also include developing more detailed knowledge of specific policies or the political process itself.

While exposure to more of the social welfare policy world increases political interest in students, it can also enhance students' sense of competence engaging with the political system.

Before, I don't think many of us knew where to go or even exactly what policies were out there. If a person is going to make a difference, you have to understand 


\section{INCREASING POLITICAL INTEREST AND EFFICACY}

what is out there. Once you know what's out there, then you can realize what's not out there. And you can look at what needs are in the community.

Students described having a greater knowledge of specific policies, their impact on people, the political committee process, and political advocacy options. All of this contributed to an increase in students' internal political efficacy.

\section{Genuine and diverse political dialogue.}

A fourth quality of the student learning experience that contributes to increased political interest and internal efficacy is participation in genuine and diverse political dialogue. Genuine political dialogue refers to people sharing their sincere thoughts and feelings about particular policy topics. Diverse political dialogue refers to a variety of political perspectives being substantively represented in the discussion. As the focus group facilitator and interviewer, I must admit it surprised me the extent to which students wanted to talk about political dialogue in the classroom. This was one area that they felt strongly about, despite not consistently experiencing it in class.

There were moments in larger class discussions where students recalled engaging in genuine and diverse political dialogue.

[Discussions on] health care I really enjoyed, because I didn't know much about all the different kinds of reform. And so being able to discuss, because even within our class, we had different opinions on health care. And then ... I remember talking about the war in Afghanistan. There was a lot of different 


\section{INCREASING POLITICAL INTEREST AND EFFICACY}

opinions on what should be done there. And so just hearing how and why people approached different subjects was good.

Students consistently assigned value to class discussions that were genuine and diverse.

Most of the genuine and diverse political dialogue, however, occurred in small group settings. "I feel like a lot of people didn't really talk, so I think that the smaller group sessions worked better." One student recalled a small group exercise on the topic of an anti-spanking policy: "It was really interesting because there were some times that we were all so different that we really brought different perspectives." Another student recalled an engaging small group conversation on gun ownership and mental health where students offered unique perspectives. The classroom observations made by the researcher confirm students' memory of genuine and diverse political dialogue occurring more in small groups than in large group discussion. Interesting topics were typically raised in the larger class setting, but students in these two courses experienced their most genuine, diverse, and thereby engaging political discussions in small group settings.

Participating in genuine and diverse political dialogue increased students' political interest in a couple of ways. First, there was the simple reality of having one's attention focused by differences of opinion being expressed. Second, interest was roused by the opportunity and challenge to personally consider other perspectives and options. The primary way in which these genuine and diverse political dialogues occurred was inclass discussion. 


\section{INCREASING POLITICAL INTEREST AND EFFICACY}

The discussions were probably ... what helped me. You could form your own opinions, maybe see the other side. But just the discussion of it makes it a whole lot more interesting. Because going out and reading about an issue ... it's a lot more ... I don't know ... when you discuss it with other people and hear different ideas, you can really figure out where you stand.

Though students also appreciated the interest raised by an assignment in which small groups created policy proposals, submitted them to an outside forum, and then presented them to the class.

I liked seeing the different presentations. It was interesting that we all had the same topic, but vast differences in how we approached it. ... It was interesting to look at that and get that different perspective and go, 'Oh, I hadn't even thought about that approach.'

These increases in interest were expressed beyond the classroom walls, as well.

We would oftentimes go after class and discuss it with our classmates, like during lunch and stuff. Like things that we talked about in class or like talked about the opposite viewpoint to try to like learn more about others' opinions. And like specifically there's one person who had a different... She had a different opinion and we would eat lunch with her and like talk about like her view versus our view on these different topics and how they differed and stuff like that. 


\section{INCREASING POLITICAL INTEREST AND EFFICACY}

Whether the genuine and diverse political dialogue emerged from a loosely structured discussion, a set of formal presentations, or a lunchtime conversation, students recognized their interest being peaked.

Students attributed a part of the increase in their internal political efficacy to participation in these genuine and diverse political dialogues, as well. Some students felt they gained greater clarity about their own political opinions because of diverse dialogue.

It was kind of hard for me to see other views unless you got kind of a broader conversation going about why people fight for certain things. It helped me to understand where other people were coming from. And it helped me to really know where I stood on that issue.

Another student felt that having their genuine opinion received respectfully in an in-class dialogue increased their confidence to have conversations outside of class:

You can throw out your ideas for the first time and it's accepted. So that second time you try and throw it out there and somebody tries to bite your head off for it, you know that not everybody is going to react that way. That first reaction is kind of a baseline.

Both speaking one's own opinion and hearing others' genuine and diverse opinions in a political dialogue contribute to students' sense of competence engaging with the political world. 


\section{INCREASING POLITICAL INTEREST AND EFFICACY}

Students offered a variety of reasons for why genuine and diverse discussions occurred more in small groups than in the larger classroom setting. One contributing factor was the challenge for many to speak up in any large group.

I think that ... the best discussions that I did have happened to be in a small group, just because the broader classroom makes it a little bit more difficult to get your voice heard. There's definitely always those couple of people that talk the most.

In addition to feeling intimidated or overwhelmed by students who do speak a lot in class, students described it being harder to overcome shyness in a large group setting versus smaller groups.

Students also felt unsure of how their classmates would respond to their political thoughts and opinions. "You don't know how people are going to react." One student recalled feeling "completely comfortable" discussing most topics, "because what we were talking about in class is what I believed." However, when an especially controversial social issue was raised, the student did not talk at all in class that day. A significant reason was her discomfort with her classmates' potential reaction. "When you don't know the opinions of everybody, but it sounds like the majority are agreeing with someone who's very outspoken and talking negatively, it's really hard to say, 'Hey, I don't think that's right,' in a classroom. 


\section{INCREASING POLITICAL INTEREST AND EFFICACY}

Finally, there was a lack of confidence on the part of some students to disagree with the instructor's perceived opinion, despite trusting that the instructor would be respectful of them.

I think it's harder to raise your hand and to chime in when you have a very strong figure as the professor, who's very knowledgeable and, like I said, has [his/her] views out there in front of you. It's harder to challenge those if you're not confident in certain cases.

For the student who did not speak when a particularly controversial social issue was discussed in class, her discomfort with disagreeing with the instructor was also a factor. Her description includes a combination of peer and instructor influences:

I didn't feel comfortable discussing in class with ... yeah, with the atmosphere in class. ... I know [the instructor's] view because I've heard it before, but I don't know if [the instructor] ever said anything actually in class. But there were two students in class particularly that were very vocal and made it sound on one particular issue that the other side was just absurd. ... I just didn't feel comfortable or that I would be supported by most of the people in the class. Not that [the instructor] wouldn't support me, but that I knew I disagreed with her view. So, I don't know, I guess it was a comfort level and that I just didn't feel comfortable. Would I almost be looked down upon, because I had a different view on that area? 


\section{INCREASING POLITICAL INTEREST AND EFFICACY}

So despite students consistently expressing their belief that their instructor would receive differences of opinion well, they still felt hesitant to disagree in the large class setting when they knew the instructor's opinion.

As alluded to earlier and despite the challenges described above, students expressed a strong desire for more genuine and diverse political dialogue in their social welfare policy class. In one focus group, a student reflected, "It might have been interesting, actually, to get other opinions. I kind of forgot that other people felt differently. [laughter from the group] I'm not joking." Another student concurred: "It just kind of seemed, kind of like we all came in and assumed we all believed the same thing."

Students identified several ways in which more genuine and diverse political dialogue would have contributed to their political interest. First, students felt that the simple presence of different opinions would make class conversations more engaging than when everyone appears to agree. "I guess there wasn't really a whole lot of new experience to take from it. ... It's always interesting to hear someone else's perspective on something."

There are certain instances when class discussion is the way to go, because you learn from teaching each other and then you remember it better. I mean, I can't remember certain textbooks I read and I read them last [term], but I can remember 


\section{INCREASING POLITICAL INTEREST AND EFFICACY}

the class discussions and just the interplay between people even if I wasn't the one speaking.

The interest created by genuine and diverse classroom discussion helps focus students' attention, and also helps them retain the material.

Students also felt that being challenged to consider and even represent opinions different from their own would increase their political interest.

It would have been interesting to find myself being like, 'Oh wow, I actually am very conservative on this topic and I had no idea.' But when it's presented to you in an already packaged, liberal perspective, you're kind of like, 'Oh yeah, that's what I think about that.'

"I think having to do something that challenges you, working with something that isn't your opinion but having to find a way to make it work, is always more engaging for me."

Finally, students felt that their interest in following and supporting a particular policy would increase, if they were exposed to people who disagree with them. "I think it would increase my interest ... because it would allow me to see another side and really believe in what I'm doing and fight for it more." Awareness of disagreement or opposition can provoke students' interest in staying connected with a political issue or movement.

Students also believed participating in more genuine and diverse political dialogues through their social welfare policy course would increase their internal political 


\section{INCREASING POLITICAL INTEREST AND EFFICACY}

efficacy, first by giving them more confidence to engage in conversation with people who disagree with them on political issues. Students felt a need to increase their knowledge and understanding of different opinions, in order to boost their confidence.

At the moment, I would have no courage to go speak with someone who believes something completely, a different political view than me ... when I have no idea why they believe what they believe, because I'm going to get questions and not know how to answer.

Students also felt discussing various perspectives would help strengthen the clarity of their own stance.

We went over a lot of things that, in my mind, it was like, 'Well, why in the world would anybody not believe this?' ... But clearly there's other approaches to it... And so it just leaves the door open for, in a conversation, someone could bring a point up to me and completely catch me off guard. And I could be, like, 'Oh, that's really ... I never thought of that in that aspect of something.' And I want to be as comfortable in a situation in knowing that I really support my side, so I need to know the other side as well.

Finally, students expressed a lack of confidence in their own skills to have such conversations. "You have to get comfortable with ... expressing your view and not being scared of someone, just being able to answer what you really believe in." 


\section{INCREASING POLITICAL INTEREST AND EFFICACY}

Second, students believed more genuine and diverse political dialogue would increase their internal political efficacy by enhancing their ability to respect clients and seek compromise with citizens and politicians with whom they disagree.

I think it ... prepares [you] not just for advocacy, but it like opens doors for how clients might think about an issue. Or when they tell you something and you're like, 'I'm not sure I agree with that. But at least I am strong enough in my own opinion not to attack yours.'

In addition to understanding and working with diverse clients, such dialogue contributes to one's ability to compromise. "I feel, like, as social workers, we should be open to hearing both sides."

I think communication is key to any problem solving, and that goes back to advocacy. In order to advocate for something, you have to have a broad understanding of what the problem is. And if you're only looking at it from one side, you can't possibly effectively change something, because you have to be able to compromise.

Students recognized the challenge of facilitating genuine and diverse political dialogue in social work classrooms, but urged instructors to do more of this.

\section{Political advocacy skill development.}

Developing concrete, practical skills for political advocacy is essential to increasing students' internal political efficacy. As discussed earlier, students equated 


\section{INCREASING POLITICAL INTEREST AND EFFICACY}

having political advocacy skills with being competent to engage the political system. When they were able to successfully engage in political conversations, read and understand bills, analyze policy, and offer testimony at a mock political committee

hearing, they felt an increased sense of competence. This increased sense of efficacy was described as "self-empowering" or as something they had not believed they could do.

I feel like I can write a policy now. I can't write a bang up, super effective, fabulous policy. But I know ... through practice, I know the steps to take now. And that's really important. You're learning the steps to at least begin to start a change.

Additional examples of political advocacy skill development were included in earlier sections.

\section{Authentic political engagement.}

The sixth important quality of the student experience in a social welfare policy course that contributes to increased political interest and internal efficacy is authentic political engagement. Political activities that students experienced as authentic included communicating directly with politicians, receiving a response from a political representative, engaging politically with other citizens outside of the classroom, and following current bills. Students regularly used the word "real" to describe these experiences. 


\section{INCREASING POLITICAL INTEREST AND EFFICACY}

The first way in which authentic political engagement positively influenced students' interest and efficacy was their realization that they have a current and meaningful place in the political process. Their political representatives value their

presence and input. One student realized this while participating at a state-level political forum:

When [the Secretary of State] came down and just, like, shook our hand, I was like, 'Oh, she came down and wanted to talk to us.' ... I liked the fact that [the Secretary of State] wanted to meet us. ... [The Secretary of State] was like, 'It's a pleasure to meet you guys.' And you're like, 'Who? Us? You wanted to meet us?"”

Students at the forum also realized they already have a political voice. One student who spoke at the microphone during the event:

felt like I was making a difference. ... Instead of talking to somebody who can talk to somebody else, I was saying directly to all of them.... I'm proud I did. That was really important to me to realize that I was important in the process. For another student, this immediate and meaningful exchange happened through a letter: For getting my [assigned political activity] hours, I decided to write both the senators of [the student's state] about the health care reform. And I, like, took it from the book we were reading. I did the whole page style thing and ... I got a response from [the student's senator] the next day. Like, within 24 hours. It was 


\section{INCREASING POLITICAL INTEREST AND EFFICACY}

really cool, because it was, like, really personalized to me. So it was kind of nice to share your story ... to have someone up high that ... will be voting on the legislation.

Students who experience a political representative valuing their input can more easily imagine engaging with the political system again in the future. They seem to find it to be a more interesting possibility, and also have greater confidence that they can make an impact.

Authentic political engagement also provided students with the opportunity to practice advocacy skills in the most realistic way possible and receive immediate feedback from the political system while doing so. As one student said, engaging in political advocacy "made the process more tangible." Another student reflected, "Stuff like this, where I personally have to use this knowledge to assist someone or to like do it as a process, I have to experience it." And students clearly valued practicing political advocacy skills, both inside and outside of the classroom. However, authentic or "real" political engagement offers the additional components of being most realistic and providing feedback from the actual system. This feedback imprinted students with a belief that they can make a political impact. The state-level political forum "gave me the chance to participate in something I could have an effect and make change. .... I just feel empowered and have that ability." Students were clearly impacted by participating in what they viewed as "real" political action. 


\section{INCREASING POLITICAL INTEREST AND EFFICACY}

\section{An expanded view of and appreciation for political advocacy.}

The final aspect of the student experience identified as contributing to an increase in political interest and internal political efficacy is an expanded view of and appreciation for political advocacy, itself. An expanded view of political advocacy means that the student identifies more skills and activities as falling within the scope of political advocacy. An increased appreciation for political advocacy means that the student places more value on the social work role of political advocate. This expanded view of and appreciation for political advocacy increases the chance that students will find a niche for themselves and embrace the identity of an advocate.

When students expand their view of political advocacy, it contributes to an increased internal political efficacy because they begin to recognize that they can make a difference in the political realm using their existing or emerging interests and skills. Political advocacy involves a wide range of potential activities from public education to lobbying political representatives, from writing a letter to testifying before a committee. When asked to reflect on the idea of being a political advocate, one student shared: "I just never thought that, like, the things that I did for my [experiential assignment] hours were really policy. ... I always feel comfortable doing testimony. And that kind of educating others piece is really important to me." Another student could not imagine advocating face-to-face with a political representative. However, that student could imagine having more conversations with other citizens "about how government affects 


\section{INCREASING POLITICAL INTEREST AND EFFICACY}

the people that I volunteer with and the agencies and stuff that they try to go through to get aid and all that." Social workers are more likely to participate in political advocacy if they can imagine a political role for which they feel well suited.

An increased appreciation for advocacy means that the student places more value on the social work role of advocate. A first step towards this increased appreciation seems to be the realization that social welfare policy has a tremendous impact on people, especially those in vulnerable circumstances. "[This class] made me realize how much government has to do with everything, especially in social work." Or as another student put it: "I just hadn't put any thought into the fact that policy affects all the services that people get." Developing greater appreciation for political advocacy also seems to include the recognition that political advocacy is an important role for all social workers, regardless of the level at which one works. "If you don't have a good understanding of policy and you don't take an active interest, you're really doing a disservice to your clients." The development of this appreciation was most notable in students who came to social work with a desire to work directly with individuals and families.

\section{The Social Welfare Policy Instructor: Themes for Effective Teaching}

If these seven qualities of the student experience contribute to an increase in political interest and internal political efficacy, then what specific steps can social welfare policy instructors take to support such an experience for their students? Eleven recommended teaching methods for social welfare policy instructors emerged from 


\section{INCREASING POLITICAL INTEREST AND EFFICACY}

qualitative data analysis that directly connect to the seven recommended qualities for students' experience of the course. These methodological themes represent what students identified as having a positive impact on their political interest and sense of efficacy.

\section{Demonstrate basic instructional competencies.}

First, the importance of social welfare policy instructors demonstrating basic instructional competencies must be acknowledged. When asked about teaching methods that helped them develop their political interest and internal political efficacy, students regularly referred to a skill of their instructor that could be conceptualized as a basic instructional competency, important regardless of course content or learning objectives. These teaching skills included the instructor (1) having a clear and interesting presentation style, (2) incorporating activities geared towards a variety of learning styles, (3) encouraging questions, (4) assessing student competencies throughout the course and adjusting instruction accordingly, and (5) providing valuable feedback on student work.

If an instructor hopes to maximize student interest and sense of competency in politics, a clear and interesting presentation style is essential. If policy is boring in class, why would it be different in the field? And if it is difficult to understand in class, why would it be any easier out in the field? One student described the instructor's presentation style as "not necessarily watered down, but it was explained in a way that was pretty easy for me to understand." Another student reflected on the way in which a clear presentation style contributes to interest: "Maybe it was [the instructor's] teaching 


\section{INCREASING POLITICAL INTEREST AND EFFICACY}

style or something, but I feel like the information was not boring ... It was just like, 'I get this, so it's really interesting.' ... I'm not lost or confused at all." Students also expressed appreciation for interesting films, guest speakers, and video clips of political satire from

the Daily Show with Jon Stewart. "You realize [policy] is not boring. It's not all serious. It can actually be really interesting and a really fun experience."

As with all subjects, social welfare policy students need their diverse learning styles matched in the classroom, if they are going to develop interest, knowledge, and skills. "The more ways you show me something, the more apt I am to actually learn it and be able to implement it." Some students pointed to the importance of being able to learn by "doing" the work. Other students appreciated the chance for discussion and reflection. One student described having a hard time engaging with the textbook, but found that the discussions were particularly helpful. "You could form your own opinions, maybe see the other side, but just the discussion of it makes it a lot more interesting." Still others found traditional lectures useful for increasing knowledge and understanding of complex political structures and processes. It is worth remembering that, as with all subjects, students' learning styles vary and so should the course activities. "I think that's just a teaching thing, where you learn things from different angles and it gets into different parts of your brain and everything kind of connects."

In order to build a solid foundation of knowledge and develop political interests, social welfare policy students need instructors to encourage questions of both basic and 


\section{INCREASING POLITICAL INTEREST AND EFFICACY}

complex topics. "The things that I felt were dumb questions that I could never ask anybody, I felt like we went over or I could ask in class. And so my basic understanding was, you know, increased, so I felt more comfortable." Another student described struggling to find relevant information for her policy analysis. She relied on the instructor's accessibility and openness to questions. "There was not a lot of information out there. ... I just felt like I was constantly, like, every time, 'Oh, can you help me find ways to find information?' But [the instructor] was really good. I mean, [the instructor] helped me a lot find other things." In a subject area like social welfare policy, which many students and practitioners find intimidating, it is especially important that instructors be viewed as accessible and welcoming of questions.

When students arrive in a class with varying levels of knowledge and skill development, it can be challenging to meet each student where they are and provide instruction that meets various stages of learning. However, it is important that social welfare policy instructors do so. As reflected in the previous paragraph, there are students who come to social welfare policy with very little exposure to the political system. They need basic knowledge of the political system as an initial step in moving toward political advocacy. Other students bring considerable policy experience to the classroom.

At the beginning of the class, if [the instructor] would have said, 'Okay, let's talk about what topics you're really interested in and we'll focus on those,' while 


\section{INCREASING POLITICAL INTEREST AND EFFICACY}

giving kind of a broader picture of the rest of the stuff, it would have been good. Or at least diving into more detail on the topics that a lot of us already knew a lot about. ... I feel like everything was very much broadly explained and brushed on. Meeting these more advanced students' learning needs requires greater detail and more challenging activities. For example, "I would like to know more details. ... Like, what is the difference between talking to a commissioner and talking to a city council member?" Students in this study did not identify effective methods for meeting the learning needs of students with various levels of knowledge and skill development. It was raised, rather, as a challenge to be addressed.

Social welfare policy students also need constructive feedback from instructors as they practice policy skills, in order to develop greater skills and increased internal efficacy. Students discussed the value of completing a policy analysis assignment in steps, so that they could receive regular feedback from the instructor and incorporate that into the following assignments. Another student expressed disappointment that an assignment to write a letter to a legislator was dropped from the course requirements. "Because I would have liked to just go through the process and have someone, you know, look at how I did and tell me if I did it right. Or, you know, just being guided through the process would have made it a lot more comfortable." As social welfare policy instructors strive to develop a unique and more effective curriculum for policy practice, students remind us that these efforts should be built upon basic instructional competencies. 


\section{INCREASING POLITICAL INTEREST AND EFFICACY}

\section{Model a political presence.}

If social welfare policy instructors wish to instill the value of and skills for political advocacy in future social workers, they should model a political presence for their students. Students identified the instructors' political involvement and passion for policy as important contributing factors to their own interest in the course. "[The instructor] is all policy and loves the stuff." "I think when [the instructor] shares [the instructor's] own, like, anecdotal experiences ... that makes the quality way better for me." The instructor's commitment to political action becomes a source of inspiration for students, expanding their view of and appreciation for political advocacy.

Students also trust instructor guidance when it comes from a place of experience. Referring to a mock testimony assignment, one student reflected:

I feel like the professors here are really good about drawing from their own experiences, but acknowledging that ... it's not necessarily going to be the same for us. ... You get most of your knowledge, you know, from experience and doing it. ... [The instructor] kind of talked about, 'Oh, yeah, and this is how [providing political testimony] was for me, and this is what I did. And I was really nervous when I first did it.' And it just makes it more on a similar level and you feel comfortable talking about your insecurities or whatever.

Other students appreciated seeing examples of their instructor's written advocacy efforts, including written testimony to a legislative committee and an op-ed piece published in a 


\section{INCREASING POLITICAL INTEREST AND EFFICACY}

regional paper. Learning from an instructor's own examples of political advocacy contributes authenticity and interest to the classroom.

\section{Communicate belief in students' ability to impact the political system.}

Communicating a sincere belief in students' ability to impact the political system is one component of providing the external motivation and support that students identify as important to the development of their political interest and internal political efficacy. This belief in students' competency can be communicated verbally or through action. "I feel like [the instructor] did a really good job of kind of instilling in us that we can do it. And, like, especially with the testimony, it was like making us feel really comfortable." When instructors express confidence in the abilities of their students, it can make those students more willing to take risks for the sake of learning.

When instructors send students out to engage in authentic political action, they are communicating through their actions a belief in the students' ability to be effective political advocates. Students who participated in a state-level political forum expressed initial insecurity in their own ability to engage with politicians and propose viable policy solutions. However, they were aware that their instructor was comfortable with them representing social work and their university in a political setting. "[The instructor] trusts us enough to put us into a situation where people are going to be reading our proposals and we're not just turning it into class." The confidence of an instructor can motivate 


\section{INCREASING POLITICAL INTEREST AND EFFICACY}

students to embrace a challenge, learn new knowledge, develop new skills, and ultimately become more self-confident in their ability to be effective political advocates.

\section{Create a course structure that encourages praxis.}

In order to develop the interest and confidence necessary to engage in future policy practice, social work students need to take political action and gain the subsequent knowledge and skills that lead to internal political efficacy. However, students also need to prepare for and reflect upon the actions taken, in order to acquire useful knowledge, clarify expectations and plans, analyze the effectiveness of actions, and establish the meaning of experiences and events. Freire refers to this cycle of action and reflection as "praxis" (Freire, 2000).

Praxis can occur through assignments that involve a cycle of action, discussion, and further action that builds on that feedback. For example, social welfare policy students gained knowledge, skill, and confidence by producing a policy brief in steps. I did terribly on the first attempt, because I really didn't have any idea what it was supposed to look like. And so after a little discussion, part of what made me feel a little more competent was that my second version, I felt really could hold up.

Praxis can also occur through assignments that involve out of class time.

I was really bummed out that I had to miss out on the [rally]. I would have really liked to go as a class, ... because then it's something you can talk about afterwards.... Just kind of debriefing on it, what everyone thought, what you 


\section{INCREASING POLITICAL INTEREST AND EFFICACY}

could take away from it. If there was something you didn't understand, you can kind of flesh it out.

Students recommend building regular feedback and discussion into learning activities, so that there is clarity about strengths and areas for improvement. And as the effectiveness of their policy efforts improve, their sense of competency increases.

In fact, students expressed a desire for more reflection both before and after political action efforts outside of the classroom. They believe it would be beneficial to their learning if they felt more prepared before going out to observe or engage in political action. One class attended a health care reform rally together.

[The rally] was interesting. I'd never been to a rally before and I didn't know a whole lot about it going into it. I could see myself possibly doing something like that in the future for something I know, because it was kind of uncomfortable being there not knowing what Single Payer was.

Another student reflected on participation at a state-level political forum:

I didn't understand ... what the point of it was and it got really boring. ... I guess it felt like it was things that I didn't necessarily know what they were talking about, where it just seemed like it was over my head. ... I wish I would have known more, so that way I felt like I could have gotten more from the actual presentation, if I would have had some kind of background information or something like that before going. 


\section{INCREASING POLITICAL INTEREST AND EFFICACY}

These examples highlight the value of reflecting on the purpose and content of activities prior to participation.

Students also desire more reflection following political action outside of the

classroom. "Because when we all do different things, yes, we got to pick, you know, but ... well, I'm not sure if what I am doing is getting the purpose, you know, of the experience." Another student expressed a similar sentiment:

I wish there would have been some way to just discuss what we were doing. Maybe not necessarily doing the same thing, but having every two weeks - like the cultural activities in the language classes - every two weeks there'd be something to do and then we'd have a half hour in class to talk about what you've done. ... I liked going out and doing stuff.

The students clearly placed a high value on experiential learning. However, they also recognized the importance of processing what was observed and done, clarifying lessons learned, and reflecting on what it means for their future work.

When students recommended activities for future social welfare policy courses, they consistently involved experiential learning followed by reflection. For example, one student recommended having guest speakers with diverse political perspectives come to speak on a topic. But this was quickly followed by, "And then be able to have a class discussion afterwards about it." Another student would have liked to go to [the state capitol] as a class, sit in on a committee hearing or legislative session, and "see what the 


\section{INCREASING POLITICAL INTEREST AND EFFICACY}

potential is to work with policy and what it would actually look like in real life. And then ... discussing that as a class." Another student imagined incorporating praxis into the larger structure of the course.

I really think the second week of class or something, going out [on a site visit] and being like, 'This is what we're going to be learning about this [term].' Okay, and then maybe having one at the end. Like possibly even going back to [the same site] and then being like, 'How has this changed? How is this experience different for you from what you've learned like from the beginning? You probably had all these questions, and now when we go back you may have noticed how the people work and what they do.' Yeah, I think it'd be cool to sort of see that change. And then it would resonate and carry deeper as I left the course.

When students are able to prepare, take action, reflect, and take action again, the quality of their learning is enhanced, contributing to interest and efficacy.

\section{Emphasize local and "real" political exposure and engagement.}

When facilitating political exposure and engagement on the part of students, social welfare policy instructors are encouraged to emphasize both local and "real" experiences. Real or authentic political exposure includes ways in which students witness the impact of policies on actual people and communities, as well as observing the political process in action. Real or authentic political engagement, as defined earlier, 


\section{INCREASING POLITICAL INTEREST AND EFFICACY}

includes communicating directly with politicians, receiving a response from a political representative, engaging politically with other citizens outside of the classroom, and following current bills. Local political activity is more difficult to define, as it varies by student. For some students, "local" meant the town or state in which the university was housed. For other students, "local" meant Hawaii or New Jersey where the students' had grown up and still had family connections. For the sake of social welfare policy education, local political exposure and engagement is that which relates to a community with which the student identifies and at a level on which the student feels it is possible to have an impact. Again, for the purposes of this study, the focus is on actions taken to change public or governmental social welfare policies at these local levels.

Real or authentic political exposure increases students' political interest, as they develop a greater appreciation for the impact of policy on people's lives and the potential for effective political action. Students appreciated guest speakers, site visits, and films that helped them better understand the connection between policy and human lives. One student recalled a video watched in class about welfare reform in New York.

I know it's a little bit outdated, but you could see the people's emotions, instead of us just talking about it. It wasn't quite the same, I mean, we're not in New York. But ... it was, like, a narrative style. So they followed the woman and she was kind of under pressure from welfare and so then she got involved in a 


\section{INCREASING POLITICAL INTEREST AND EFFICACY}

political group. And you could see how someone who doesn't even have a college degree or anything, just went and got ... involved and [did] something.

Another student was positively impacted by a site visit to a local community of homeless persons: "I was able to see and feel more what they were going through and it made me want to do more."

Real or authentic political exposure also increases students' internal political efficacy, because concrete learners can better understand the political system when they see it in action. In one course, students visited a community of homeless persons and listened to the stories of one of the community's early and key political leaders.

It was interesting to ... hear from her, like, her perspective of everything they had to go through, all the logistics, ... everything that, you know, happened. I felt like it was ... hands on, like I understand how this kind of policy works. ... It was really interesting to me and I felt like I understood more like the relationship between like the city and different ... How like the logistics of different organizations and the government and stuff, in order to make these kind of policies and where to kind of like hide problems in the sense of not letting them be seen.

As one student said, “I'm definitely big on putting human stories or human faces on what you're learning in the classroom." 


\section{INCREASING POLITICAL INTEREST AND EFFICACY}

Real or authentic political exposure can also occur through assigned readings. In one of the observed courses, students were assigned a policy text that tells the story of a fictional nonprofit social service agency coping with the long-term impact of welfare reform from 1996 and Hurricane Katrina in 2005. Though it is a fictional narrative, it is based on research and practice experience, and incorporates actual policies and historical events. Students clearly found it believable and useful. "After reading the [assigned] book, I thought that was a great part to factor into the efficacy, because I was able to see a real live story of the struggles and ... that a group would go through to make a really good proposal." Another student pointed to the realistic case study in this particular book as enhancing interest and efficacy.

It's good to have the background in what these [policy concepts] are, that the traditional textbook has. But then the examples they gave were, like, really dumb. Like, this person deserves one dollar. They were lazy, but they still get the dollar. Like, 'Great. That's really an in-depth, today problem that I can relate to my life.' You know, it was really lacking in that regard. And so I think for me that's why I like the [case study] textbook where it's like, 'OK, this makes sense.' It's a fictitious town and stuff, but it makes sense. You could see where their errors were and how they were able to fix them and make them more effective. And the whole cost-benefit analysis going on and stuff like that. 


\section{INCREASING POLITICAL INTEREST AND EFFICACY}

Another student appreciated the way in which the case study textbook helped him understand the more abstract five point circle of the policy process that had been presented in another textbook and in class. "I think for me, what really came out of it was I was a little disgruntled until I read the [case study] book. And I was reading through it and I was like hey, I recognize what's going on here from ... that little circle of policy process. And I was reading it and I was like, 'This makes sense. ... Displayed in this manner, ... I can use this."

As discussed in an earlier section, real or authentic political engagement positively influences students' political interest and internal efficacy in two primary ways: (1) students realize that they have a current and meaningful place in the political process, and (2) students are able to practice advocacy skills in the most realistic way possible and receive immediate feedback from the political system while doing so. One of the students who spoke at a state-level political forum benefitted in both ways from the real political engagement:

I feel like, actually, I was important in the process. Because a lot of times, like, you watch on TV and, oh yeah, they' re talking to me, but they're also talking to the rest of the world, the rest of everybody whose watching the TV program. And for me, ... it made me realize that my voice is important, which I kind of never ... You always hear it, but when it actually happens, it's like, 'Oh, it actually is.' So that's what increased my interest, is knowing that it's not just being told, 'Oh, 


\section{INCREASING POLITICAL INTEREST AND EFFICACY}

you're important.' It's, like, actually seeing it and getting that chance to see what you hear in class. It's like you can hear it and read it in a book ..., but until you get to talk about it and until you actually get to see it, it's not reality.

It is the authenticity of the experience that creates this sense of having a current and meaningful role to play, and adds value to the feedback received.

Though both exposure and engagement are important factors in supporting students' political interest and efficacy, real engagement does seem to increase the degree of impact. For example, one student who attended a health care rally with her class described herself as an observer, because she was not sure she supported the cause of the rally. This was an important distinction, in terms of impact:

It would have been nice to participate in some sort of actual political action, rather than just observing or practicing. I did have fun, but I think it would have been more ... impactful maybe, if I felt like, 'Oh, wow, I'm really being a part of this.' Whereas, I was being a part of it, but faking it almost.

When students engage in authentic political action, they develop their identity and sense of efficacy as a political advocate.

These benefits of authentic political exposure and engagement are only amplified when the political action taken is also local. Again, local political exposure and engagement is that which relates to a community with which the student identifies and at 


\section{INCREASING POLITICAL INTEREST AND EFFICACY}

a level on which the student feels it is possible to have an impact. What local means will vary, based on the student.

Local political exposure enhances the students' interest, because it relates to "their" community. In one course, students received a guest speaker from a local nonprofit that provides low-income housing services. A student who closely identifies with the town in which the university is housed, recalled:

I was driving with some friends around town and I turned around and saw the housing [provided by the guest speaker's organization]. And I recognized it immediately from the picture. And I really got excited, because I was like, 'Oh, I know where that is now.' And every time I drive past it, I'm like, 'Oh, I know what this is for.' And it kind of makes you be able to look into your world and see, you know, the places that I drive past everyday. ... understanding the dynamics of where you're living and the different things that are there that you didn't even know. You just drive past them every day and don't think about it. And now it's like, 'Oh, I know what that's for.' You know, 'This is how my city is doing it.'

When students identify with the community being impacted by a particular policy, it only adds to their interest.

Local political exposure also adds the benefit of practicality. Students are much more likely to believe it is possible for them to understand and impact the political 


\section{INCREASING POLITICAL INTEREST AND EFFICACY}

system at the local level. "I feel like people listen a lot more on the local level, because it's a lot more relevant or easier to be well informed about." Another student felt empowered for local political advocacy by site visits and conversations with guest speakers:

I feel like ... I can go talk to politicians or go to town hall meetings and actually give my opinion. And not just give my opinion, but give personal experience.... I feel like it's more than just, 'Oh, well, I read this book and it stated.' But now I can be like, 'Well, I spoke with this...' you know. ... I just feel like I have more experience ... from other people's experiences, that allow it to be more effective. Yet another student decided to seek a practicum placement at a local agency, because of exposure to a local agency engaged in both direct service and political action.

It is important not to underestimate the importance of students feeling it is possible to have a political impact on an issue being discussed. Many students discussed their sense of being overwhelmed and discouraged by national politics, even those students with policy experience.

I feel like I'm comfortable in politics. I still left [class] a couple days feeling really overwhelmed and ineffectual in politics.... I think the process itself is so complex. And there are so many parties and jargon involved that we're not used to. That especially when you're talking about a large scale, when you have industries that are involved and corporations and all these different committees 


\section{INCREASING POLITICAL INTEREST AND EFFICACY}

and subcommittees and things like that, understanding that whole, huge web of process was really overwhelming. ... Not to say that local policy isn't just as complex and crazy sometimes, but it's at least a scale that I think is more palatable to understanding.

During the time these two courses were observed, federal health care reform was a major policy issue. Students expressed considerable interest in the topic, but when it came to being an effective advocate, they were mostly discouraged. One student put it quite succinctly: "I don't see [health care reform] going anywhere." Another student contrasted her feelings about impacting health care reform with her ability to have an impact on local policy:

It's just almost like it's too big of a beast to tackle. ... Especially being new to the scene, you don't feel like you can jump in and go testify in Washington, D.C. about health care. And so easing into it and being able to say, 'Okay, I picked this local bill that's really important to me and here's why I can go testify. And here's why I might be able to see some results or see some changes or just have people hear me out.' I think that's the part that's more appealing.

Local politics are a potential antidote to students' discouragement with national politics. Local political engagement only adds to the benefits of increased interest and practicality by contributing the advantage of concrete skill development. As discussed earlier, developing concrete advocacy skills is essential to increasing students' internal 


\section{INCREASING POLITICAL INTEREST AND EFFICACY}

political efficacy. Students feel more competent when they are able to engage in political conversations, read and understand bills, analyze policy, write and visit their political representatives, get a letter to the editor published, or offer testimony before a governmental body. And students are more likely to practice and strengthen these concrete political advocacy skills in their local communities. Local and "real" political exposure and engagement is more concrete, inspiring, and more likely to lead to longterm action. Students have a personal connection with the issue and believe it is possible to have an impact on it.

\section{Ground learning activities in generative themes.}

Grounding learning activities in generative themes for the students will also positively impact future social workers' political advocacy efforts. A "generative theme" is an issue about which a person has a strong feeling, a feeling that breaks through apathy and generates energy and hope (Hope \& Timmel, 1996, p. 17). It is a concept borrowed from Freire's theory of conscientization (2000), though similar ideas emerge in adult learning theory. These feelings are viewed as central to students' learning and development, and are best identified through intentional listening. Centering classroom activities on generative themes contributes directly to the intrinsic value of the course for students, as well as to their internal interest.

One way in which the observed instructors tapped into students' generative themes was integration of current events into classroom activities. During both courses, 


\section{INCREASING POLITICAL INTEREST AND EFFICACY}

national health care reform was a dominant news item. Though some students felt overwhelmed by the federal political process involved in health care reform, as discussed previously, it also proved to be a generative theme for many students. "We spent a long time talking about health care, which I liked just because it helped me stay engaged as ... it's going on right now." Substantial integration of current events into a course requires flexibility on the part of instructors, which students recognized and appreciated. "If something big happens, you know, we'd start off class talking about it." "I think being able to adapt. You know, it's nice to have a course outline, but being able to adapt when circumstances arise, like having the health care [bill] pass and being able to talk about that, I think benefits the class." Other current events that students referred to with interest were the war in Afghanistan and local tax measures.

Instructors also tapped into generative themes by introducing controversial topics, which peaked interest and elicited strong feelings. In one course, students recalled small group activities in which policy-related challenges or skills were explored, using controversial topics such as spanking or gun control and mental illness.

We had a small group assignment to write a proposal bill about gun control for people with mental disabilities. And I think that was one of the more challenging tasks that we ever got, and so we actually focused on it and we actually talked about it and debated it and argued it. And there was myself and another [student] 


\section{INCREASING POLITICAL INTEREST AND EFFICACY}

in the group who had totally different views about it, and so we actually got to hash it out. ... That was really, really helpful.

Students were also encouraged to select a somewhat controversial policy for their policy analysis assignment. One student described the benefits of analyzing the Dream Act: "There was more to talk about. There was other people opposing it. And, you know, it was talked about in the news. There was a ton of articles on it. That sort of thing." These sincere disagreements tap into strong feelings, which engage students in the course content and activities.

One other way in which instructors engaged students through generative themes was intentional identification of and building upon students' personal interests. As one student concisely observed, "It's hard to teach something to somebody if they have no interest in it. It's just hard to pay attention." For a policy analysis assignment, students selected their own topic. A student with strong interest in international issues selected an international hunger-related policy. Another student with strong interest in child welfare selected a policy related to the care of foster youth. More specific examples and discussion of the benefits of tapping into students' personal interests was provided earlier in the section on students' intrinsic value of and internal interest in the course.

\section{Prioritize, model, and facilitate respectful and diverse political dialogue.}

Prioritizing, modeling, and facilitating respectful and diverse political dialogue emerged as a central method for enhancing students' political interest and internal 


\section{INCREASING POLITICAL INTEREST AND EFFICACY}

efficacy. Respectful dialogue is discussion during which students feel all participants' ideas, opinions, and questions will be valued. Diverse political dialogue refers to a variety of political perspectives being substantively represented in the conversation. In

the earlier section on students' experience of dialogue in the classroom, the emphasis was on genuineness and diversity. As was explained, the genuinely diverse perspectives already present in students do not always emerge due to mistrust of whether or not different opinions will be valued in the classroom. Therefore, the focus recommended for instructors is to facilitate respectful political dialogue, in which genuine differences will naturally emerge. And then to incorporate a diversity of perspectives wherever it is not already present.

As previously discussed, there are several benefits to students engaging in respectful, genuine, and diverse political dialogue. Differences of opinion increase students' focus and raise their political interest. Diverse political dialogue helps students to "flesh out" their own ideas and eventually gain clarity about their political opinions. Students also develop the fundamental advocacy skill of engaging in effective political discourse with people from a variety of perspectives. Clarity of thought and strengthened dialogue skills ultimately contribute to an increase in internal political efficacy and a greater likelihood that students will engage the political system as social work practitioners. 


\section{INCREASING POLITICAL INTEREST AND EFFICACY}

There are also common challenges to engaging social welfare policy students in these conversations. As explained in greater detail earlier, many students are reluctant to speak up in larger classroom settings. They may be shy. They may not trust their classmates' reactions. And though many students expressed the belief that their instructors would be respectful of different political opinions, they were still hesitant to disagree with their professor's stance on an issue.

Instructors are the central tool for addressing these challenges and creating respectful, genuine, and diverse political dialogue in the social welfare classroom. Students recommended three methods for instructors to use towards this goal. First, instructors can create a relatively safe classroom for students to express the genuine differences of opinion that naturally exist among them. Second, instructors can bring in diverse perspectives where they do not naturally exist among the students. Third, instructors can facilitate students being the ones to bring in diverse perspectives where they do not already exist within the classroom.

Students reflected on the tendency of social work classrooms to have many similarly minded people. "I think that social work tends to draw a more, sort of liberal crowd, and people that are more interested in, I guess, progressive, changing policies." I mean, even being in social work, you're kind of subscribing to certain political stances. Just by the very fact that you're participating in providing government services. That, in itself, is making a political statement. So I think there's kind of 


\section{INCREASING POLITICAL INTEREST AND EFFICACY}

a slant to it, but I don't think that's necessarily something that needs to be fixed. It is important to cover other opinions.

Despite these students' observations regarding the tendency of social work programs to attract a greater number of politically progressive students, they also believe that there are different political opinions among students that often do not come out in classroom discussion. Students regularly referred to a specific person or two in their class whose opinions they either knew or suspected were different than the dominant conversation. Instructors are encouraged to tap into these naturally existing diverse perspectives by (1) facilitating a safe environment for differences of opinion, (2) utilizing small groups within the classroom setting, and (3) tapping into generative themes. Students acknowledged the challenge of facilitating a safe environment for diverse political dialogue. "I've seen it in some of my other classes, people get uptight when they start hearing other views and the possibility of that view being right."

A lot of my classmates don't see the difference between attacking the issue and attacking the person, which I feel that if you're going to advocate or do policy work, that when you go to direct certain issues, it's not about who's right or wrong. It's ... about, like, how the issue is right or wrong and how it can be addressed.

In order to create a relatively safe environment for political dialogue, students recommended that instructors set ground rules for class discussion, clearly state their 


\section{INCREASING POLITICAL INTEREST AND EFFICACY}

appreciation for the value of different perspectives, and emphasize the need for compromise in politics. One student reflected back on a previous course, as an example:

Like, for example, in my sex class ... The first day of class, ground rules were set. Everyone has the right to their opinion. Everything that's said in this room is confidential. And people are free to express either side. No harsh words will be exchanged. Let people finish their conversation.

It was never suggested that instructors can control all messages that get sent, both verbally and nonverbally, in a classroom. However, students clearly felt that the instructor was key to establishing a safe and respectful environment for diverse views to be expressed.

There was some disagreement among students about whether or not knowledge of an instructor's political opinion discourages diverse dialogue. No one argued that it encourages diverse political dialogue, though one student did place value on knowing the instructor's bias. There were a couple opinions expressed that it is neutral, as long as differences of opinion are also welcomed.

I think it's hard with this kind of class.... If you know [the instructor] and [the instructor's] a social worker, I think you can guess on most things. [The instructor] did say, 'I agree,' and stuff like that. But I think that, I felt like I'd know anyways. So I can't tell if it was really like [the instructor] was telling us or we just knew. But for me, at least, I felt ... I never really disagreed, I guess ... 


\section{INCREASING POLITICAL INTEREST AND EFFICACY}

but I felt comfortable, if I did. And I felt like [the instructor] kind of said, you know, a lot, 'If anybody disagrees, you know, it's OK.'

However, more students expressed the belief that instructors should maintain a largely objective political stance in a social welfare policy course, in order to limit the focus on their own political opinions. "I think it really needs to be taught from both sides or from a place of no opinion." Another student recommended that instructors:

Try and keep the playing field as level as possible. And to present both sides rationally. To try and keep opinions going, but not negative thoughts about one side or the other. And then ... try and keep [the instructor's] opinions out as much as possible or present them after discussion is over or something like that. So playing devil's advocate, those kinds of things. Just so that every side is heard. Raising the confidence level of the student.

The potential uses and implications of social welfare policy instructors' political opinions is an area ripe for future research.

Students consistently encouraged the use of small group discussion, in order to facilitate more diverse political discussions. As was explored in an earlier section, more students feel comfortable expressing their political opinion in a small group setting rather than in a large classroom discussion.

The discussions were good, the way [the instructor] ... broke us up into smaller groups to discuss this or that. And we did that a couple of different times. And I 


\section{INCREASING POLITICAL INTEREST AND EFFICACY}

think that's important, because you do see other perspectives. You know, it's just like, 'Oh, I didn't think about it that way. Well, how about this, how about that? And you can bounce ideas off each other. And then comparing what we all talked about, you know, I think that worked really well.

Using generative themes, especially within a small group setting, is also recommended.

If students feel safe, when they have a strong feeling about an issue, they are more likely to engage in discussion and other activities.

It might be good to kind of have the facts presented very unbiasedly, go down to small groups with a challenging kind of ethical dilemma or something like that, and then maybe open it up to the bigger classroom again. Kind of how [the instructor] had done ... have people go around and talk about what they discussed. Because some groups have great discussions that others don't experience.

Establishing ground rules, modeling appreciation for different perspectives, limiting the focus on the instructor's political opinions, and use of small groups and generative themes are all likely to help an instructor tap into the diversity of political opinion that naturally exists within a classroom.

Instructors are also encouraged to intentionally, consistently, and respectfully bring in a diversity of political perspectives for student consideration in their lectures and classroom discussion, especially in those areas where it does not naturally emerge from 


\section{INCREASING POLITICAL INTEREST AND EFFICACY}

the students gathered. Doing so is likely to contribute to students' perception of a safe environment for different opinions. It will also provide students with valuable knowledge for political advocacy.

Hearing both sides of the story is important, because a lot of class is getting the background knowledge to use in the future. And so by doing that, you're learning what both sides of the stories are in a calm and professional manner and then it's up to you to decide what you want.

Students recommended that instructors play “devil's advocate" and challenge students from various positions during class discussions. They also recommended bringing in guest speakers from diverse political perspectives to "speak personally about how they feel about a certain issue." Such diversity was at times described according to political party, but most often students referred to the ideological range from conservative to progressive.

Finally, students recommended that instructors create assignments and activities through which students themselves bring in diverse perspectives, even where they do not already exist within the classroom. Students could be assigned specific political positions to represent in a classroom discussion or debate. Students could provide testimony on the same bill from different perspectives. They could also be required to substantively present various perspectives in a policy analysis presentation.

\section{Maintain an andragogical perspective; use pedagogical methods as needed.}




\section{INCREASING POLITICAL INTEREST AND EFFICACY}

Although students clearly want to be viewed and treated as adult learners (i.e. from an andragogical perspective), they expressed a need for more foundational or basic content, in order to fully understand the advanced discussions and tasks asked of them in a social welfare policy course. This does not contradict adult learning theory or the idea of teaching from an "andragogical" perspective. Rather, it is a phenomenon with adult learners that the theorists anticipated. As discussed in Chapter 3, there are situations in which adult students must learn a completely new body of knowledge and are, therefore, solely dependent on their teacher. In such situations, traditional pedagogical methods would be appropriate. However, according to Knowles (1979), approaching adult learners from an andragogical perspective would require doing "everything possible to provide [students] with whatever foundational content [they] would need and then encourage [them] to take increasing initiative in the process of further inquiry" (as cited in Knowles et al., 2005, p. 146). Thus, social welfare policy instructors are encouraged to maintain an andragogical perspective, but recognize the need to transition from pedagogical to andragogical teaching methods over the course of the term.

One significant gap in foundational knowledge identified by students is economics, especially in terms of budgets and taxation. One student recalled feeling like the state-level political forum focused on state budgeting and taxation issues was "over my head. ... They were talking about all these specifics about things that, it was like, I wish I would have known more, so that way I felt like I could have gotten more from the 


\section{INCREASING POLITICAL INTEREST AND EFFICACY}

actual presentation." A couple other students perceived themselves as "guessing" while working on a policy proposal.

I think one of the areas I definitely do not feel confident in is where the money and the numbers, how that all works out, where that's coming from. 'Cause, like, I think I could come up with ideas, but I really, like, during our proposal, I had no idea where you would pull and how much you would pull to fund the proposal.... I was just guessing all the time.

Between classroom observation and student interviews, it appears that most students lack the basic economic knowledge necessary to appreciate the factors in and potential impacts of policies, such as taxation, unemployment insurance, and minimum wage.

The second significant gap in foundational knowledge that requires some pedagogical assumptions and methods is the political process or, as a number of students described it, "civics."

I definitely think there needs to be more civic information or education, just how a bill becomes a law, if you will, or how you know who does what.... The civics stuff is very important and, I think, that it demystifies it, the more you know about

it. So dealing with the government can be scary and can be very intimidating. As described in an earlier section, many students felt that they learned important information about the political process that they had not known coming into the course. It is helpful for students if social welfare policy instructors assess and create curriculum 


\section{INCREASING POLITICAL INTEREST AND EFFICACY}

for these foundational areas of knowledge early in the term, in order to prepare students to be more fully andragogical learners who can identify and pursue their learning goals in social welfare policy.

\section{Expose students to a range of political advocacy methods.}

Exposing students to a range of political advocacy methods is the only element of the model that comes from what students did not say, rather than what they did say. When asked how they imagined being a political advocate in the future, students consistently referred to the advocacy methods that had been presented in their social welfare policy course. For students in the course that involved a policy brief, political testimony, and a letter to the student's legislator (even though the letter was later removed from the course requirements), their vision of political advocacy included the potential to research and testify on issues relevant to clients. A couple of those students also imagined writing to their representatives. For students in the course that involved a needs assessment and policy proposal, their vision of political advocacy included conducting needs assessments and proposing policy ideas. There was mention of voting from students in both courses. But it seemed difficult for students to envision or articulate political advocacy roles beyond those they had experienced in the course.

Because social welfare policy is a new area of study for most undergraduate social work students and most have little previous exposure to political advocacy, these students leave their program with a vision for political advocacy that directly reflects 


\section{INCREASING POLITICAL INTEREST AND EFFICACY}

what they were presented and what they practiced. If they do not write a letter to their legislator, they are not likely to incorporate letter writing into their political advocacy potential. If they do not witness or practice political testimony, likewise, they are not likely to incorporate political testimony into their advocacy potential.

Social welfare policy instructors should, therefore, maximize the range of political advocacy methods to which they expose their students. It would also be beneficial to engage in a profession-wide conversation and research concerning the advocacy methods in which it is most important for social workers to gain competence. Should all generalist social work practitioners be prepared to conduct policy analysis, write a policy brief, testify before a legislative committee, write a letter to their representative, visit their representative in person, write an op-ed, write a letter to the editor, gain media exposure, organize a mass demonstration or a letter-writing campaign? What is the possible range of political advocacy methods and which are most relevant for generalist social work practitioners?

\section{Support self-directed learning.}

Social welfare policy instructors can enhance their students' political interest and internal political efficacy by supporting self-directed learning through the course design, regular and individualized communication with students, and practical support. Selfdirected learning is defined here as the significant involvement of students in goalsetting, decision-making, and evaluation within a course. Two methods that have already 


\section{INCREASING POLITICAL INTEREST AND EFFICACY}

been outlined in this model will contribute to self-directed learning: praxis and generative themes. Students also identified participation in decision making regarding the course structure as influential to their motivation, interest, and quality of learning. Regular and individualized communication between the instructor and student, including the provision of practical support, were important to students' success with self-directed learning.

Building opportunities for praxis - a constant cycle of reflection and action - into a course supports self-directed learning by involving students in the process of clarifying learning goals, deciding what information is needed, gathering relevant data, and reflecting on what worked well and what did not in their practical efforts. Praxis can be incorporated through in-class activities and outside assignments. Though this was explained in an earlier section, it is worth repeating here that praxis requires preparation before activity as well as reflection after the action is taken. If a primary goal of praxis is self-directed learning, then those reflections prior to and after action will wield power. Information needed and lessons learned by students will help form the upcoming course activities, which requires flexibility on the part of the instructor.

As previously discussed, grounding learning activities in generative themes also allows students to build on their own interests and natural motivations. When students work on issues about which they have strong feelings, they describe a greater motivation to learn and invest more time and energy in doing so. "If I hadn't been able to pick my own bill, I would have been absolutely miserable. Every bill that I searched through, I 


\section{INCREASING POLITICAL INTEREST AND EFFICACY}

couldn't even stand the thought of having to research. But then I found one on crack cocaine..." For another student, it was important to learn about and analyze topics relevant to her practicum in child welfare. "That was right around the time that I was getting into my internship and so it was helpful for me to learn about other policies, because people referred to them in acronyms at my internship and I'd be like, 'I have no

idea what that is."” Or as another student reflected, "You have to actually care."

But beyond praxis and generative themes, an instructor's commitment to support self-directed learning will require meaningful involvement of students in determining course structure. In both courses, students emphasized the positive impact of being able to influence the course structure. In some cases, students directed in-class discussion topics:

We had that flexibility to discuss things as we wanted to. I'm not sure if there were days where we didn't get through every ... I mean, it was never like, 'We have to get through this section by the end of the day,' which some classes are like.

In another case, students felt their participation in a state-level political forum was enhanced by the instructor's willingness to change the final paper assignment of the course. Organizers of the forum had formally invited any students attending to submit a policy proposal following the event. When the students observed for this study expressed an interest in doing so, the instructor agreed to change the final paper from a policy 


\section{INCREASING POLITICAL INTEREST AND EFFICACY}

analysis to a policy proposal. Reflected one student: "I appreciated that [the instructor] is flexible enough and ... more concerned with us actually learning stuff than us just meeting the requirements. Like, [the instructor] was willing to give up ... the final paper, so we could participate in the [forum] better." Students benefitted from the flexibility of their instructors, who were willing to discuss topics and course changes as they became relevant to the students. Allowing students to guide course activities helps develop their political interest and sense of efficacy by increasing the students' intrinsic value for and interest in the course.

An instructor's commitment to support self-directed learning will also involve a commitment on the part of the instructor to regularly communicate with and offer practical support to students on an individual basis. Students in this study recalled their instructor helping them identify a policy in their area of interest, clarify the extent of research necessary for a policy brief, brainstorm the relevant social context for their policy, integrate their past experiences with new policy knowledge, and locate relevant advocacy organizations. These individualized conversations and provisions of practical support happened outside of the scheduled class time and were viewed by students as a critical component of their developing internal political efficacy.

There may be issues of equity raised by this recommendation, however, if students are required to ask for or initiate this individualized support. Building individual conversations between instructor and student into the class structure may be one way to 


\section{INCREASING POLITICAL INTEREST AND EFFICACY}

help assure that all students can benefit from individualized feedback from the instructor. This could be done through assigned e-mail communications between students and the instructor, formal proposals for projects on which instructors will provide individualized feedback, or substituting brief individual meetings for a class session or two. It is recognized that relatively small class sizes are required for these last recommendations.

\section{Help students connect with advocacy groups relevant to their interests.}

Students expressed a desire to be connected with advocacy groups relevant to their interests, "things that we can start doing now." One student imagined such connections being made intentionally near the end of the term:

Maybe near the end of the course ... like, what next? And had a whole topic or a whole section devoted to what can we do now that we know this information?

Our interest has increased for the most part, and our confidence has increased.

Like, what can we do with the knowledge that we've learned? ... I guess what I'm trying to say is, now, if I were to be active in something, I'm more likely to say 'yes.'

When I asked a student about whether or not she could imagine offering political testimony in the future, she replied, "I think if I found something that I really cared about and was passionate enough about to go the extra step for it, I would. ... I mean, obviously I'd be more likely to do it if I was invited, but I think if I really found an issue that I care about, that I would." 


\section{INCREASING POLITICAL INTEREST AND EFFICACY}

Two students were connected to an advocacy organization by their social welfare policy instructor. At the time of our interview, one of the students had not signed up to receive e-mail alerts yet, but described checking the website "all the time" to "see what kinds of things are offered. They have internships and things like that, so looking at options." The other student had arranged to complete her practicum at the organization, and had already begun attending local advocacy events through them. "It all started with this organization being introduced in class." Social welfare policy courses can help students intentionally connect with advocacy organizations, in order to support long-term "attachment to recruitment networks" (Ritter, 2008). Doing so will help students translate their increased political interest and internal efficacy into effective political advocacy as social work practitioners.

\section{Influences Outside of the Classroom}

The ultimate goal of this study is to help social welfare policy instructors prepare generalist social work students for increased and effective political advocacy efforts. However, it is important to acknowledge the myriad of factors outside of the classroom that can and do influence social workers' policy practice. In addition to political interest and internal political efficacy, the following factors were identified by Ritter (2008) as demonstrating a statistically significant influence on licensed social workers' political participation: family influences, political knowledge, attachment to recruitment networks, and NASW membership. Students in the current study confirmed the first three of these 


\section{INCREASING POLITICAL INTEREST AND EFFICACY}

"outside of the classroom" influences during focus groups and interviews. They also brought up anticipated job demands, current economic and political factors, NASW mandates, the larger social work curriculum, co-curricular activities, and other experiences and knowledge as influencing their feelings and behaviors related to political advocacy.

Two particularly strong themes emerged in terms of the impact of outside factors on students. First, most students interviewed came to the class with strong feelings about politics that reflected their personal experiences within their families of origin.

My family is very, I mean, we always talk about politics and stuff like that. But

... I always felt that it was an area of conflict, really, and I don't like that at all. ...And being the youngest in the family, I listened, ... but I never felt like I was able to contribute. So I would say I had a very weak, you know, interest. And it was just something like, 'Oh ... I want to stay away from it.'

A different student who came into the class with a strong interest in politics described the influence of her father:

My dad... would never tell us like which way he voted and things. ... He would always play devil's advocate for us. ... He would always ask us questions and make sure to ask us, "Do you know who the president is?" and all those like different heads of different bodies of government. But then when we said we believed something he would play devil's advocate even if he believed the same 


\section{INCREASING POLITICAL INTEREST AND EFFICACY}

thing, just because he didn't want us to be ignorant of the other side. ... So I guess that would probably be where it all started. I've talked about it since I was little." These personal experiences impact students' political interest and sense of efficacy in ways social welfare policy instructors cannot create or prevent. They are existing factors brought into the classroom.

Second, a number of students reflected on their past exposure to and experience with political activity when discussing whether or not they can imagine themselves being political advocates in the future. One student described watching her high school friend engage in political advocacy through Planned Parenthood. "That example is really strong for me, to see that she not only did it and got results, but that she was 16 when she was doing it." A number of students had attended a social work advocacy day at the state capitol in the previous year. They consistently described this as a positive factor that increased their ability to imagine engaging in political advocacy. All references to previous political activity were described as contributing to an increased desire to be politically active. 


\section{INCREASING POLITICAL INTEREST AND EFFICACY}

\section{Chapter 7: Synthesis}

The integration of previous research, current survey data, and analysis of focus group and interview transcripts within the context of classroom observations has resulted in the development of a model for social welfare policy instruction aimed at increasing students' political interest and internal political efficacy. Most of this model is consistent with the professional literature on political advocacy among social workers, social welfare policy instruction, and this study's foundational theories. However, prioritizing the student voice in this research study also resulted in fresh insights and new questions. Following an explanation of the proposed model and the way in which it relates to the literature review in Chapters 2 and 3, opportunities and challenges for social welfare policy instruction will be discussed.

\section{A Model for Social Welfare Policy Instruction}

The focus of this study is on what social welfare policy instructors can do within the structure of a course to best support the development of students' political interest, internal political efficacy, and ultimately political advocacy efforts. What are concrete steps professors can take to support these goals? And what is the process by which those steps contribute to students' interest and efficacy in policy practice? The proposed model, therefore, centers on three key components: (1) effective teaching methods for the social welfare policy instructor, (2) specific aspects of the student experience positively influenced by implementation of these recommended teaching methods, and (3) the 


\section{INCREASING POLITICAL INTEREST AND EFFICACY}

theoretical links between the students' learning experience in a social welfare policy

course, political interest, internal political efficacy, and political advocacy. A visual presentation of these theoretical concepts and linkages can be viewed in Figure 2, followed by further explanation. 


\section{INCREASING POLITICAL INTEREST AND EFFICACY}

Figure 2

\section{$\underline{\text { A Model for Social Welfare Policy Instruction }}$}

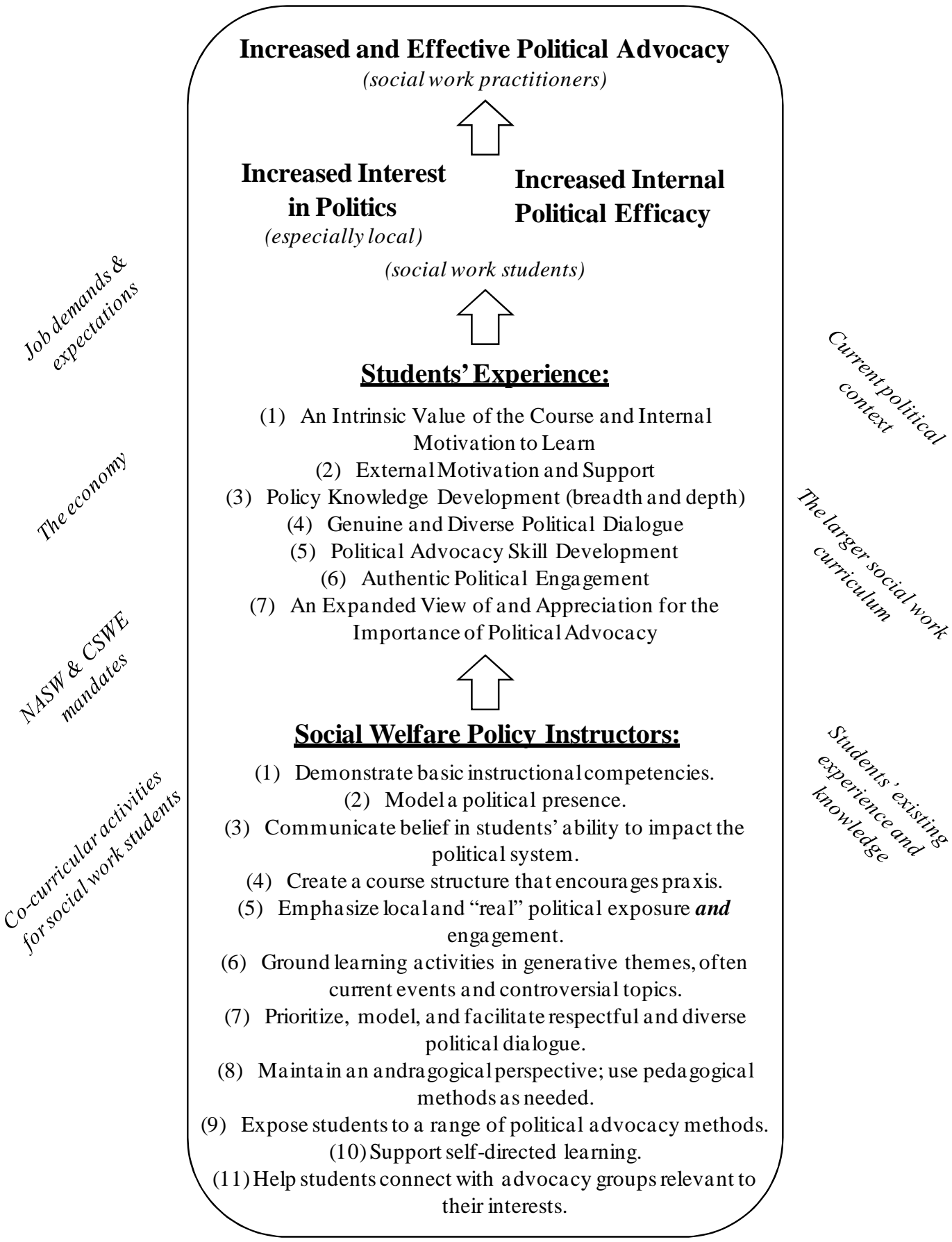




\section{INCREASING POLITICAL INTEREST AND EFFICACY}

\section{Increasing political advocacy: The impact of interest and efficacy.}

First, it is important to reiterate a theoretical link incorporated into this model from earlier research. It is accepted as a part of the proposed model that an increase in students' political interest and internal political efficacy will lead to increased and effective political advocacy efforts by future social work practitioners. This causal link is represented at the top of the model for social welfare policy instruction and supported by research explained in greater detail in the literature review of Chapter 2 (Anderson \& Harris, 2005; Ezell, 1993; Hamilton \& Fauri, 2001; Ritter, 2007, 2008; Weiss et al., 2006).

\section{Inside the course.}

The proposed model also incorporates a belief that social welfare policy courses can contribute to an increase in students' political interest and internal political efficacy, which is supported by data from this study. A combination of quantitative and qualitative data suggest that students' political interest and internal political efficacy were positively impacted by the two courses, though to differing degrees. Students described having their political interest increased or broadened during their time in the social welfare policy course, though no statistically significant change was noted. An increase in students' internal political efficacy was found across both participating courses, through both statistically significant changes on the Internal Political Efficacy Scale and students' descriptions of the impact of the course. 


\section{INCREASING POLITICAL INTEREST AND EFFICACY}

Seven aspects of the student experience in a social welfare policy course that contribute to an increase in political interest and internal political efficacy emerged from qualitative data analysis. These seven themes represent the internal and external experiences of the students themselves within the course. They are represented in the middle of the model for social welfare policy instruction and are explained in greater detail in Chapter 6.

Ultimately, the model seeks to provide social welfare policy instructors with specific teaching recommendations, as well as an appreciation for the theoretical links that help explain how a social welfare policy course can increase students' political advocacy efforts when out in the field. What specific steps can instructors take to facilitate the type of student experience believed to positively impact students' political interest and internal political efficacy? Eleven recommended teaching methods for social welfare policy instructors emerged from qualitative data analysis that directly connect to the seven recommended qualities for students' experience of the course. These methodological themes are represented at the bottom of the proposed model, symbolically providing a curricular foundation on which students can build interest, skills, values, and confidence for political advocacy.

The qualitative data are supportive of the idea that professors' presence and instructional choices have a direct impact not only on what students do to learn, but also on the attitude and motivation with which they engage in those activities. Instructors 


\section{INCREASING POLITICAL INTEREST AND EFFICACY}

cannot hand out interest and a sense of efficacy to students. Interest and internal efficacy are just that, internal qualities that must develop within the student and future social worker. However, instructors can create a learning environment, inspire interest and motivation, and provide concrete opportunities that initiate and support a learning experience for students that lead to the specific outcomes of increased political interest and internal political efficacy. It is not argued here that professors are the sole or even

primary influence on students' attitudes and motivations. However, data from this study support the idea that instructors can have a meaningful influence on students' learning activities, attitudes, and motivation in the eleven ways outlined in the model.

\section{Outside of the course.}

As discussed at the end of Chapter 6, students identified a number of factors outside of the classroom that have also impacted their political interest and internal political efficacy. These outside influences confirmed those previously identified by Ritter (2008), but were not a central focus of this study. They are, therefore, represented outside of the central circle of the model. It is important for any instructional model to acknowledge the many influences on students outside of the classroom.

There may be ways to effectively tap into these "outside" factors during a social welfare policy course that have not been explored here, both because of the study's focus and what the participating instructors chose to incorporate into their courses. Reflecting on these outside influences might serve as rich discussion points in class or impactful 


\section{INCREASING POLITICAL INTEREST AND EFFICACY}

exercises that help develop the intrinsic political interests of students. Additional means for effectively incorporating these outside factors are recommended as a potential focus of future research. However, for the purposes of this study, these "outside of the classroom" variables are acknowledged as relevant influences not to be ignored, but also not yet placed at the center of the instructional model.

\section{Integrating the Student Voice with the Professional Literature}

The student perspective is not often prioritized in the research and theoretical literature on social work instruction. Undergraduate students, in particular, are rarely involved in conducting research that gets published. They are typically the recipients of, rather than contributors to theoretical knowledge. This leaves a significant gap in our knowledge of and models for instruction. While this study does not go as far as it could in this regard by incorporating participatory action research methods, it does clearly prioritize the undergraduate social work students' voice. Many ideas from the existing literature on teaching methods and theory have been confirmed by these students, while other ideas have been challenged or expanded and new ideas and questions have emerged.

\section{Areas of convergence.}

In many ways, social welfare policy students in this study reflected the principles of adult learning theory, Freire's theory of conscientization, and Ritter's (2007, 2008) research based on the Citizen Participation Model. In terms of aspects of the student 


\section{INCREASING POLITICAL INTEREST AND EFFICACY}

experience that contribute to increased political interest and internal political efficacy, four components of the proposed model have strong connections to the existing literature. First, the power of intrinsic value and internal motivation identified by students is consistent with the adult learning theory principle that adults are internally motivated learners who seek "intrinsic value" and a sense of "personal payoff" through their education (Knowles et al., 2005, p. 159). Students felt motivated by challenges and issues of personal importance to them. Second, students clearly valued dialogue as a critical component for developing political interest and internal political efficacy. This is consistent with both adult learning theory and Freire's theory of conscientization. Third, students communicated the importance of experiencing authentic or "real" political engagement. This is consistent with adult learning theory's principle that adults become ready to learn when presented with a relevant challenge or specific task to complete. It also resonates with Freire's insistence on the importance of engaging students with meaningful content or generative themes. Finally, students recognized the important contribution of their expanded view of and appreciation for the importance of political advocacy. This was an important motivating factor for them in the learning process, as adult learning theory predicts through its assertion that adults need to understand why they need to learn something before they engage in the learning process.

In terms of recommended teaching methods, six components of the proposed model have clear and consistent connections to the existing literature. First, students 


\section{INCREASING POLITICAL INTEREST AND EFFICACY}

valued their instructor being a model of political presence. Learning from an instructor's own examples of political advocacy contributes authenticity and interest to the classroom. This is consistent with Freire's assertion that education is inherently political; the teacher is an important model of critical consciousness and political presence (Freire, 1998).

Second, cycling between reflection and action in a course enhanced students' learning. Freire referred to this idea as "praxis" and identified it as central to education for the sake of positive social change (Freire, 2000). Students also encouraged instructors to emphasize local political exposure and engagement in their courses. Local politics are a potential antidote to students' discouragement and lack of internal political efficacy with national politics. This is consistent with the results of Ritter's (2008) study, in which one of the two strongest predictors of social workers' political participation was interest in local politics. Grounding learning activities in generative themes is a teaching method which emerged out of student stories; the conceptual name was borrowed directly from Freire's (2000) theory of conscientization, though adult learning theory also speaks to the importance of basing education in students' experiences and interests. Fifth, supporting self-directed learning through course design and instruction is a central principle of adult learning theory. Finally, by highlighting the value of instructors helping students to connect with advocacy groups relevant to their interests, students reinforced what Ritter (2008) documented through her research: that social workers are more likely to engage in 


\section{INCREASING POLITICAL INTEREST AND EFFICACY}

political advocacy if attached to "recruitment networks," such as advocacy organizations and NASW (p. 175).

Students also echoed the call of instructors, researchers, and theorists for more experiential components to social welfare policy instruction. This is reflected in the teaching methods section of the proposed model, both in terms of praxis and emphasizing "real" political exposure and engagement. Adult learning theory speaks to the value of having students address relevant problems. Freire speaks to the importance of educators posing real life problems and engaging students in the search for practical solutions (Hope \& Timmel, 1996). And a host of social work instructors and researchers have both encouraged and demonstrated the effectiveness of incorporating more experiential learning techniques into social welfare policy instruction (Anderson \& Harris, 2005; Butler \& Coleman, 1997; Keller et al., 2001; Rocha, 2000; Saulnier, 2000; Spicuzza, 2003; Tower \& Hartnett, 2011; Weaver \& Nackerud, 2005).

\section{Areas of divergence.}

Students consistently acknowledged external motivation and support as a key quality of their learning experience that increased their political interest and internal political efficacy, though this idea is not emphasized in the foundational theories of the study. Students identified the benefits of external motivation provided through course structure and assignments, especially in terms of engaging in activities they would have otherwise ignored or avoided. More details on this theme are available in Chapter 6. 


\section{INCREASING POLITICAL INTEREST AND EFFICACY}

Both adult learning theory and Freire's theory of conscientization emphasize internal motivation and self-directed learning to such a degree that there may be an apparent contradiction between student input and these instructional theories. What this means for social welfare policy instruction will be explored further in the following section.

A second area of potential divergence from adult learning theory relates to the recommendation that teachers maintain an andragogical perspective, while using pedagogical methods as needed. As explained in Chapter 6, this proposed instructional approach does not actually contradict adult learning theory. Rather, it stretches instructors to embrace a tension that was already anticipated by adult learning theorists. When adult learners are approaching a completely new body of knowledge, they become more dependent on their teacher to provide a basic foundation of knowledge on which they can build (Knowles et al., 2005). As has been discussed in the literature review of Chapter 2 and by students in Chapter 6, politics, economics, and social welfare policy in general are often new bodies of knowledge for social work students. In order for these adult learners to take maximum initiative for their own learning and benefit from the motivation that ensues, they sometimes need pedagogical methods of instruction to provide an initial layer of knowledge.

While this need expressed by social work students for basic knowledge development in the political economy may stretch the application of adult learning theory, it is actually consistent with a number of authors who have called for or created 


\section{INCREASING POLITICAL INTEREST AND EFFICACY}

such opportunities within social work programs (Abel \& Kazmerski, 1994; Dempsey, 2008; Hoefer, 1999; Tully et al., 2005). Most of these authors focus on the creation of a new social work course or the requirement of additional liberal arts coursework. These may be valuable avenues for meeting the initial pedagogical needs of social welfare policy students. However, in the meantime, social welfare policy instructors have current students who need at least some of this content integrated early in the course to address foundational gaps in knowledge, while not losing the andragogical focus on students' innate interests and life experience.

Students raised unique ideas for effective social welfare policy instruction, as well. An instructor's clear belief in students' ability to impact the political system was identified as an important contribution to students' development of political interest and internal efficacy. Being exposed to and practicing a variety of political advocacy methods allowed students to appreciate how their own interests and gifts could fit within policy practice. Students also shed light on their hesitation, but desire to engage in more genuine and diverse political dialogue in the classroom.

\section{Raising new questions.}

As mentioned in Chapter 6, I was surprised by the extent to which students wanted to talk about political dialogue in the classroom. They proposed a number of potential benefits of experiencing genuine, diverse, and respectful political dialogue in the social welfare policy classroom. First, the existence of differences of opinion and the 


\section{INCREASING POLITICAL INTEREST AND EFFICACY}

challenge of personally considering other options roused their political interest. Second, students felt they gained or would gain greater clarity about their own political opinions through engagement in diverse political dialogue. Students expressed a belief that they would have greater confidence engaging in political conversations outside of class if they felt successful speaking their own opinions and hearing conflicting opinions in the classroom setting. And they suspected that their ability to engage in productive compromises in the political realm would also be strengthened by genuine, diverse, and respectful political dialogue in the social welfare policy classroom.

Students explained that the genuinely diverse political perspectives already present in social work students do not always emerge in classroom conversation. They identified common challenges to engaging social welfare policy students in genuine, diverse, and respectful political dialogue in the social welfare policy classroom, including personal traits of students (e.g. shyness), a mistrust of classmates' reactions, and a hesitancy to disagree with an instructor's stance on an issue. At the same time, students recognized that social work classrooms do not always represent the full spectrum of mainstream political opinion in the United States. They encouraged instructors to incorporate a diversity of political perspectives wherever it is not already present.

In both focus groups, students initiated lively conversation about whether or not knowledge of an instructor's political opinion discourages diverse political dialogue. This is the only area in which students demonstrated a clear difference of opinion 


\section{INCREASING POLITICAL INTEREST AND EFFICACY}

between themselves, in terms of the impact of teaching methodologies on political interest and internal political efficacy. As discussed in Chapter 6, several students in each group expressed the opinion that knowledge of an instructor's political opinion discourages diverse political dialogue in the classroom. A couple students in each group felt that it did not have a significant impact one way or the other, as long as differences of opinion were clearly welcomed. No one argued that knowing an instructor's political opinion encourages diverse political dialogue, but one student did place value on knowing the instructor's bias.

Students volunteered specific ideas for how genuine, diverse, and respectful political dialogue can be facilitated by instructors in the social welfare policy classroom. Use of small group discussion was the most commonly recommended method, especially if the small group activities focus on themes about which students have strong feelings (i.e. generative themes). Students reported feeling more comfortable expressing differences of opinion in a small group setting rather than in a large classroom discussion. Instructors were encouraged by students to establish ground rules for political discussion, model appreciation for different opinions, and limit the focus on the instructor's political opinion. And on topics where diverse perspectives do not naturally emerge from those present, students recommended that instructors intentionally and respectfully bring a diversity of political perspectives into lectures and classroom discussion. This could 


\section{INCREASING POLITICAL INTEREST AND EFFICACY}

include playing the role of "devil's advocate," inviting guest speakers, and creating assignments in which students are assigned specific political positions to represent.

This summary of students' insights on political dialogue in the social welfare policy classroom is offered as context for a set of new questions raised by the student voice in this study. What range of political perspectives should be substantively or cursorily included in the social welfare policy classroom? How can social welfare policy instructors best facilitate a respectful and diverse political dialogue in the classroom? Specifically, how can social welfare policy instructors limit the focus on their own political opinion in order to encourage diverse political dialogue, while also serving as a model of political presence for students? And what is the impact of social workers' political training on their interactions with diverse clients?

Though the following additional questions may not be new, they have a unique resonance coming from the student perspective. In a profession with a clearly stated social justice mandate and public policy statements, what should students and instructors do with honest disagreements over specific policy issues? What is the role and responsibility of educators with regard to preparing future social work political advocates? Is it solely about knowledge and skill development for the sake of increased political interest, internal political efficacy, and ultimately political advocacy? Or are there clear policy values that social work education should be emphasizing or teaching, beyond the general emphasis on social justice? If there are specific policy value 


\section{INCREASING POLITICAL INTEREST AND EFFICACY}

objectives, how do those interact with the development of students' interest and internal efficacy in politics?

\section{Opportunities and Challenges for Teaching Social Welfare Policy}

This study began in response to my professional struggle to create an undergraduate social welfare policy course that successfully met a significant set of expectations within a very limited timeframe. These expectations represented a combination of goals laid out by myself, my social work program, a diverse student body, and CSWE. Amidst these many requirements, the fundamental goal for me was to inspire effective policy practice efforts. The available literature on social welfare policy instruction seemed to be lacking a comprehensive methodological framework for preparing students for political advocacy. Also missing was a substantial student voice.

After observing and listening to the student experience in two distinct social welfare policy courses, the instructional process of supporting students' development of political interest and internal political efficacy is clearer for me now. These ideas are succinctly represented in the proposed Model for Social Welfare Policy Instruction. To varying degrees, I incorporated the teaching themes of the proposed model in my latest social welfare policy course, though I did not formally evaluate the model as I did so. I am inspired by students' responses to the revised course, including one student's shift of career goals and recent employment as a political campaign manager. 


\section{INCREASING POLITICAL INTEREST AND EFFICACY}

Having said that, there are also inherent tensions and challenges in the teaching themes of the proposed Model for Social Welfare Policy Instruction. How can instructors effectively balance students' internal and external motivations for the sake of increasing their political interest and internal political efficacy? When some students lack basic civics education and others arrive to class with a resume full of political activism, what are effective ways for meeting the learning needs of a diverse set of students? How can instructors best facilitate diverse political dialogue and simultaneously model a political presence, when many students are hesitant to disagree with their instructor's position on issues? And in what ways can instructors integrate their own instructional styles and strengths with the core elements of this model? Some of these challenges became clear as I wrapped up my interviews with students. Others emerged as I attempted to apply the model in an actual course.

It is beyond the data of this study to comprehensively answer any of these questions. More than anything, I raise them to begin a conversation among my colleagues and acknowledge the challenges and opportunities before us as social welfare policy instructors committed to inspiring future policy practice by social workers in the

field. Instructional ideas presented below are grounded in themes that emerged from the study's data, though no specific instructional methods were tested. They also reflect my own teaching experience, to the extent that it is consistent with the study's themes. They are an initial offering to which others will hopefully add. 


\section{INCREASING POLITICAL INTEREST AND EFFICACY}

\section{Balancing internal and external motivation.}

Students attributed their increased political interest and internal political efficacy in part to a combination of internal and external motivation to actively engage with the content and activities of their social welfare policy course. An internal source of motivation arose when students recognized that social welfare policy and political advocacy have an intrinsic, personal value to them. This intrinsic value came from students' personal experiences, relationships, community membership, and professional interests. This internal motivation created a desire and willingness to spend more time and energy on their research and advocacy efforts. Students cared more about the quality and impact of their work in the course.

External motivation came from the assignments and accountability of a formal course. Students felt challenged and motivated by the requirements of their social welfare policy course to gain new knowledge and develop new research and advocacy skills that they would have otherwise ignored or avoided. This initial reluctance was attributed to intimidation, lack of time, or lack of interest. However, when the activities and assignments of the course required them to engage in these areas, students discovered new topics of interest and developed new competencies which contributed to their overall

political interest and internal political efficacy. Students also identified the importance of receiving instructor support for these externally-motivated, challenging activities. Specific examples of both internal and external motivation are provided in Chapter 6. 


\section{INCREASING POLITICAL INTEREST AND EFFICACY}

While this combination of internal and external motivation appears important to the development of students' political interest and internal political efficacy, students seemed to place a slightly greater emphasis on the value of internal motivation, through both the quality and quantity of their feedback. It is, therefore, recommended that social welfare policy instructors do the same. Early in a course, instructors could engage the class in conversation and activities designed to help students identify and clarify the ways in which social welfare policy impacts their lives. When different content areas are covered, the knowledge can be grounded in real-life examples that are likely to resonate with students, including the personal experiences of students, their friends and families, and their clients for those students who are in practicum or already employed in the field. Meaningful opportunities for students to select their own topics for discussion, research, and advocacy activities can be incorporated into the course design and assignments.

External motivation seems likely to benefit students by broadening their knowledge base and encouraging them to attempt advocacy activities that are initially intimidating. Assignments and in-class activities can expose students to a breadth of social welfare policy and political perspectives that they may not have otherwise considered. Incorporation of current events into course activities may raise students' interest and support a habit of attending to politics and economics that could benefit their future social work practice. Engaging students in political testimony, whether real or within a mock committee hearing, can help them realize they are capable and that this is 


\section{INCREASING POLITICAL INTEREST AND EFFICACY}

an option for them out in the field. This would apply to other forms of political advocacy, as well.

\section{Teaching students with a range of political knowledge and skills.}

While the majority of students communicated a desire for more foundational knowledge in politics and economics, in both courses there were a couple students who came with substantial political exposure and advocacy experience. These more advanced students had questions and interests that seemed less likely to be addressed in the generalist practice course. Students at a variety of levels identified teaching students with a range of policy knowledge and skills as a challenge for instructors. They did not offer specific ideas for doing so.

Though meeting diverse instructional needs is not a challenge unique to social welfare policy, there are some specific ways in which social welfare policy instructors might approach this challenge and opportunity. An initial assessment at the beginning of a social welfare policy course can inform instructors of the range of political exposure and experience present in the group. This could be an informal appraisal through conversation or a more formal written assessment. The measurement tools employed for this study could prove useful in this regard, providing instructors with an understanding of students' previous political activity, their political interests, and their current level of internal political efficacy. 


\section{INCREASING POLITICAL INTEREST AND EFFICACY}

Providing choice within or between assignments is another means for engaging social welfare policy students at different knowledge and skill levels. If there is a wide range of political knowledge within a class, assigned readings could vary to provide students with foundational or advanced knowledge as appropriate. If a policy analysis or policy brief assignment is included within a course, students could be guided to select a topic about which they do not already have extensive knowledge. For political advocacy assignments, students could select from a range of advocacy options, again being guided to engage in actions in which they have less experience. With any assignment, students can create brief proposals which include an assessment of their existing knowledge, their personal learning objectives, their topic, and their proposed methods.

Another means for effectively teaching a range of social welfare policy students is to introduce them to policy resources which can be utilized in a variety of ways. For example, a state legislative website can be used by students new to the subject to identify their own representatives and the committees on which they serve. All students can use it to look up a particular piece of legislation and follow it through the legislative process. More advanced students can evaluate fiscal implications and relevant policy history through the same website. The websites of the U.S. Census Bureau, think tanks, local and national legislative websites, and advocacy organizations can be utilized by students in a similar variety of ways.

Facilitating diverse political dialogue, while modeling a political presence. 


\section{INCREASING POLITICAL INTEREST AND EFFICACY}

There is a tension in the teaching themes of the proposed model between objectivity and activism on the part of the social welfare policy instructor. Objectivity in the social welfare policy classroom involves presenting a variety of political views and facilitating dialogue with minimal influence from one's own political opinions. As discussed earlier, students expressed a desire for more genuine, diverse, and respectful political dialogue in the social welfare policy classroom. One of the students' specific recommendations was that instructors attempt to limit attention paid to instructors' own political opinions, in order to minimize students' hesitancy to speak up when they may disagree with a professor. At the same time, students identified their social welfare policy instructor as an important role model for political advocacy. Instructors' passion for and experience with political advocacy inspires students and provides them with trusted guidance. Serving as a role model of political presence requires having advocated for a specific policy position.

This balancing act is similar to what is expected of social work students when they enter the field. A social worker is expected to respect human diversity and work effectively with people from a variety of backgrounds, including a diversity of political opinion. At the same time, social workers are called upon to be political advocates on behalf of social justice, which includes taking a stand. Self awareness, good judgment, and professional skills of engagement and advocacy are important qualities as social workers seek to effectively strike this balance. It may be no different for social welfare 


\section{INCREASING POLITICAL INTEREST AND EFFICACY}

policy instructors. In fact, talking with students about one's use of objectivity and activism as an instructor may prove useful to students in their overall development as social work professionals.

Students' hesitancy to disagree with instructors' political opinions, whether stated or assumed, is reflective of the power differential between instructors and students and can limit the emergence of genuinely diverse political dialogue in the classroom. Again, both instructors in this study were described by students as respectful and welcoming of different opinions, yet students remained hesitant to disagree with them. It is important to recognize that social welfare policy instructors hold power that can intentionally or unintentionally discourage appropriate self-disclosure of students' political perspectives and questions. If not aware of and responsible for the impact of one's power in the classroom, instructors can also create adversarial and divisive stances that polarize a class. However, there is also the potential for instructors to use their power to model consideration of alternate points of view in a respectful, non-dogmatic, and welcoming manner. Students in this study suggest that when they experience such genuine and diverse political dialogue, their political interest and internal political efficacy are increased.

Objectivity suggests an impartial or detached stance. In the social welfare policy classroom, it may include a tactical absence of the instructor's own political opinions, an active welcoming of diverse ideas from others, and an intentional voicing of perspectives 


\section{INCREASING POLITICAL INTEREST AND EFFICACY}

that are otherwise not represented. I would argue that an objective stance on the part of a social welfare policy instructor does not require shying away from the importance of political advocacy for the sake of social justice. Rather, it requires the intentional creation of an environment in which multiple perspectives on what it means for a policy to be just are fairly considered, as well as the individual instructor choosing not to advocate for a single answer to that important question.

Based on student feedback, social welfare policy instructors might consider maintaining a more objective stance in the classroom for three specific purposes. First, maintaining an objective stance early in a course may help create a learning environment conducive to the sharing of students' diverse political opinions. Second, an objective stance can assist instructors in recognizing what political perspectives are not inherently represented in a classroom and giving voice to those. Third, maintaining an objective stance when teaching about various political and economic perspectives may enhance students' learning and ability to respectfully interact with people from a variety of backgrounds. Hearing an instructor effectively articulate diverse political perspectives may assist students to develop the skill of political listening and civic dialogue.

While students encouraged social welfare policy instructors to facilitate constructive and open dialogue in the classroom, they also placed value on their instructor being an authentic role model of political activism. Based on student feedback, social welfare policy instructors might also consider utilizing their political advocacy 


\section{INCREASING POLITICAL INTEREST AND EFFICACY}

experience for three specific purposes. First, when a course shifts from political knowledge to political advocacy, the instructor's own experience can provide students with inspiration and enhance student interest. Stories from an instructor's practice, whether it is case management or political advocacy, make course content more meaningful for students. Second, when students engage in advocacy activities for the first time, stories of an instructor's challenges and successes can help create realistic expectations for students and minimize fear of failure. Third, specific examples from an instructor's advocacy work, such as written testimony or a letter to the editor, can provide students with real and tangible examples from which to learn and a reason to value the instructor's guidance on specific advocacy techniques. They may also help students grapple with abstract concepts and understand complex political systems, though this use of an instructor's advocacy experience was not directly observed or proposed by students in this study.

Timing and clarity of purpose are essential considerations as social welfare policy instructors determine the balance they will establish between objectivity and the role modeling of political advocacy. The importance of establishing diverse and respectful political dialogue in the classroom suggests the use of objectivity early in a social welfare policy course. And when examples from an instructor's activism are utilized in the classroom, it would be important to do so in a manner consistent with the original goal of maintaining diverse and respectful political dialogue. One way of doing so may be to 


\section{INCREASING POLITICAL INTEREST AND EFFICACY}

emphasize the strategies, techniques, and personal experience of the activism more than the content itself. It may also be effective to discuss directly with students the purpose and impact of the instructor's advocacy examples on their learning and participation in the course. These initial ideas about the role of objectivity and activism on the part of social welfare policy instructors are consistent with the student voice from this study. Hopefully, they will contribute to and encourage on-going dialogue.

\section{Incorporating one's instructional style and strengths into the core elements.}

Through this study, social work students have offered social welfare policy instructors themes for effective teaching that can bolster students' political interest and internal political efficacy. It is important to remember, however, that these themes emerged from students in two distinct courses taught by instructors with different teaching styles. As discussed in Chapter 6, both instructors combined didactic and experiential components in their course and emphasized the importance of political advocacy in social work practice. But their teaching styles and assignments were substantially different.

This suggests an opportunity for social welfare policy instructors to incorporate their own teaching styles and strengths into the core elements of the proposed instructional model, with a reasonable expectation that students will experience an increase in political interest and internal political efficacy. There are as many ways to model a political presence as there are ways to engage in political advocacy. Instructors 


\section{INCREASING POLITICAL INTEREST AND EFFICACY}

have different ways of communicating their belief in students' ability to impact the political system. Local politics offer many possibilities for engaging students. The range of student interests is another source for diverse topics, advocacy opportunities, and linkages with outside organizations. A cycle of action and reflection can be used in a variety of classroom activities and outside assignments. There are also many different activities through which students can engage in self-directed learning and be exposed to a range of political advocacy methods. Finally, instructors can facilitate respectful and diverse political dialogue using a variety of personal styles. Social welfare policy instructors and their students may benefit from the conceptual clarity and clear purpose of the teaching themes in the proposed Model for Social Welfare Policy Instruction. It is not intended, however, to restrict instructors from utilizing their own strengths and styles. Instead, it will hopefully provide a focused, empowering, and effective opportunity to do so. 


\section{INCREASING POLITICAL INTEREST AND EFFICACY}

\section{Chapter 8: Conclusion}

\section{Study Limitations}

This was an exploratory study, intended to identify salient themes of teaching social welfare policy that positively influence students' political interest and internal political efficacy. It had a mixed methods design, incorporating a small quantitative element into a larger qualitative study. The qualitative portion of the study was based in grounded theory methodology. Data were gathered through classroom observations, preand post-test surveys, focus groups, and individual interviews. All data other than classroom observations reflect student voice. The methods outlined in Chapter 4, including triangulation of data, were intended to maximize the strengths and minimize the limitations of each data collection and analysis method. However, there are limitations which it is important to consider when evaluating and applying the conclusions of this study.

\section{Sample.}

The results of this study are based on a small, nonprobability sample of undergraduate social work students. While this is fully appropriate for the qualitative portion of the study, it is a quantitative limitation that has been partially addressed by the use of nonparametric data analysis techniques. Still, generalizability to other social work students cannot be assumed. 


\section{INCREASING POLITICAL INTEREST AND EFFICACY}

Though it is appropriate to use nonprobability purposive sampling techniques for a grounded theory study, the resultant sample must be critically considered in terms of its representativeness of the larger population, in this case all undergraduate social work students. As with all qualitative studies, applicability of conclusions to different locations or circumstances depends largely on context. For this reason, the reader is urged to review the description of participant selection in Chapter 4 and the demographic description of participating students in Chapter 5 before determining what, if anything, can be applied to a different situation. The students in this study attended universities in the Pacific Northwest. Though there is some demographic diversity, the sample is primarily female, white, and young. There may be different or additional themes that would emerge with a more diverse sample, based on unique considerations of geographic region, sex, race and ethnicity, age, or other relevant factors. The sample also represents a slice in time: students attending a social welfare policy course in the 2009-2010 academic year. Current events, such as federal health care reform, may have impacted students' experience in these social welfare policy courses in a unique way that contributed to the data and themes that emerged.

There remains the question of whether the findings from this study are applicable to first-year Masters of Social Work (MSW) students who also take generalist social welfare policy courses. Though undergraduate social work students from accredited programs share many commonalities with most first year MSW students, including a 


\section{INCREASING POLITICAL INTEREST AND EFFICACY}

generalist practice emphasis and similar curriculum, there may be unique attributes of MSW students as compared to BSW students that could lead to different results.

Another caution when evaluating and applying the results of this study is the potential for selection bias, both in terms of the courses observed and individual student participants. It is not easy to identify instructors willing to have a researcher observe their classroom for an entire term and follow that up with in-depth interviews of students' experience in the course. The two courses selected to serve as the cases for this study represent two such instructors. On the one hand, this may support the idea that the observed courses were taught in such a way that political advocacy was valued and emphasized. However, there is a degree of self-selection involved, as well. The recommendations reflected in the proposed model are also partially limited by the methods used by the two observed instructors. In a number of cases, students drew from their past academic experiences and their imagination for what else would be possible. Nevertheless, they were primarily responding to what they experienced in these two selected courses.

In terms of individual students, all 39 potential participants chose to complete one or both surveys. However, only 28 students consented to participation in a focus group. Twenty-one students consented to potential participation in an interview, with eleven such interviews being conducted. Because the qualitative data at the heart of this study emerged from the focus groups and interviews, all students from both courses are not 


\section{INCREASING POLITICAL INTEREST AND EFFICACY}

represented and their reasons for not participating in the qualitative data collection are unknown. It is possible that those who agreed to participate in focus groups and interviews are in some way different from those who did not; those who did not participate in an interview or focus group may have raised unique considerations that are not incorporated in the proposed model.

Finally, the sample represents students at the beginning and end of a single term course. All post-test surveys were completed on the last day of class. All interviews were completed within two months of the completion of the course. It is not known whether the changes in students' political interest and internal political efficacy are longterm or not.

\section{Researcher bias.}

It is also important to acknowledge the reality of researcher bias and subjectivity. As the classroom observer, focus group facilitator, interviewer, and analyst, I brought my own experiences and biases to this project. I am a social worker, a student, and a social welfare policy instructor. It is difficult to determine the degree to which my own experiences influenced the dynamics I observed, the questions I pursued in focus groups and interviews, and the ideas I attended to in the analysis. Therefore, from a qualitative viewpoint, trustworthiness is a fundamental goal. Specific steps taken to establish trustworthiness are described in detail in Chapter 4.

\section{Summary}




\section{INCREASING POLITICAL INTEREST AND EFFICACY}

While there may be a professional mandate for social workers to engage in political advocacy on behalf of social justice (Council on Social Work Education, 2008; National Association of Social Workers, 2008), research suggests that political participation and social activism among professional social workers is moderate and inconsistent (Byers \& Stone, 1999; Ezell, 1993, 1994; Hamilton \& Fauri, 2001; Ritter, 2007, 2008; J. L. Wolk, 1981). One contributing factor to this was highlighted by Ritter's 2007 study, in which almost half of licensed social workers surveyed disagreed with the notion that they were adequately prepared for political engagement by their social work education. How can our preparation of students be improved?

Social welfare policy instructors have a central role to play in the achievement of that aim. The social welfare policy course is where undergraduate social work students receive the bulk of their education on policy and policy practice. This study does not assume that social welfare policy instructors are solely responsible for students' preparation for political advocacy nor their engagement in it following graduation. There are important factors within the larger social work and liberal arts curriculum, as well as factors outside of school and in the work setting that should not be ignored. Yet the role of the social welfare policy instructor remains key in terms of academic preparation of social workers to engage the political system for the sake of enhancing the well-being of people and communities. 


\section{INCREASING POLITICAL INTEREST AND EFFICACY}

Students in this current study have shed light on specific ways in which instructors can create and facilitate social welfare policy courses, such that social work students' political interest and internal political efficacy will increase. Students' feedback was thematically analyzed and integrated into a proposed Model for Social Welfare Policy Instruction. The model incorporates the assumption, based on research, that increased political interest and internal efficacy will lead to increased and effective political advocacy (Anderson \& Harris, 2005; Ezell, 1993; Hamilton \& Fauri, 2001; Ritter, 2007, 2008; Weiss et al., 2006). It then highlights seven key experiences in a social welfare policy course that are likely to lead to increased political interest and internal efficacy on the part of students. Finally, eleven teaching methods are outlined

and described, which are expected to create the context in which those seven key student experiences will be realized. The complete model can be viewed in Figure 2.

Social work instructors are encouraged to incorporate the proposed model in their undergraduate social welfare policy courses. Students' political interest and internal political efficacy may be strengthened by instructors who commit to the following: (1) demonstrating basic instructional competencies, (2) modeling a political presence, (3) communicating belief in students' ability to impact the political system, (4) creating a course structure that encourages praxis, (5) emphasizing local and "real" political exposure and engagement, (6) grounding learning activities in generative themes, (7) prioritizing, modeling, and facilitating respectful and diverse political dialogue, (8) 


\section{INCREASING POLITICAL INTEREST AND EFFICACY}

maintaining an andragogical perspective, while using pedagogical methods as needed, (9) exposing students to a range of political advocacy methods, (10) supporting self-directed learning, and (11) helping students connected with advocacy groups relevant to their interests.

\section{Future Directions for Research}

Due to this study's exploratory nature, there are an abundance of future directions for research related to the preparation of social work students for political advocacy. First, because the data from this study were intended for the development rather than testing of a theory or model, the proposed Model for Social Welfare Policy Instruction could be tested and further refined. In particular, it would be beneficial to test the model with a more diverse set of students and within a more diverse set of universities. Specific techniques for and implications of each recommended teaching theme could be explored. For example, what are the various options for facilitating respectful and diverse political dialogue in the social welfare policy classroom? A longitudinal study that examines the impact of graduates' various levels of political interest and internal political efficacy on longer-term political advocacy efforts would help clarify the connection between the two. It would also be beneficial to conduct a longitudinal study that examines the longer-term political advocacy efforts of students taught from the proposed model, perhaps compared to those taught from a different model of instruction. Finally, research on effective 


\section{INCREASING POLITICAL INTEREST AND EFFICACY}

teaching methods for MSW students in the area of political advocacy could clarify whether or not the proposed model is applicable to that population of student, as well.

Because this study was limited to the instructional choices of two professors, there are a number of other curricular options to explore, in terms of their impact on students' political interest, internal political efficacy, and/or longer-term political advocacy efforts. What impact might political advocacy mentoring have on students? Would the creation of a community of support for students around political advocacy efforts make a positive difference? Does the study of and intentional involvement in social movements impact students' interest and sense of efficacy in politics? Would time spent working in a political representative's office or campaign have a positive influence? What is the impact of requiring a political science or economics course prior to social welfare policy? Individual social welfare policy instructors could use the measurement tools employed in this study to evaluate the impact of particular teaching strategies and assignments on their students' political interest and internal political efficacy.

The proposed instructional themes are focused on the preparation and motivation of social work students for a particular form of macro-practice. It would be interesting to explore whether the proposed teaching methods apply to the preparation and motivation of students for community practice and other forms of direct action. There are also different theories relevant to adult learning and the preparation of students for engagement in social change, such as the theory of transformative learning (Mezirow, 


\section{INCREASING POLITICAL INTEREST AND EFFICACY}

1997). Applying a new theoretical lens to the same research question or to the proposed model for instruction might suggest new questions, research methodologies, and instructional options.

\section{Implications for Social Welfare Policy Curriculum}

The proposed model for social welfare policy education is about more than teaching methodologies and student experience in the classroom. It is, ultimately, a call for a shift in curricular thinking. Social work practitioners are expected to be political advocates, among many other roles. Doing so effectively requires considerable skill development. However, social welfare policy courses appear to emphasize history and knowledge development more than skill development. It is time for undergraduate social work programs to emphasize political advocacy skill development in the same way they emphasize the development of interviewing, assessment, documentation, and intervention skills. Through this research, students have expressed the positive impact of experiential teaching methods in social welfare policy, especially when they are backed up by knowledge development, political role modeling, and the emotional and practical support necessary for students to reflect and take risks for the sake of learning.

It is time for social welfare policy to be conceptualized and treated as a practice course. Practice courses require knowledge and value development, but emphasize the practice and development of specific skills. The experiential methods required to develop political advocacy skills will not only enhance students' internal political 


\section{INCREASING POLITICAL INTEREST AND EFFICACY}

efficacy, but they have the added benefit of raising student interest. Thus, social work graduates will feel better prepared to participate in political action and the social work profession's political advocacy efforts will be strengthened. 


\section{INCREASING POLITICAL INTEREST AND EFFICACY}

\section{References}

Abel, E. M., \& Kazmerski, K. J. (1994). Protecting the Inclusion of Macro Content in Generalist Practice. Journal of Community Practice, 1(3), 59-72.

Anderson, D. K. (2006). Mucking through the swamp: Changing the pedagogy of a social welfare policy course. Journal of Teaching in Social Work, 26(1/2), 1-17.

Anderson, D. K., \& Harris, B. M. (2005). Teaching social welfare policy: A comparison of two pedagogical approaches. Journal of Social Work Education, 41(3), 511526.

Austin, M. J., Coombs, M., \& Barr, B. (2005). Community-centered clinical practice: Is the integration of micro and macro social work practice possible? Journal of Community Practice, 13(4), 9-30.

Bailey, D., \& Koney, K. M. (1996). Interorganizational community-based collaborative: A strategic response to shape the social work agenda. Social Work, 41(6), 602611.

Belcher, J. R. (1994). Understanding the process of social drift among the homeless: A qualitative analysis. In E. Shermand \& W. J. Reid (Eds.), Qualitative research in social work (pp. 126-134). New York: Columbia University Press.

Blank, J., \& Russell, J. D. (2000). The program planning model for adult and continuing education. Educational Technology, 40(2), 47-51. 


\section{INCREASING POLITICAL INTEREST AND EFFICACY}

Brawley, E. A. (1997). Teaching social work students to use advocacy skills through the mass media. Journal of Social Work Education, 33(3), 445-460.

Butler, S. S., \& Coleman, P. A. (1997). Raising our voices: A macro practice assignment. Journal of Teaching in Social Work, 15(1/2), 63-80.

Butler, S. S., \& Seguino, S. (2000). Working in coalition: Advocates and academics join forces to promote progressive welfare policies. Journal of Community Practice, 7(4), 1-20.

Byers, K., \& Stone, G. (1999). Roots of activism: A qualitative study of BSW students. The Journal of Baccalaureate Social Work, 5(1), 1-14.

Carey, L. A. (2007). Teaching macro practice: An experiential learning project. Journal of Teaching in Social Work, 27(1/2), 61-71.

Coates, J. (1994). Education for social transformation. Journal of Teaching in Social Work, 10(1/2), 1-17.

Corvo, K., Selmi, P., \& Montemaro, S. M. (2003). Icons of conformity: The marketing of social work education. Journal of Community Practice, 11(1), 85-99.

Council on Social Work Education. (2003). Educational Policy and Accreditation Standards. Retrieved from http://www.cswe.org/

Council on Social Work Education. (2008). Educational Policy and Accreditation Standards. Retrieved from http://www.cswe.org/ 


\section{INCREASING POLITICAL INTEREST AND EFFICACY}

Creswell, J. W. (2007). Qualitative inquiry and research design: Choosing among five approaches (2nd ed.). Thousand Oaks, CA: Sage Publications, Inc.

Creswell, J. W., \& Plano Clark, V. L. (2007). Designing and conducting mixed methods research. Thousand Oaks, CA: Sage Publications, Inc.

Daniel, C. (2007). Outsiders-Within: Critical Race Theory, Graduate Education and Barriers to Professionalization. Journal of Sociology \& Social Welfare, 34(1), 2542.

Dempsey, D. (2008). The path to social justice goes through politics and economics. Journal of Policy Practice, 7(2-3), 94-105.

Dickinson, J. C. (2005). Atittudes of members in one NASW Chapter about social action: A 1972 and 2003 comparison study. Professional Development: The International Journal of Continuing Social Work, 8(1), 46-55.

Dickinson, J. C. (2007). A survey of social policy placements in BSW education. Journal of Policy Practice, 6(1), 47-63.

Dodd, S.-J., \& Rivera, H. P. (2003). Addition and subtraction: Cost-benefit analysis as a tool for teaching diversity content in social policy. The Social Policy Journal, 2(2/3), 107-121.

Domanski, M. D. (1998). Prototypes of social work political participation: An empirical model. Social Work, 43(2), 156-167. 


\section{INCREASING POLITICAL INTEREST AND EFFICACY}

Ersing, R. L., \& Loeffler, D. N. (2008). Teaching students to become effective in policy practice: Integrating social capital into social work education and practice. Journal of Policy Practice, 7(2-3), 226-238.

Ezell, M. (1993). The political activity of social workers: A post-Reagan update. Journal of Sociology and Social Welfare, 20(4), 81-97.

Ezell, M. (1994). Advocacy practice of social workers. Families in Society, 75(1), 36-46.

Fayers, P. (2011). Alphas, betas and skewy distributions: Two ways of getting the wrong answer. Advances in Health Sciences Education, 16(3), 291-296.

Fisher, R. (1995). Political social work. Journal of Social Work Education, 31(2), 194203.

Fisher, R., Weedman, A., Alex, G., \& Stout, K. D. (2001). Graduate education for social change: A study of political social workers. Journal of Community Practice, 9(4), 43-64.

Fitzgerald, E., \& John, M. (1999). Electronic advocacy in policy practice: A framework for teaching technologically based practice. Journal of Social Work Education, 35(3), 331-341.

Freddolino, P. P., Moxley, D. P., \& Hyduk, C. A. (2004). A differential model of advocacy in social work practice. Families in Society, 85(1), 119-128.

Freire, P. (1998). Pedagogy of freedom: Ethics, democracy, and civic courage. Lanham, MD: Rowman \& Littlefield Publishers, Inc. 


\section{INCREASING POLITICAL INTEREST AND EFFICACY}

Freire, P. (2000). Pedagogy of the Oppressed (M. B. Ramos, Trans. 30th Anniversary ed.). New York: Continuum Books.

Gibbons, J., \& Gray, M. (2005). Teaching social work students about social policy. Australian Social Work, 58(1), 58-75.

Gorman, J. (1993). Postmodernism and the conduct of inquiry in social work. Affilia, $8(3), 247-264$.

Gray, K. A., Wolfer, T. A., \& Maas, C. (2005). The decision case method: Teaching and training for grassroots community organizing. Journal of Community Practice, 13(1), 105-120.

Gray, M., Collett van Rooyen, C., Rennie, G., \& Gaha, J. (2002). The political participation of social workers: A comparative study. International Journal of Social Welfare, 11, 99-110.

Gregory, M., \& Holloway, M. (2005). The debate as a pedagogic tool in social policy for social work students. Social Work Education, 24(6), 617-637.

Hamilton, D., \& Fauri, D. (2001). Social workers' political participation: Strengthening the political confidence of social work students. Journal of Social Work Education, 37(2), 321-332.

Hardina, D. (1995). Do Canadian social workers practice advocacy? Journal of Community Practice, 2(3), 97-121. 


\section{INCREASING POLITICAL INTEREST AND EFFICACY}

Hardina, D. (1997). Empowering students for community organization practice: Teaching confrontation tactics. Journal of Community Practice, 4(2), 51-63.

Hatch, J. A. (2002). Doing qualitative research in education settings. Albany: State University of New York Press.

Hawkins, C. (1996). Minding the media and analyzing the agenda: Teaching critical thinking skills to social work undergraduates. The Journal of Baccalaureate Social Work, 1(2), 15-26.

Heidemann, G., Fertig, R., Jansson, B., \& Kim, H. (2011). Practicing policy, pursuing change, and promoting social justice: A policy instructional approach. Journal of Social Work Education, 47(1), 37-52.

Hodge, D. R. (2003). Value differences between social workers and members of the working and middle classes. Social Work, 48(1), 107-119.

Hoefer, R. (1999). The social work and politics initiative: A model for increasing political content in social work education. Journal of Community Practice, 6(3), $71-87$.

Hope, A., \& Timmel, S. (1996). Training for transformation: A handbook for community workers (2nd ed. Vol. 1). Gweru, Zimbabwe: Mambo Press.

Horton, M., \& Freire, P. (1990). We make the road by walking: Conversations on education and social change. Philadelphia: Temple University Press. 


\section{INCREASING POLITICAL INTEREST AND EFFICACY}

Iversen, R. R. (2001). Using African American narratives to analyze social policy. Journal of Teaching in Social Work, 21(3/4), 7-26.

Jansson, B. S. (2008). Becoming an effective policy advocate: From policy practice to social justice (5th ed.). Belmont, CA: Thomson Brooks/Cole.

Johnson, A. K. (1994). Teaching students the task force approach: A policy-practice course. Journal of Social Work Education, 30(3), 336-347.

Jones, S. R., Torres, V., \& Arminio, J. (2006). Negotiating the complexities of qualitative research in higher education: Fundamental elements and issues. New York: Routledge.

Keller, T. E., Whittaker, J. K., \& Burke, T. K. (2001). Student debates in policy courses: Promoting policy practice skills and knowledge through active learning. Journal of Social Work Education, 37(2), 343-355.

Kirst-Ashman, K. K., \& Hull, G. H., Jr. (2006). Generalist practice with organizations and communities (3rd ed.). Belmont, CA: Thomson Brooks/Cole.

Knowles, M. S., Holton III, E. F., \& Swanson, R. A. (2005). The adult learner: The definitive classic in adult education and human resource development (6th ed. ed.). Burlington, MA: Elsevier, Inc.

Leighninger, L. (1978). Professionalism and social work education: Substance and structure. Journal of Sociology \& Social Welfare, 5(2), 188-215. 


\section{INCREASING POLITICAL INTEREST AND EFFICACY}

Leighninger, L. (1984). Graduate and Undergraduate Social Work Education: Roots of Conflict. Journal of Education for Social Work, 20(3), 66-77.

Lens, V. (2002). Sound bites, spin and social change: Analyzing the news media in the classroom. Journal of Teaching in Social Work, 22(3/4), 39-53.

Lens, V. (2005). Advocacy and argumentation in the public arena: A guide for social workers. Social Work, 50(3), 231-238.

Long, D. D., Tice, C. J., \& Morrison, J. D. (2006). Macro social work practice: A strengths perspective. Belmont, CA: Thomson Brooks/Cole.

Mary, N. L. (2001). Political activism of social work educators. Journal of Community Practice, 9(4), 1-20.

McNutt, J. (2007). Political blogging and social welfare policy: Internet resources for research and scholarship. Journal of Policy Practice, 6(1), 85-89.

Medina, C. K. (2010). The need and use of process recording in policy practice: A learning and assessment tool for macro practice. Journal of Teaching in Social Work, 30, 29-45.

Meenaghan, T. M., \& Gruber, M. (1986). Social policy and clinical social work education: Clinicians as social policy practitioners. Journal of Social Work Education, 22(2), 38-45. 


\section{INCREASING POLITICAL INTEREST AND EFFICACY}

Mendes, P. (2003a). Social workers and social action: A case study of the Australian Association of Social Workers' Victorian branch. Australian Social Work, 56(1), $16-27$.

Mendes, P. (2003b). Teaching social policy to social work students: A critical reflection. Australian Social Work, 56(3), 220-233.

Mezirow, J. (1997). Transformative learning: Theory to practice. New Directions for Adult \& Continuing Education, Summer 97(74), 5-12.

Montgomery, R. L. (1980). The reluctant profession: Undergraduate social work education and the manpower issue., Brandeis University.

Moon, S. S., \& DeWeaver, K. L. (2005). Electronic advocacy and social welfare policy education. Journal of Teaching in Social Work, 25(1/2), 57-68.

Moore, L. S., \& Dietz, T. J. (1999). Four months to system change: Teaching baccalaureate students to affect policy. Journal of Community Practice, 6(1), 3344.

Moore, L. S., \& Johnston, L. B. (2002). Involving students in political advocacy and social change. Journal of Community Practice, 10(2), 89-101.

National Association of Social Workers. (2008). Code of Ethics of the National Association of Social Workers. Retrieved from http://www.socialworkers.org/pubs/code/code.asp 


\section{INCREASING POLITICAL INTEREST AND EFFICACY}

Niemi, R. G., Craig, S. C., \& Mattei, F. (1991). Measuring internal political efficacy in the 1988 national election study. American Political Science Review, 85, 14071413.

Norman, G. (2010). Likert scales, levels of measurement and the "laws" of statistics. Advances in Health Sciences Education, 15(5), 625-632.

Pawar, M. (2004). Social policy curricula for training social workers: Towards a model. Australian Social Work, 57(1), 3-18.

Payne, M. (2005). Modern social work theory (3rd ed.). Chicago, IL: Lyceum Books, Inc. Payne, M. (2007). What is professional social work? (2nd ed.). Chicago: Lyceum Books, Inc.

Raber, M., \& Richter, J. (1999). Bringing social action back into the social work curriculum: A model for "hands-on" learning. Journal of Teaching in Social Work, 19(1/2), 77-91.

Reeser, L. C. (1988a). Specialization, professionalization, and social activism. Journal of Independent Social Work, 2(4), 43-58.

Reeser, L. C. (1988b). Women and social work activism in the 1980s. Affilia, 3(3), 51-62.

Reeser, L. C. (1991). Professionalization, striving, and social work activism. Journal of Social Service Research, 14(3/4), 1-22.

Reeser, L. C. (1992). Professional role orientation and social activism. Journal of Sociology and Social Welfare, 19(2), 79-94. 


\section{INCREASING POLITICAL INTEREST AND EFFICACY}

Reeser, L. C., \& Epstein, I. (1987). Social workers' attitudes toward poverty and social action: 1968-1984. Social Service Review, 61(4), 610-622.

Ritter, J. A. (2007). Evaluating the political participation of licensed social workers in the new millennium. Journal of Policy Practice, 6(4), 61-78.

Ritter, J. A. (2008). A national study predicting licensed social workers' level of political participation: The role of resources, psychological engagement, and recruitment networks. Social Work, 53(4), 347-357.

Rocha, C. J. (2000). Evaluating experiential teaching methods in a policy practice course: The case for service learning to increase political participation. Journal of Social Work Education, 36(1), 53-63.

Rosenthal, B. S. (1992). Does the social work profession value research based knowledge as a basis for social policy? . Arete, 17(1), 38-46.

Rosenthal, J. A. (1996). Qualitative descriptors of strength of association and effect size. Journal of Social Service Research, 21(4), 37-59.

Saulnier, C. F. (2000). Policy practice: Training direct service social workers to get involved. Journal of Teaching in Social Work, 20(1/2), 121-144.

Segal, E. A. (2007). Social welfare policy and social programs: A values perspective. Belmont, CA: Thomson Brooks/Cole.

Seipel, M. M. O. (1986). Content analysis of social welfare curriculum. Journal of Social Work Education, 22(2), 53-60. 


\section{INCREASING POLITICAL INTEREST AND EFFICACY}

Sherman, E., \& Reid, W. J. (Eds.). (1994). Qualitative research in social work. New York: Columbia University Press.

Spicuzza, F. J. (2003). Preparing students for social work advocacy. The Journal of Baccalaureate Social Work, 8(2), 49-68.

Strauss, A., \& Corbin, J. (1990). Basics of qualitative research: Grounded theory procedures and techniques. Newbury Park, CA: Sage Publications, Inc.

Sundet, P. A., \& Kelly, M. J. (2002). Legislative policy briefs: Practical methodology in teaching policy practice. Journal of Teaching in Social Work, 22(1/2), 49-60.

Thyer, B. A. (2008). The quest for evidence-based practice?: We are all positivists! Research on Social Work Practice, 18(4), 339-345.

Tower, L. E., \& Hartnett, H. P. (2011). An Internet-based assignment to teach students to engage in policy practice: A three-cohort study. Journal of Policy Practice, 10(1), $65-77$

Trattner, W. I. (1999). From poor law to welfare state: A history of social welfare in America (6th ed.). New York: Simon \& Schuster.

Tully, G., Nadel, M., \& Lesser, M. (2005). Providing economics content for the $21 \mathrm{st}$ century BSW student. Journal of Teaching in Social Work, 25(3/4), 19-34.

van Soest, D. (1996). Impact of social work education on student attitudes and behavior concerning oppression. Journal of Social Work Education, 32(2), 191-202. 


\section{INCREASING POLITICAL INTEREST AND EFFICACY}

Van Voorhis, R. M., \& Hostetter, C. (2006). The impact of MSW education on social worker empowerment and commitment to client empowerment through social justice advocacy. Journal of Social Work Education, 42(1), 105-121.

Verba, S., Schlozman, K. L., \& Brady, H. E. (1995). Voice and equality: Civic voluntarism in American politics. Cambridge, MA: Harvard University Press.

Vodde, R., \& Gallant, J. P. (2002). Bridging the gap between micro and macro practice: Large scale change and a unified model of narrative-deconstructive practice. Journal of Social Work Education, 38(3), 439-458.

Weaver, R. D., \& Nackerud, L. G. (2005). Evaluating the effects of an applied learning exercise on students' interest in social policy. Journal of Teaching in Social Work, 25(3/4), 105-120.

Weiss-Gal, I., \& Gal, J. (2008). Social workers and policy-practice: The role of social and profesisonal values. Journal of Social Service Research, 34(4), 15-27.

Weiss, I., Cnaan, R. A., \& Gal, J. (2005). Does social work education have an impact on social policy preferences? A three-cohort study. Journal of Social Work Education, 41(1), 29-47.

Weiss, I., Gal, J., \& Katan, J. (2006). Social policy for social work: A teaching agenda. British Journal of Social Work, 36(5), 789-806. 


\section{INCREASING POLITICAL INTEREST AND EFFICACY}

Witkin, S. L., \& Saleebey, D. (Eds.). (2007). Social work dialogues: Transforming the canon in inquiry, practice, and education. Alexandria, VA: Council on Social Work Education, Inc.

Wolk, J., Pray, J., Weismiller, T., \& Dempsey, D. (1996). Political practica: Educating social work students for policymaking. Journal of Social Work Education, 32(1), 91-100.

Wolk, J. L. (1981). Are social workers politically active? Social Work, 26, 283-288.

Zubrzycki, J., \& McArthur, M. (2004). Preparing social work students for policy practice: An Australian example. Social Work Education, 23(4), 451-464. 


\title{
INCREASING POLITICAL INTEREST AND EFFICACY
}

\author{
Appendix A \\ Consent Form for Instructor \\ Increasing social work students' political interest and efficacy: \\ The impact of a social welfare policy course from the students' perspective
}

You are invited to participate in a research study conducted by Christie Bernklau Halvor, a doctoral student from Portland State University, School of Social Work. This dissertation research is being conducted under the supervision of Ann Curry-Stevens, Ph.D., Assistant Professor of Social Work. The researcher hopes to develop a theoretical framework for teaching social welfare policy in such a way that social work students are supported in their development of political interest, internal political efficacy, and ultimately political advocacy efforts. You were selected as a possible participant in this study based on the following three criteria: (1) at least one of your social welfare policy course learning objectives or assignments indicate a clear intention to enhance students' political advocacy skills, (2) there is evidence of experiential teaching methods in your course, determined by personal communications and/or the syllabus, and (3) you have expressed an initial willingness to have a researcher present throughout your course.

If you decide to participate, you will be asked to do the following:

(1) Allow the researcher to be present in your social work policy course throughout the [term], in order for her to become familiar with your teaching methods and with the in-class engagement and experiences of the students in the study. She will sit quietly in the back of the room, making written observations.

(2) Allow the researcher to use 25-30 minutes of the first day of your social work policy course to introduce the study to students, collect consent forms, and administer the first written survey.

(3) Allow the researcher to use 45 minutes of one of your final class sessions, in order to administer the second written survey and conduct a focus group with participating students.

(4) Once the student data and observations have been analyzed, meet with the researcher to review the conceptual results and offer insights and ideas.

When students are deciding whether or not to participate in the study, completing written surveys, and participating in the focus group, you would agree not to be present, in order to maximize the comfort level for participating students.

This study is focused on identifying effective teaching methods and published results will not include instructor or university names. For these reasons, there is only one 


\section{INCREASING POLITICAL INTEREST AND EFFICACY}

foreseeable risk to participating instructors. There is a possibility that the researcher will misinterpret some of your teaching practices. To guard against this, the researcher will share the results of the study with you before they are finalized, with the goal of clarifying any misinterpretations of your teaching methods.

You may not receive any direct benefit from taking part in this study, but the results are expected to assist social work educators in the future and ultimately strengthen social work education and practice. It is possible that you may benefit from the opportunity to reflect on and discuss your teaching methods with the researcher.

Because students will be present in the classroom and participating in a focus group conversation regarding the impact of the course, confidentiality cannot be guaranteed. However, every effort will be made to maximize your confidentiality. Instructors will be assigned a code, which will be used on written classroom observation forms. Audiotapes from the focus groups and interviews, in which instructors' names are likely to be mentioned, will be kept in a locked file cabinet. Instructors' names will be substituted with their code on any transcripts made. If an outside transcriptionist is used, s/he will sign a confidentiality agreement. The study materials will be kept for a minimum of three years. Audiotapes will be destroyed at that point, though coded transcripts and field notes may be maintained for future reference and use. If study results are published, the instructor and university's names will not be included. All published results will reflect integrated data from two courses, two instructors, and two universities.

Your participation is voluntary. You do not have to take part in this study, and it will not affect your relationship with Portland State University. You may also withdraw from this study at any time without affecting your relationship with Portland State University. If you withdraw from the study, any data gathered from your class and students will not be used.

If you have concerns or problems about your participation in this study or your rights as a research subject, please contact the Human Subjects Research Review Committee, Office of Research and Sponsored Projects, 600 Unitus Bldg., Portland State University, (503) 725-4288 or 1-877-480-4400. If you have questions about the study itself, contact Christie Bernklau Halvor at [deleted for confidentiality] or [deleted for confidentiality].

Your signature indicates that you have read and understand the above information and agree to take part in this study. Please understand that you may withdraw your consent at any time without penalty, and that, by signing, you are not waiving any legal claims, rights or remedies. The researcher will provide you with a copy of this form for your own records. 
INCREASING POLITICAL INTEREST AND EFFICACY

Your Name (please print)

Your Signature

Today's Date 


\section{INCREASING POLITICAL INTEREST AND EFFICACY}

\section{Appendix B \\ Pre-Test Survey \\ Survey on Political Interest and Participation}

Thank you for participating in this study on social work education. This survey is confidential; your name will not be associated with any of your answers. You do not have to answer any question that you are not comfortable answering and you may stop at any time. For more information, please see your copy of the consent form for this study.

\section{Political Interest and Participation}

For the following questions, please circle the answer or fill in the blank in the way that most accurately reflects you.

1. Are you currently registered to vote?

Yes No Not Eligible

(If you are not eligible to register to vote, please skip questions \#2-4.)

2. Think about the presidential elections that have occurred since you were old enough to vote. Which statement best reflects the degree to which you have voted in presidential elections since being old enough to do so?

a. I have voted in all of them.

b. I have voted in most of them.

c. I have voted in some of them.

d. I have rarely voted in them.

e. I have never voted in a presidential election. 


\section{INCREASING POLITICAL INTEREST AND EFFICACY}

3. Think about the state and local elections that have occurred since you were old enough to vote. Which statement best reflects the degree to which you have voted in state and local elections since being old enough to do so?
a. I have voted in all of them.
b. I have voted in most of them.
c. I have voted in some of them.
d. I have rarely voted in them.
e. I have never voted in a state or local election.

4. Think back to the national election that was held in November 2008, when the presidential candidates were Barack Obama, the Democrat, and John McCain, the Republican. Did you vote in that election?

Yes No

Questions 5-9 can pertain to candidates running for local, state, or national office:

5. During the 2008 campaign, did you talk to any people and try to show them why they should vote for or against one of the parties or candidates?

Yes No

6. During the 2008 campaign, did you wear a campaign button or T-shirt, put a campaign sticker on your car, or place a sign in your window or in front of your residence?

Yes No 


\section{INCREASING POLITICAL INTEREST AND EFFICACY}

7. During the 2008 campaign, did you go to any political meetings, rallies, speeches, dinners, or things like that in support of a political candidates?

Yes No

8. Since January 2008 , the start of the last national election year, have you worked as a volunteer (i.e. for no pay at all or for only a token amount) for a political party or for a candidate running for national, state, or local office?

Yes No

9. Since January 2008 , have you contributed money to an individual political candidate, a political party, a political action committee, or any other organization that supported political candidates?

Yes No

10. How often do you discuss local and state political or local community affairs with others?

Every Day Nearly Every Day Once or Twice a Week Less Than Once a Week Never

11. How often do you discuss national political or national affairs with others?

Every Day Nearly Every Day Once or Twice a Week

Less Than Once a Week Never 


\section{INCREASING POLITICAL INTEREST AND EFFICACY}

Questions 12 and 13 refer to contacts you may have made with government officials or someone on the staff of such officials about problems or issues with which you were concerned. These contacts may have been in person or by phone, letter, or e-mail. Please do not count any contacts you have made as a regular part of your paid job.

12. In the past 12 months, have you contacted a federally elected official or someone on the staff of such an official about problems or issues with which you were concerned? In other words, have you made such a contact with someone in the White House, the U.S. Senate, or the U.S. House of Representatives?

Yes No

13. In the past 12 months, have you contacted a state or locally elected official (e.g. a governor, mayor, state legislator, city or town council member) or someone on the staff of such an official about problems or issues with which you were concerned?

Yes No

14. In the past 12 months, have you testified at a public hearing on a local or national government problem?

Yes No

15. In the past two years, have you served in a voluntary capacity (i.e. for no pay at all or for only a token amount) on any official local governmental board or council that deals with community problems and issues, such as a town council, a school board, a zoning board, a planning board, or the like?

Yes No 


\section{INCREASING POLITICAL INTEREST AND EFFICACY}

16. In the past 12 months, have you taken part in forming a new group or a new organization to try to solve some community problems?

Yes No

17. In the past 12 months, have you gotten together informally with or worked with others in your community or neighborhood to try to deal with some community issue or problem?

Yes No

18. Are you a member of a political organization or an organization that regularly takes political stands on public issues at either the national, state, or local level? (Either formal membership or financial contributions to such an organization would count.)

Yes No

19. In the past two years, have you taken part in a protest, boycott, march, or demonstration on some national or local issue (not counting a strike against your employer)?

Yes No

Questions 20-22 pertain to activities you may have conducted as a part of your paid employment:

20. In the past 12 months, have you lobbied legislators as part of your job?

Yes No Not Employed 


\section{INCREASING POLITICAL INTEREST AND EFFICACY}

21. In the past 12 months, as part of your job, have you worked to change legislation or to get new social work/social welfare legislation passed?

Yes No Not Employed

22. In the past 12 months, as part of your job, have you engaged in a media awareness campaign that was designed to affect public opinion on a social work/social welfare policy?

Yes No Not Employed

Questions 23 and 24 pertain to your interest in politics:

23. Thinking about your state and local community, how interested are you in local politics and local community affairs?

$\begin{array}{cccc}\text { Very } & \text { Somewhat } & \text { Slightly } & \text { Not At All } \\ \text { Interested } & \text { Interested } & \text { Interested } & \text { Interested }\end{array}$

24. How interested are you in national politics and national affairs?

$\begin{array}{cccc}\text { Very } & \text { Somewhat } & \text { Slightly } & \text { Not At All } \\ \text { Interested } & \text { Interested } & \text { Interested } & \text { Interested }\end{array}$




\section{INCREASING POLITICAL INTEREST AND EFFICACY}

25. Please check the box next to any social welfare policy issue in which you are particularly interested:
Affordable Housing
Aging/Older Adult
Services
Child Abuse and Neglect
Civil Rights
Criminal Justice System
Disability Issues
Early Childhood
Education
Employment/Job Training
Food, Nutrition, and
Hunger

Globalization

Health Care

Homelessness

Immigration

Mental Health and Substance

Abuse

Poverty

Social Security

Tax Policy

Welfare

Other:

Other:

For questions 26-29, please rate your level of agreement with each statement.

26. I feel I have a pretty good understanding of the important political issues facing our country.
a. Strongly Agree
b. Somewhat Agree
c. Neither Agree Nor Disagree
d. Somewhat Disagree
e. Strongly Disagree 


\section{INCREASING POLITICAL INTEREST AND EFFICACY}

27. I consider myself to be well qualified to participate in politics.
a. Strongly Agree
b. Somewhat Agree
c. Neither Agree Nor Disagree
d. Somewhat Disagree
e. Strongly Disagree

28. I think that I am better informed about politics and government than most people.
a. Strongly Agree
b. Somewhat Agree
c. Neither Agree Nor Disagree
d. Somewhat Disagree
e. Strongly Disagree

29. I feel that I could do as good a job in public office as most other people.
a. Strongly Agree
b. Somewhat Agree
c. Neither Agree Nor Disagree
d. Somewhat Disagree
e. Strongly Disagree 


\section{INCREASING POLITICAL INTEREST AND EFFICACY}

30. In terms of political party identification, where would you place yourself on the following scale?
a. Strong Democrat
b. Democrat
c. Independent, Lean to the Democrats
d. Independent, No Leaning
e. Independent, Lean to the Republicans
f. Republican
g. Strong Republican
h. Other (e.g. Green Party, Libertarian)

31. In terms of political views, where would you place yourself on the following scale?
a. Very Liberal
b. Liberal
c. Moderate
d. Conservative
e. Very Conservative 


\section{INCREASING POLITICAL INTEREST AND EFFICACY}

\section{Demographic Information}

For the following questions, please circle the answer or fill in the blank in the way that most accurately reflects you.

32. What is your gender?

Female Male

33. Which category best describes your racial or ethnic background?

Caucasian African-American Asian or Pacific Islander
Latino/Hispanic $\quad$ American Indian
Other (Please specify:

34. What is your age in years?

35. How many years of experience do you have in a paid social work position? 


\section{INCREASING POLITICAL INTEREST AND EFFICACY}

36. Which of the income groups listed below includes the total 2008 income before taxes of all members of your family living in your home? Please include salaries, wages, pensions, dividends, interest, and other income. (If you are claimed as a dependent on someone else's taxes, please indicate the total income of that household.)
a. Under $\$ 15,000$
b. $\$ 15,000-\$ 34,999$
c. $\$ 35,000-\$ 49,999$
d. $\$ 50,000-\$ 74,999$
e. $\$ 75,000-\$ 124,999$
f. $\$ 125,000$ or higher

37. Are you working as a social work practicum student this [term]? Yes No

38. Are you a member of the National Association of Social Workers (NASW)?

Yes No

Thank you for taking the time to participate in this study! 


\section{INCREASING POLITICAL INTEREST AND EFFICACY}

\section{Appendix C \\ Post-Test Survey \\ Survey on Political Interest}

Thank you, again, for participating in this study on social work education. This survey is confidential; your name will not be associated with any of your answers. You do not have to answer any question that you are not comfortable answering and you may stop at any time. For more information, please see your copy of the consent form for this study.

1. Are you a member of the National Association of Social Workers (NASW)?

Yes No

2. Are you a member of a political organization or an organization that regularly takes political stands on public issues at either the national, state, or local level? (Either formal membership or financial contributions to such an organization would count.)

Yes No

3. Are you currently registered to vote?

Yes No Not Eligible 


\section{INCREASING POLITICAL INTEREST AND EFFICACY}

Questions 4 and 5 pertain to your interest in politics:

4. Thinking about your state and local community, how interested are you in Local politics and local community affairs?

$\begin{array}{cccc}\text { Very } & \text { Somewhat } & \text { Slightly } & \text { Not At All } \\ \text { Interested } & \text { Interested } & \text { Interested } & \text { Interested }\end{array}$

5. How interested are you in national politics and national affairs?

$\begin{array}{cccc}\text { Very } & \text { Somewhat } & \text { Slightly } & \text { Not At All } \\ \text { Interested } & \text { Interested } & \text { Interested } & \text { Interested }\end{array}$

6. Please check the box next to any social welfare policy issue in which you are particularly interested:

Affordable Housing

Aging/Older Adult Services

Child Abuse and Neglect

Civil Rights

Criminal Justice System

Disability Issues

Early Childhood

Education

Employment/Job Training

Food, Nutrition, and Hunger
Globalization

Health Care

Homelessness

Immigration

Mental Health and Substance Abuse

Poverty

Social Security

Tax Policy

Welfare

Other:

Other: 


\section{INCREASING POLITICAL INTEREST AND EFFICACY}

For questions 7-10, please rate your level of agreement with each statement.

7. I feel I have a pretty good understanding of the important political issues facing our country.
a. Strongly Agree
b. Somewhat Agree
c. Neither Agree Nor Disagree
d. Somewhat Disagree
e. Strongly Disagree

8. I consider myself to be well qualified to participate in politics.
a. Strongly Agree
b. Somewhat Agree
c. Neither Agree Nor Disagree
d. Somewhat Disagree
e. Strongly Disagree 


\section{INCREASING POLITICAL INTEREST AND EFFICACY}

9. I think that I am better informed about politics and government than most people.
a. Strongly Agree
b. Somewhat Agree
c. Neither Agree Nor Disagree
d. Somewhat Disagree
e. Strongly Disagree

10. I feel that I could do as good a job in public office as most other people.
a. Strongly Agree
b. Somewhat Agree
c. Neither Agree Nor Disagree
d. Somewhat Disagree
e. Strongly Disagree 


\section{INCREASING POLITICAL INTEREST AND EFFICACY}

11. In terms of political party identification, where would you place yourself on the following scale?
a. Strong Democrat
b. Democrat
c. Independent, Lean to the Democrats
d. Independent, No Leaning
e. Independent, Lean to the Republicans
f. Republican
g. Strong Republican
h. Other (e.g. Green Party, Libertarian)

12. In terms of political views, where would you place yourself on the following scale?
a. Very Liberal
b. Liberal
c. Moderate
d. Conservative
e. Very Conservative 


\section{INCREASING POLITICAL INTEREST AND EFFICACY}

Questions 13-16 pertain to your participation in this Social Welfare Policy course:

13. How would you describe the impact this course has had on your interest in politics?

a. My interest in politics has increased as a result of this course.

b. My interest in politics remains the same as at the beginning of this course.

c. My interest in politics has decreased as a result of this course.

14. If your interest in politics has increased or decreased as a result of this course, what about the course do you believe made this difference? Please be as specific as possible.

15. How would you describe the impact this course has had on your ability to influence policy and the political system?

a. My political advocacy skills have increased as a result of this course.

b. My political advocacy skills remain the same as at the beginning of this course.

c. My political advocacy skills have decreased as a result of this course. 


\section{INCREASING POLITICAL INTEREST AND EFFICACY}

16. If your political advocacy skills have increased or decreased as a result of this course, what about the course do you believe made this difference? Please be as specific as possible.

Thank you for taking the time to participate in this study! 
INCREASING POLITICAL INTEREST AND EFFICACY

\section{Appendix D}

\section{Classroom Observation Guide}

Lecture Topics and Timeframe:

Discussion Topics and Timeframe:

Skill Practice Activities and Timeframe:

Political advocacy questions and examples ( $\mathrm{S}=$ student, $\mathrm{I}$ = instructor): 


\section{INCREASING POLITICAL INTEREST AND EFFICACY}

\section{Checklist (and Related Reflections) Following Classroom Observation:}

Communication of importance of policy practice skills.

Classroom structure, materials, activities, and assignments that supported student autonomy and self-direction.

Evidence of students finding intrinsic value or a personal pay-off in the learning of policy practice skills.

Evidence of transformation (at the individual, community, and/or societal level).

Students developing or presenting knowledge.

Teacher modeling curiosity, not having to know it all.

Experiential teaching methods

Students reflecting or working on political issues of importance to them.

Strong feelings and/or differing opinions about politics being valued.

Evidence of critical reflection (teacher and/or students posing questions related to power, roots of problems, etc.)

Action plans being developed.

Discussion of political advocacy actions taken by students.

Discussion of or exposure to political advocacy actions taken by others.

Teacher demonstrating respect for the continuum of political opinion.

Other emerging observations/concepts? 


\section{INCREASING POLITICAL INTEREST AND EFFICACY}

\section{Appendix E \\ Focus Group Guide (2010)}

Begin with an introduction to the focus group goals and guidelines, including confidentiality. Then use these questions as a guide, always aiming for relevant discussion between participants and as specific of answers as possible.

1. How many people (by a show of hands) believe that their interest in politics

(a) Increased as a result of this course?

(b) Stayed the same?

(c) Decreased?

2a. If your interest in politics increased as a result of this course, what about the course do you believe made this difference? (Please be as specific as possible.)

2b. If your interest in politics decreased as a result of this course, what about the course do you believe made this difference? (Please be as specific as possible.)

3. If your interest in politics decreased or stayed the same throughout this course, do you think it could have been different? Do you think a course such as this could have increased your interest in politics? And if so, how could it have done that? What could have been different to positively impact your interest in politics?

Now let's talk about your confidence participating in and trying to influence the political system now...

4. How many people (by a show of hands) believe that their ability to influence policy and the political system (or their political advocacy skills) has

(a) Increased as a result of this course?

(b) Stayed the same?

(c) Decreased? 


\section{INCREASING POLITICAL INTEREST AND EFFICACY}

5a. If your sense of confidence participating in and trying to impact the political system increased as a result of this course, what about the course do you believe made this difference? (Please be as specific as possible.)

5b. If your sense of confidence participating in and trying to impact the political system decreased as a result of this course, what about the course do you believe made this difference? (Please be as specific as possible.)

6. If your sense of confidence participating in and trying to impact the political system decreased or stayed the same throughout this course, do you think it could have been different? Do you think a course such as this could have increased sense of confidence participating in politics? And if so, how could it have done that? What could have been different to positively impact your interest in politics?

\section{Further Probes...}

Tell me more about the term paper and presentation you created in groups in response to the [state-wide political forum]. What did you think about that assignment? (What was it like for you to practice creating a policy proposal? Do you think that impacted your interest or confidence in politics? How so? Or why not?)

Tell me more about how you selected the topics for your [forum] proposal. Did the topic picked by your group interest you? Did you feel as though you were picking your own topic as a group or did it feel fairly limited? If you felt like you had choice, did picking your own topic help you complete the assignment in any way? (How so? Or why not?)

What about the field trips to the [food bank] and [local community of homeless people]? Did either of those visits impact your interest in or confidence with politics? (How so? Or why not?)

Tell me more about the balance between lecture and discussion in this course. Did that impact you? How so? 


\section{INCREASING POLITICAL INTEREST AND EFFICACY}

Did your understanding of the role of policy and political action in social work change during this course? (How so?)

Did you get to work on anything of personal importance to you during this course? What impact did that have on you?

Did you feel like differing opinions or feelings about politics were valued during this course? (How so?)

What about the textbooks? The policy reflection papers?

Is there anything else about being a student in this course that you want me (and future teachers) to understand? Especially as it relates to your interest and confidence in politics and political advocacy. Anything about the style of teaching? The assignments? The activities? The topics covered? 


\section{INCREASING POLITICAL INTEREST AND EFFICACY}

\section{Appendix F}

\section{Interview Guide 1}

Review Consent Form points (e.g. purpose of study with emphasis on political interest and political efficacy, confidentiality, can choose not to answer any question or stop the interview at any time, will record and transcribe, name will not be included on transcript, etc.).

1. What were your thoughts and feelings heading into the Social Welfare Policy course, before you arrived on the first day?

2. Do you remember how you felt after reading through the syllabus, hearing the professor introduce the class, and all that happens on the first day of class? Did you have any immediate reactions to the assignments, the instructor, or the class environment itself? (could look at syllabus, if it helps)

3. What was most important to you about the social welfare policy course?

4. During the focus group on the last day of class, we talked briefly about people's interest in politics.

4a. Can you tell me more about your own interest in politics (in general)?

4b. Has your interest in politics changed during your time in the social work program?

4c. Do you believe that your interest in politics increased as a result of this course, stayed the same, or decreased? (follow up)

5a. How do you feel about the idea of being a political advocate?

5b. Have you always felt that way?

5c. If something has changed, how would you explain how that change happened?

5d. Do you believe that your sense of confidence and competence in being able to interact with and influence the political system (your political advocacy skills) has increased, stayed the same, or decreased as a result of taking this particular social welfare policy course? (follow up) 


\section{INCREASING POLITICAL INTEREST AND EFFICACY}

further questions...

- specific content

- discussions

- activities

- assignments

- teaching methods

- classroom roles

- emerging concepts/categories/connections from research

Did you get to work on anything of personal importance to you during this course? What impact did that have on you?

Tell me more about the Mock Committee Hearing you participated in near the end of the class. What did you think about that assignment? (What was it like for you to practice testifying? Do you think that impacted your interest or confidence in politics? How so?)

Tell me more about how you selected the topic for your policy analysis brief. Did the topic you picked interest you? Did picking your own topic help you complete the assignment in any way? Do completing the policy analysis impact your interest or confidence in politics? (How so?)

Tell me more about the balance between lecture and discussion in this course. Did that impact you? How so?

Did your understanding of the role of policy and political action in social work change during this course? (How so?)

Did you feel like differing opinions or feelings about politics were valued during this course? (How so?)

Is there anything else about being a student in this course that you want me (and future teachers) to understand?

Thank you! 


\section{INCREASING POLITICAL INTEREST AND EFFICACY}

\section{Appendix G}

\section{Interview Guide 2}

Review Consent Form points (e.g. purpose of study with emphasis on political interest and political efficacy, confidentiality, can choose not to answer any question or stop the interview at any time, will record and transcribe, name will not be included on transcript, etc.).

1. What were your thoughts and feelings heading into the Social Welfare Policy course, before you arrived on the first day?

2. Do you remember how you felt after reading through the syllabus, hearing the professor introduce the class, and all that happens on the first day of class? Did you have any immediate reactions to the assignments, the instructor, or the class environment itself? (could look at syllabus, if it helps)

3. What was most important to you about the social welfare policy course?

4. During the focus group on the last day of class, we talked briefly about people's

interest in politics.

4a. Can you tell me more about your own interest in politics (in general)?

4b. Has your interest in politics changed during your time in the social work program?

4c. Do you believe that your interest in politics increased as a result of this course, stayed the same, or decreased? (follow up)

5a. How do you feel about the idea of being a political advocate?

5b. Have you always felt that way?

5c. If something has changed, how would you explain how that change happened?

5d. Do you believe that your sense of confidence and competence in being able to interact with and influence the political system (your political advocacy skills) has increased, stayed the same, or decreased as a result of taking this particular social welfare policy course? (follow up) 


\section{INCREASING POLITICAL INTEREST AND EFFICACY}

further questions...

- specific content

- discussions

- activities

- assignments

- teaching methods

- classroom roles

- emerging concepts/categories/connections from research

Did you get to work on anything of personal importance to you during this course? What impact did that have on you?

Tell me more about the term paper and presentation you created in groups in response to the [state-wide political forum]. What did you think about that assignment? (What was it like for you to practice creating a policy proposal? Do you think that impacted your interest or confidence in politics? How so? Or why not?)

Tell me more about how you selected the topic for your [forum] proposal. Did the topic picked by your group interest you? Did you feel as though you were picking your own topic as a group or did it feel fairly limited? If you felt like you had choice, did picking your own topic help you complete the assignment in any way? (How so? Or why not?)

What about the field trips to the [food bank] and [local community of homeless people]? Did either of those visits impact your interest in or confidence with politics? (How so? Or why not?)

Tell me more about the balance between lecture and discussion in this course. Did that impact you? How so?

Did your understanding of the role of policy and political action in social work change during this course? (How so? Or why not?)

Was there anything you'd hoped to learn or practice or cover in Social Welfare Policy that you didn't this [term]? 


\section{INCREASING POLITICAL INTEREST AND EFFICACY}

Did you feel like differing opinions or feelings about politics were valued during this course? (How so? Or why not?)

What about the textbooks? The policy reflection papers?

Is there anything else about being a student in this course that you want me (and future teachers) to understand?

Thank you! 


\section{INCREASING POLITICAL INTEREST AND EFFICACY}

\section{Appendix H}

\section{Human Subjects Application to IRB}

\section{Investigator's Assurance Form attached.}

\section{Project Title \& Prospectus}

Title: Increasing social work students' political interest and efficacy: The impact of a social welfare policy course from the students' perspective

Prospectus: This project seeks to develop and propose a theory for how social welfare policy instructors can effectively support students in the development of political interest and efficacy, with the long-term goal of increased political advocacy. The professional mandate for today's social worker includes a clear call for political advocacy on behalf of social justice. This mandate can be found in the National Association of Social Workers' Code of Ethics, as well as in the profession's educational accreditation standards. The results of a recent study suggest that social work programs have significant room for improvement in the preparation of social work students for political advocacy (Ritter, 2007). Almost half of licensed social workers surveyed disagreed with the notion that they were adequately prepared for political engagement by their social work education. Existing research on the relationship between self-efficacy, motivation, and political action supports a renewed focus on how we teach social welfare policy rather than on what we teach. Students and social workers who exhibit higher levels of interest and self-efficacy in politics are more likely to engage in political action.

Fundamental principles of adult learning theory and Freire's theory of conscientization have been integrated by the researcher into a single set of concepts and inserted into a developing theory that represents the researcher's current thinking on how students' policy practice development might be most effectively supported in a social welfare policy course. These initial conceptualizations are based on research and practice, but require deliberate examination and further exploration in order to develop into a more complete and sound theory. Consistent with Freire's theory of conscientization, student voices will be the primary source and interpretive lens for the study.

Because of the study's exploratory nature, a mixed method approach which emphasizes qualitative data collection will be used. Two social welfare policy courses in two separate social work programs have been selected based on their learning objectives and experiential teaching methods. These two courses will be observed, in order to familiarize the researcher with the teaching methods employed by the instructors and the 


\section{INCREASING POLITICAL INTEREST AND EFFICACY}

in-class engagement and experiences among the students in the study. Students will complete a pre-test survey, exploring their level of political interest, participation, and efficacy. At the final class meeting, students will complete a post-test survey, as well as participate in a focus group discussion. Students who represent a diversity of experience in the course and/or demonstrate a strong ability to communicate the personal impact of the course will be invited to participate in a more in-depth interview. Once the data have been analyzed for thematic content, the researcher will create an initial summary and seek the instructors' feedback on her interpretation of the instructor's teaching methods; written notes will be taken during this conversation. The final conclusions of the study will serve to clarify for social work educators the methodologies by which they can effectively support students in the development of political interest and efficacy, and ultimately advocacy.

\section{Exemption Claim for Waiver of Review}

A Waiver of Review is being requested based on exemption category \#1. The proposed research centers on development of an educational theory for social welfare policy instructors seeking to more effectively support social work students in the development of political interest, efficacy, and ultimately advocacy. As such, it qualifies as "research on the effectiveness of ... instructional techniques, curricula, or classroom management methods." The research will be conducted at two [deleted for confidentiality] accredited universities: [deleted for confidentiality].

\section{Subject Recruitment}

The Social Work Program Directors at [deleted for confidentiality] have agreed to have the proposed researcher present in their social welfare policy courses in the 2009-2010 academic year. After official written consent has been received from the instructors of those two courses [deleted for confidentiality], student participants will be recruited during their first social welfare policy class. The study will be explained by the researcher, both verbally and in writing, after which informed consent forms will be distributed, completed, and collected.

The voluntary subject population will consist of social welfare policy students enrolled in a Bachelor of Social Work (BSW) program accredited or granted candidacy for accreditation by the Council on Social Work Education (CSWE). It is anticipated that approximately 30 students will be enrolled in the two participating social welfare policy courses and that most, if not all, of these students will consent to basic participation in the 


\section{INCREASING POLITICAL INTEREST AND EFFICACY}

study (i.e. completion of two surveys and an end-of-class focus group). In terms of the interviews, it is difficult to determine in the planning stages of qualitative research how many respondents will be needed to successfully complete the project. It seems likely that between 8-15 students will be interviewed. There is no specific inclusion or exclusion criteria related to gender, age, ethnicity, or any other demographic characteristic. In the interest of inclusivity and theoretical relevance, special consideration will be given to conducting interviews with a diverse set of students (e.g. political experience and identity, age, ethnicity, gender, etc.). Specific inclusion and exclusion criteria are described further here:

Inclusion criteria:

(1) Age 18 or older.

(2) Capable of giving informed consent.

(3) Enrolled in a BSW program that is accredited or granted candidacy for accreditation by the Council on Social Work Education.

(4) Participating in a social welfare policy course that has been selected based on its having (a) at least one learning objective related to political skill development, (b) experiential teaching methods, and (c) an instructor willing to have the course observed, audio taped, and minimally interrupted for completion of surveys or a final group conversation.

\section{Exclusion Criteria:}

(1) Under age 18.

(2) Unable to give informed consent.

(3) Not enrolled in a BSW program that is accredited or granted candidacy for accreditation by the Council on Social Work Education.

(4) Not participating in one of the selected social welfare policy courses, as described above.

\section{Informed Consent}

\section{Instructors}

The researcher will meet with both instructors prior to the beginning of his/her respective social welfare policy course. Written and verbal information will be provided regarding the study and any questions answered. Two copies of the informed consent form will be signed by each instructor/participant, one for the researcher and one for the instructor/participant. At any time, they may withdraw from the study and any data gathered from their class and students will not be used. Contact information for the researcher will be included on the consent form. 


\section{INCREASING POLITICAL INTEREST AND EFFICACY}

\section{Students}

During the first class session, the researcher will distribute written information related to the study and make a verbal presentation to the students. The presentation will include the purpose of the study, the research procedures and activities, potential risks and benefits, emphasis on participation in the study being voluntary, and procedures for confidentiality. The instructor of the course will be asked to reinforce for the students that their choice of whether or not to participate in the study will have no impact on their grade. After that, the instructor of the course will leave, so that students can ask questions and decide whether or not to participate. Any questions will be answered by the researcher. The researcher will also offer to stay after class and speak with anyone who wishes to do so. Students will have an opportunity to consent or not to participation in the study. Two copies of the informed consent form will be signed by each student/participant, one for the researcher and one for the student/participant. At any time, they may withdraw from the study and their data will not be used. Contact information for the researcher will be included on the consent form. If the student is willing to be contacted with a request for an in-person interview, they will be asked to include their preferred method of contact on the form.

\section{V. $\quad$ First-Person Scenario}

\section{Instructors}

"The researcher contacted me by e-mail to set up a time to meet and discuss her study further. When we met, she described the study to me in more detail and provided me with written information and an informed consent form. I understand that if results of her study are published, my name and the name of the university will not be included in the publication. Because I agreed to participate, the researcher attended each session of my social welfare policy course that [term], sitting quietly in the back and taking notes. At the first class, I left time at the end for her to introduce herself and the study to my students. I left the room after ensuring the students that their decision of whether or not to participate in the course would have no impact on their grade. This gave the students time to ask the researcher questions, complete their consent forms, and take the first written survey without me being present. On the last regular day of class, I left the class again so that the students could complete the second written survey and participate in a focus group with the researcher. A couple months after the [term] ended, the researcher called and arranged a meeting with me to review her results. I was able to share my own reflections on the data she gathered and clarify her interpretations of my teaching methods. The researcher took written notes during our conversation." 


\section{INCREASING POLITICAL INTEREST AND EFFICACY}

\section{Students}

"On the first day in Social Welfare Policy class, my instructor invited a researcher to speak to the class. The researcher explained that she is studying effective methods for teaching social welfare policy and political advocacy skills. She explained that she would be observing the instructor during class time and making written observations, but that no student names or identifying information would be included in her notes.

Then she mentioned that for her study, she is also interested in hearing about the experience of social work students in social welfare policy courses. She handed out a letter that described more about the study and an informed consent form. She walked the class through the main points in the letter. She emphasized that the notes, surveys, and audiotapes from the study will be kept confidential, though confidentiality in the focus group is reliant on everyone respecting others' confidentiality. My instructor will not be told by the researcher who is participating in the study. My participation in the study will not affect my grade in the class, which my instructor also said before leaving the room. I can decide I no longer want to participate in the study at any time. My questions were answered and I agreed to participate in the surveys, focus group, and potentially an interview. I kept a copy of my signed consent form, which includes contact information for the researcher.

Because I agreed to participate in the study, I completed a written survey on that first day of class. The researcher attended all of our classes. She sat in the back of the room and quietly took notes. At our last class meeting, my instructor left the room for the final hour, while the students who were participating in the study completed a second written survey and had a group conversation led by the researcher. She asked us questions about the course and our experiences in it.

At the end of the [term], I got a phone call from the researcher at the number I had given her on my consent form. She asked whether I was still willing to be interviewed regarding my experience in the class. I agreed and we set up a time and place to meet on campus. The interview lasted about 50 minutes. The researcher taped our conversation and took some notes. When I asked what would happen to the tape, she reminded me that it would be destroyed after the study was complete. She asked me questions about the role of political advocacy in social work, about the activities and conversations in the social welfare policy course, how I experienced those activities and conversations, and how they had or had not changed my feelings about taking part in political action. When we were done, the researcher asked if it would be okay for her to contact me again if she needed to clarify anything about our conversation and I said that was okay." 


\section{INCREASING POLITICAL INTEREST AND EFFICACY}

\section{Potential Risks and Safeguards}

\section{Instructors}

Because the study is focused on identifying effective teaching methods and published results will not include the name of the instructor or university, there is only one foreseeable risk to the instructor/participants. There is a possibility that the researcher will misinterpret some of the teaching practices used. To guard against this, the researcher will share the results of the study with the instructor/participants before they are finalized, with the goal of clarifying any misrepresentations of their teaching methods..

\section{Students}

There are no foreseeable physical, legal, or economic risks to participants in this study. For students who agree to participate in the surveys, questions will be asked regarding their political interest, political participation, and internal political efficacy. It is not anticipated that these questions will cause any social or psychological discomfort. However, it will be made clear in writing and verbally that students may choose not to answer any question and may stop at any time. On the final written survey, students will also be asked for reflections on the course. It is expected that students will not experience any discomfort outside of what is typical when students regularly complete course evaluations.

For students who participate in the focus group, it is possible that they could experience a minimal level of social and/or psychological discomfort if there are disagreements related to experiences in the course. The researcher is an experienced social worker who has conducted focus groups previously; her contact information will be available to all participants, if they want to discuss their experience in the study further. It is also important for students to recognize that confidentiality cannot be guaranteed in a focus group setting; this will be outlined in the consent form and reiterated at the beginning of each focus group. Students will be encouraged to respect the confidentiality of their classmates by not talking outside of the group about who was there or what was shared.

For students who participate in an interview, it is also possible that a minimal level of social and/or psychological discomfort could be experienced. However, the topic of research is not anticipated to be a distressing one. Again, all students who participate in an interview will have the researcher's contact information if they want to discuss their experience in the study further.

Student participation will not affect their grade, status, or relationship with their university or instructor. 


\section{INCREASING POLITICAL INTEREST AND EFFICACY}

\section{Potential Benefits}

\section{Instructors}

Instructors may benefit from reflecting on their teaching methods and discussing those with the researcher. They may also benefit from the results of the study, as its purpose is to strengthen social work education.

\section{Students}

For students who participate in the surveys and in-class discussion, no direct benefit to the participant is likely to occur, except the opportunity to have had their experience and opinions sought out and listened to. Students who participate in an interview will receive a $\$ 10$ gift certificate to a local restaurant or store as a modest "thank you" for their time. It is intended that information from the study will inform the future education of social workers as it relates to political advocacy participation and skill development.

\section{Records and Distribution}

\section{Instructors}

Because students will be present in the classroom and participating in a focus group conversation regarding the impact of the course, instructor confidentiality cannot be guaranteed. However, every effort will be made to maximize instructors' confidentiality. Instructor/participants will be assigned a code, which will be used on written classroom observation forms. Audiotapes from the focus groups and interviews, in which the instructor's name is likely to be mentioned, will be kept in a locked file cabinet. The instructor's name will be substituted with their code on any transcripts made. If an outside transcriptionist is used, s/he will sign a confidentiality agreement. The study materials will be kept for a minimum of three years. Audiotapes will be destroyed at that point, though coded transcripts and field notes may be maintained for future reference and use. If study results are published, the instructor and university's names will not be included. All published results will reflect integrated data from two courses, two instructors, and two universities.

\section{Students}

Confidentiality of student/participants will be maintained throughout the research process and in the period thereafter. Participants will be assigned a code number that will be used on all field notes and audiotapes. These codes and participant consent forms will be maintained in a locked file cabinet separate from other study materials and will be accessible only to the researcher. Field notes, audiotapes, and transcripts will be 


\section{INCREASING POLITICAL INTEREST AND EFFICACY}

maintained in a locked file cabinet separate from other study materials and will be accessible only to the researcher, except for the purposes of audiotape transcriptions and peer debriefing with professionals who sign a confidentiality agreement. No videotapes will be used in this study. The study materials will be maintained for a minimum of three years. Audiotapes will be destroyed at that point, though coded transcripts and field notes may be maintained for future reference and use.

\section{Appendices}

Appendix A: Consent Form for Instructor Appendix B: Consent Form for Student Appendix C: Classroom Observation Guide Appendix D: Pre-Test Survey

Appendix E: Post-Test Survey Appendix F: Initial Focus Group Guide Appendix G: Initial Student Interview Guide Appendix H: Initial Instructor Interview Guide Appendix I: Letter of Agreement from [University 1] Appendix J: Copy of E-mail Agreement from [University 2] 


\section{INCREASING POLITICAL INTEREST AND EFFICACY}

\section{Appendix I}

\section{Notification of Approval from IRB}

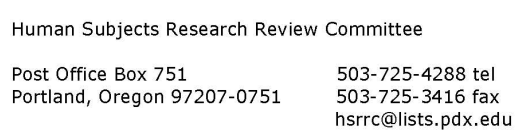

August 31, 2009

To: Christie Halvor

From: Nancy Koroloff, HSRRC Chair

Re: Approval of your application titled, "Increasing Social Work Students' Political Interest and Efficacy" (HSRRC Proposal \# 091063).

Dear Christie,

In accordance with your request, the Human Subjects Research Review Committee has reviewed your proposal referenced above for compliance with DHHS policies and regulations covering the protection of human subjects. The committee is satisfied that your provisions for protecting the rights and welfare of all subjects participating in the research are adequate, and your project is approved. Please note the following requirements:

Changes to Protocol: Any changes in the proposed study, whether to procedures, survey instruments, consent forms or cover letters, must be outlined and submitted to the Chair of the HSRRC immediately. The proposed changes cannot be implemented before they have been reviewed and approved by the Committee.

Continuing Review: This abonoval will expire on Auoust 31.2010. It is the investigator's responsibility to ensure that a Continuing Review Report (available in ORSP) of the status of the project is submitted to the HSRRC two months before the expiration date, and that approval of the study is kept current.

Adverse Reactions: If any adverse reactions occur as a result of this study, you are required to notify the Chair of the HSRRC immediately. If the problem is serious, approval may be withdrawn pending an investigation by the Committee.

Completion of Study: Please notify the Chair of the Human Subjects Research Review Committee (campus mail code ORSP) as soon as your research has been completed. Study records, including protocols and signed consent forms for each participant, must be kept by the investigator in a secure location for three years following completion of the study.

If you have questions or concerns, please contact the HSRRC in the Office of Research and Sponsored Projects (ORSP), (503) 725-4288, 6th Floor, Unitus Building, 4th \& Lincoln.

Cc: Ann Curry-Stevens 